\title{
The Parent-Child Interaction Therapy Family Experiences and Feedback Study: A Follow-up Examination of Attrition in an Evidence-Based Treatment in Community Settings Statewide
}

\author{
Brittany K. Liebsack \\ bkliebsack@mix.wvu.edu
}

Follow this and additional works at: https://researchrepository.wvu.edu/etd

Part of the Clinical Psychology Commons

\footnotetext{
Recommended Citation

Liebsack, Brittany K., "The Parent-Child Interaction Therapy Family Experiences and Feedback Study: A Follow-up Examination of Attrition in an Evidence-Based Treatment in Community Settings Statewide" (2019). Graduate Theses, Dissertations, and Problem Reports. 4093.

https://researchrepository.wvu.edu/etd/4093

This Dissertation is protected by copyright and/or related rights. It has been brought to you by the The Research Repository @ WVU with permission from the rights-holder(s). You are free to use this Dissertation in any way that is permitted by the copyright and related rights legislation that applies to your use. For other uses you must obtain permission from the rights-holder(s) directly, unless additional rights are indicated by a Creative Commons license in the record and/ or on the work itself. This Dissertation has been accepted for inclusion in WVU Graduate Theses, Dissertations, and Problem Reports collection by an authorized administrator of The Research Repository @ WVU. For more information, please contact researchrepository@mail.wvu.edu.
} 
The Parent-Child Interaction Therapy Family Experiences and Feedback Study: A Follow-up Examination of Attrition in an Evidence-Based Treatment in Community Settings Statewide

Brittany K. Liebsack, M.S.

Dissertation submitted to the Eberly College of Arts and Sciences at West Virginia University

in partial fulfillment of the requirements for the degree of

Doctor of Philosophy in

Psychology

\author{
Amy D. Herschell, Ph.D., Chair \\ Jennifer M. Ludrosky, Ph.D. \\ Cheryl B. McNeil, Ph.D. \\ Amy E. Root, Ph.D. \\ Nicholas A. Turiano, Ph.D. \\ Department of Psychology \\ Morgantown, West Virginia \\ 2018
}

Keywords: Attrition, Competence, Parent-Child Interaction Therapy, Satisfaction, Therapeutic Alliance

Copyright 2018 Brittany K. Liebsack 


\begin{abstract}
The Parent-Child Interaction Therapy Family Experiences and Feedback Study: A Follow-up Examination of Attrition in an Evidence-Based Treatment in Community Settings Statewide

Brittany K. Liebsack, M.S.
\end{abstract}

Attrition is a significant problem in child psychotherapy (De Haan, Boon, De Jong, Hoeve, \& Vermeiren, 2013) and has serious implications (Barrett et al., 2008). Predictors of attrition include those at the client, therapist, and treatment levels. The current study investigated variables associated with attrition in Parent-Child Interaction Therapy (PCIT), an evidence-based parent training program for families with young children (ages 2.5- to 7-years-old) with disruptive behavior disorders. The sample of 67 caregivers were treated by 25 therapists from 19 different licensed psychiatric outpatient clinics across one state and were part of a larger study (RO1 MH09750; A Statewide Trial to Compare Three Training Models for Implementing an EBT; PI: Herschell). The effects of caregivers' attitudes toward therapy, expectations of therapy, perceived therapist cultural competence, and commitment on the likelihood that families left PCIT prematurely were examined using Binomial Logistic Regression. The logistic regression model explained $36.1 \%$ of the variance in attrition and correctly classified $73.1 \%$ of cases. Therapy expectations and commitment to treatment added significantly to the model predicting attrition. Fleiss' kappa was used to examine caregiver-therapist agreement on completion status, reasons PCIT ended, barriers to treatment experienced by families, and caregiver compliance with post-treatment therapist referrals. Results suggest low agreement across each variable, suggesting that therapists may not be aware of caregiver barriers or reasons they leave PCIT prematurely. Limitations, suggestions for future research, and clinical implications are discussed. 


\section{Acknowledgements}

I would like to thank Dr. Amy Herschell for each of the endless opportunities and support she has provided throughout my graduate training. I am incredibly grateful to her for allowing me to use data from her large grant, RO1 MH09750: A Statewide Trial to Compare Three Training Models for Implementing an EBT, for this project; for allowing me to meet with the study steering committee and to include additional follow-up assessments in her project; and for helping me to develop a study that I am so interested in and proud of. I would also like to thank Dr. Cheryl McNeil for her kindness and encouragement throughout my graduate training, for inspiring my love of and interest in Parent-Child Interaction Therapy through her training and supervision, and for her input and suggestions during study development. I am grateful for my other committee members Dr. Jennifer Ludrosky, Dr. Amy Root, and Dr. Nicholas Turiano and their valuable feedback during the development and implementation of this study. I would like to thank my research lab, the Implementation Science Group, especially Laurel Brabson and Carrie Jackson, who helped with the consent process for this study. I am also incredibly grateful for the endless help, education, and support I received from the current and former members of the PCIT Across PA team at the University of Pittsburgh School of Medicine, especially Shelley Heigel, Jon Hart, Dr. Kristen Schaffner, and Chris Owen. I am indebted to Chris for the many hours he spent helping me with the consent process for this project, for organizing and implementing the payment process, and for his never-ending encouragement along the way. Finally, I would like to thank my wonderful family and friends for their unwavering love and support. 


\section{Table of Contents}

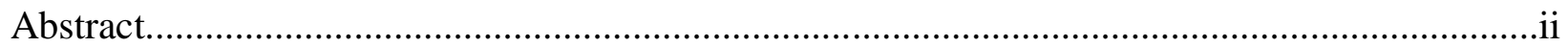

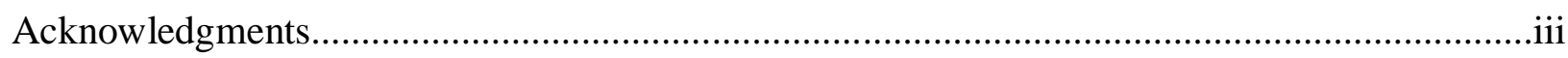

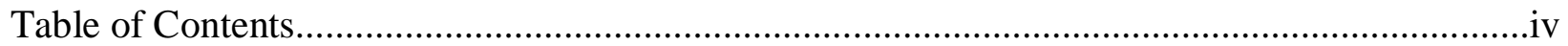

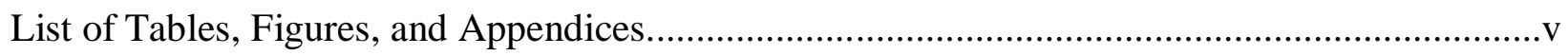

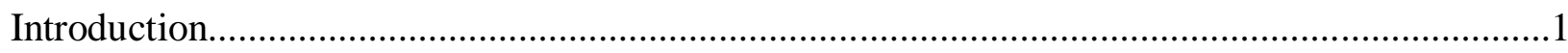

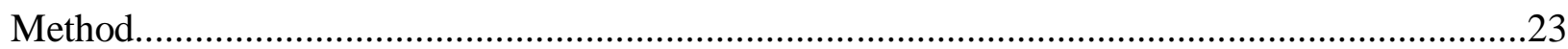

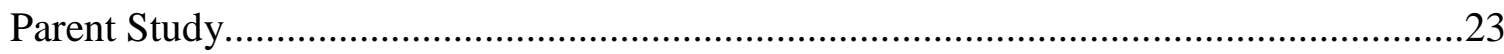

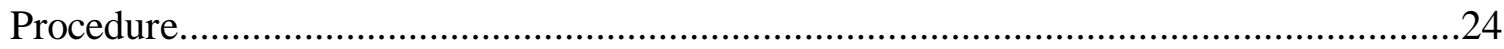

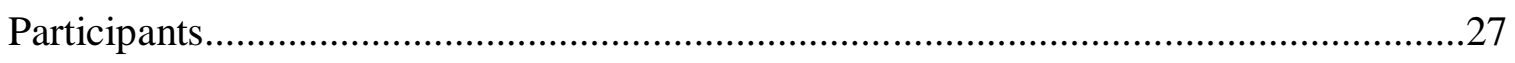

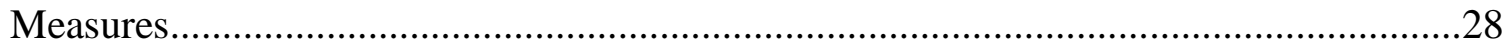

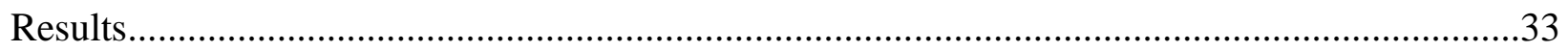

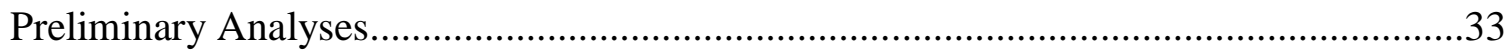

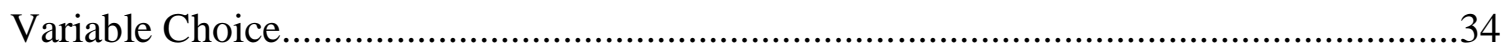

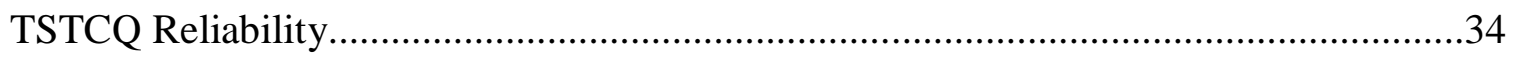

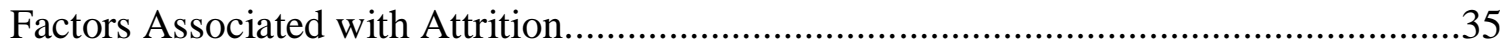

Caregiver-Therapist Agreement on Treatment Characteristics...................................36

Family Compliance with Post-Treatment Therapist Recommendations........................41

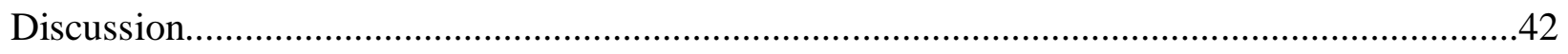

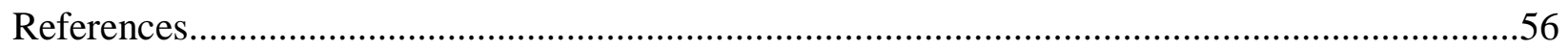

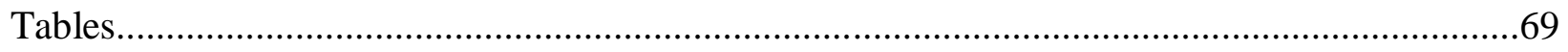

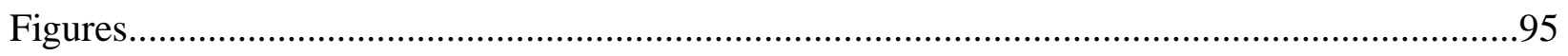

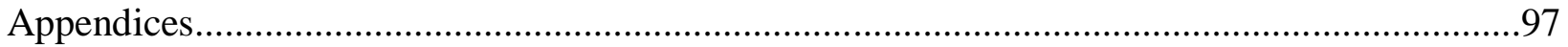


List of Tables and Figures

Table 1: Demographics for Children and Caregivers.............................................................69

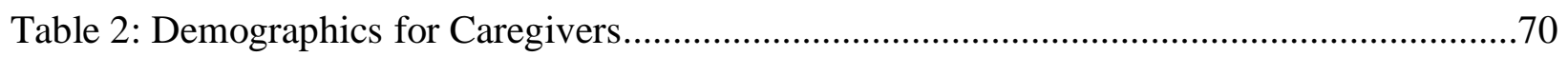

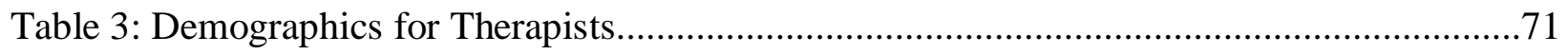

Table 4:Means and Standard Deviations for Variables Examined..............................................72

Table 5: Intraclass Correlations Between Logistic Regression Predictor Variables.......................73

Table 6: Reliability of Measures Used....................................................................................74

Table 7: Logistic Regression Predicting Likelihood of Attrition Based on Treatment Attitudes,

Expectations, Perceived Cultural Competence, and Commitment..................................................75

Table 8: Caregiver and Therapist Impressions of Treatment Progress..........................................76

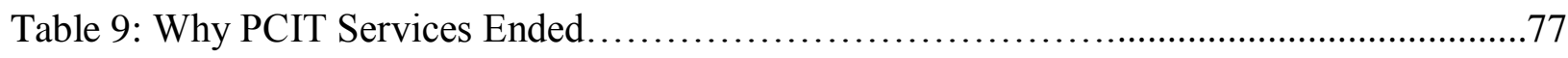

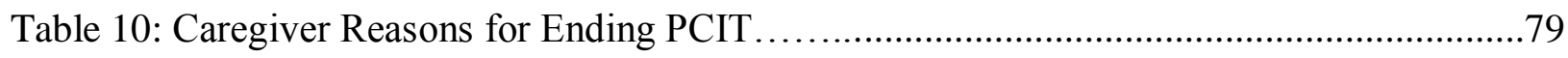

Table 11: Completer Reported Reasons for Ending PCIT Services..............................................8

Table 12: Premature Terminator Reported Reasons for Ending PCIT Services............................81

Table 13: Negative Impacts on Overall Course and Outcome of Treatment..............................82

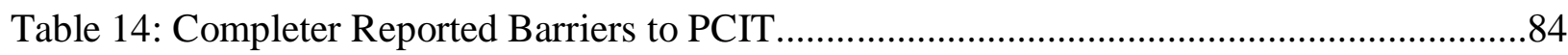

Table 15: Premature Terminator Reported Barriers to PCIT .........................................................85

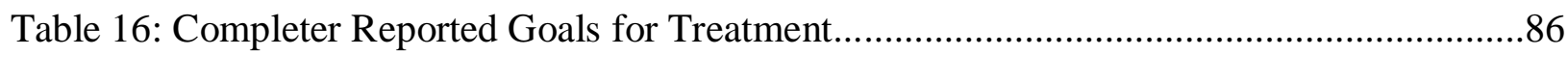

Table 17: Premature Terminator Reported Goals for Treatment..............................87

Table 18: Completer Reported Most Helpful Components of PCIT .............................................8

Table 19: Premature Terminator Reported Most Helpful Components of PCIT...........................89

Table 20: Completer Reported Most Frustrating Components of PCIT.......................................90

Table 21: Premature Terminator Reported Most Frustrating Components of PCIT.....................91

Table 22: Completer Recommendations for Other Caregivers and Therapists.............................92 
Table 23: Premature Terminator Recommendations for Other Caregivers and Therapists. .93

Table 24: Family Use of Other Services after PCIT and Compliance with Post-Treatment

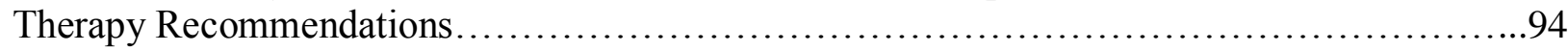

Figure 1. Flow chart showing participant re-consent................................. 95

Figure 2. ROC curve for logistic regression............................................ 96

Appendix A. Instructions for Calling Families to Re-consent …..........................................97

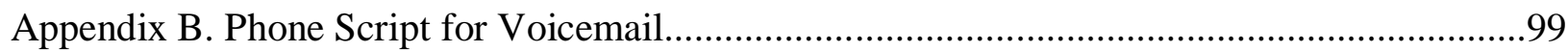

Appendix C Phone Script for Re-consent....................................................................... 100

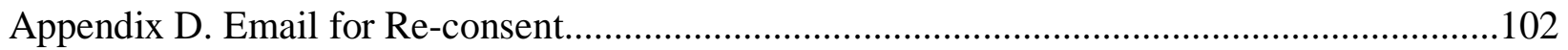

Appendix E. Cover Letter for Mailed Questionnaires......................................................103

Appendix F. Procedure for Administering Over the Phone Assessments to Families................104

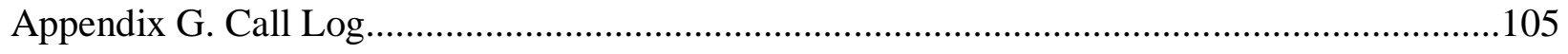

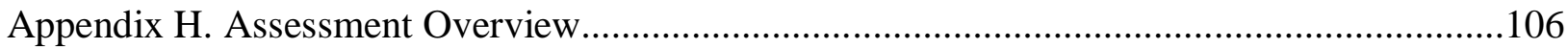

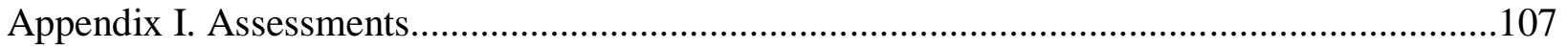




\section{Introduction}

\section{Attrition}

Attrition is a term used for the act of leaving therapy prematurely. It is a pervasive problem that affects research, clinical practice, and service delivery across various settings, populations, and treatment modalities (Barrett, Chua, Crits-Cristoph, Gibbons, \& Thompson, 2008). Treatment completion is strongly related to therapeutic change (Kazdin \& Wassell, 1998) so the effectiveness of interventions for mental health and behavioral health problems is limited by treatment attrition (Barrett et al., 2008). Untreated child disorders can lead to serious negative outcomes, as psychopathology often persists and worsens over time if left untreated (Costello, Copeland, Angold, 2011). In fact, evidence suggests that children with untreated psychopathology are more likely to leave school before graduating, become unemployed, engage in criminal behavior, and abuse drugs and alcohol (Aebi, Plattner, Metzke, Bessler, \& Steinhausen, 2013; Copeland, Shanahan, Costello, \& Angold, 2009).

Additionally, treatment attrition increases per unit costs for clinical services provided because of the non-reimbursed appointments, decreases in staff productivity, and wasted treatment materials that occur when clients leave treatment prematurely or unexpectedly. Attrition also increases the wait time for those on the waitlist for services because missed appointments occupy appointment slots that could be filled by others (Barrett et al., 2008). Thus, attrition also limits the number of people an agency is able to serve. Increased wait time for treatment can allow untreated psychological disorders to worsen and more severe psychopathology can be more difficult and time intensive to treat (Barrett et al., 2008). Therefore, understanding, predicting, and preventing attrition in children and families in treatment is essential. 
Researchers and therapists alike have recognized the importance of treatment retention and there has been considerable interest in and work conducted to examine attrition in psychotherapy. Different studies use different terms to describe the problem of attrition (e.g., premature termination, dropout). "Attrition" will be used for the remainder of this paper and participants will be referred to as either "completers" or "premature terminators." Different studies also use different definitions of attrition, including (a) therapist or research team determination, (b) leaving therapy before experiencing a reliable improvement in symptoms, or (c) no-showing or cancelling the last appointment without rescheduling, (d) failure to attend a predetermined number of sessions, or (e) failure to receive a full course of therapy or complete the treatment protocol (Swift, Callahan, \& Levine, 2009).

Attrition rates tend to be lower when attrition is defined according to therapist decision than when it is defined as failure to complete a predetermined number of sessions or lack of attendance at the last scheduled session (de Haan, Boon, de Jong, Hoeve, \& Vermeiren, 2013). In fact, results of meta-analyses of child and adult treatment attrition have indicated that the definition of attrition used is correlated with or moderates overall attrition rates across different studies (de Haan et al., 2013; Swift \& Greenberg, 2012).

\section{Rates and Pattern of Attrition in Psychotherapy}

Several previous studies of attrition have examined the rates and patterns of attrition in psychotherapy. In a meta-analysis of attrition in adult psychotherapy, Swift and Greenberg (2012) found an average attrition rate of $19.7 \%$. A meta-analysis conducted by de Haan and colleagues (2013) found an even higher percentage of attrition in child and adolescent therapies, with attrition rates ranging from $28 \%$ to $75 \%$. This number is striking, especially considering the estimation that as many as three-quarters of children who need mental health services receive no 
mental health care in the first place (Kataoka, Zhang, \& Wells, 2002). On top of that, of the children who do receive mental health care, a large proportion of cases result in attrition.

Researchers have also examined patterns of attrition in order to better understand at what point in treatment clients are likely to leave and to begin to understand what might predict or explain attrition. Findings suggest that attrition typically occurs early in treatment (Kazdin \& Mazurick, 1994). In a meta-analysis of premature terminators from adult psychotherapy, Fernandez, Salem, Swift, and Ramtahal (2015) found that $15.9 \%$ adults left therapy before attending a single therapy session; at pre-treatment. McCabe (2002) found that families of children in treatment who perceived more barriers to treatment were also more likely to attend just one treatment session before leaving therapy prematurely. In a sample of adults, $28 \%$ of clients also left after just one session (Bados, Balaguer, \& Saldana, 2007). Though a larger percentage stayed a bit longer, over half (52\%) left before the fifth session (Bados et al., 2007). Similarly, another study found that five to six sessions tends to be the median length of time adults spend in treatment, and $65 \%$ of the sample left therapy before the tenth session (Garfield, 1994). So, most therapy clients leave during the early phase of treatment (Luk, Staiger, Mathai, Wong, Birleson, \& Adler, 2001), attending just six or fewer sessions. Kazdin and Mazurick (1994) suggest that this is before the core features of treatment are even implemented.

\section{Predictors of Attrition}

In addition to rates and patterns of attrition, a great deal of the attrition literature has examined predictors of attrition. The literature indicates that treatment attrition can be influenced and predicted by many variables including those at client-, therapist-, and treatment-levels, as well as therapy elements, attrition definition, and study design (de Haan et al., 2013; Swift \& Greenberg, 2012). Because of caregivers' active participation in their child's treatment and 
because of their responsibility for entering and completing treatment, client level variables in child treatment include caregiver and family characteristics.

Child variables. Child demographics, including gender, with males more likely to become premature terminators; lower IQ; and poorer academic functioning have been found to predict treatment attrition (de Haan et al., 2013). Other studies have examined the effect of ethnic minority status, with some results suggesting that ethnic minority children are more likely to leave therapy prematurely (de Haan et al. 2013; Miller, Southam-Gerow, \& Allin, 2008; Warnick, Gonzalez, Weersing, Scahill, \& Woolston, 2012) and others finding no difference between ethnic minority children and white children (Armbruster \& Fallon, 1994; Johnson, Mellor, \& Brann, 2009).

Families with children with diagnosis of an externalizing disorder, more disturbed behavior, and more severe dysfunction are more likely to terminate treatment prematurely (Baruch, Vrouva, \& Fearon, 2009; de Haan et al., 2013; Friars \& Mellor, 2007; Nock \& Kazdin, 2001). Children and adolescents experiencing greater symptom severity (Miller at al., 2008), including those with depression symptoms and increased avoidance (Chasson, Vincent, \& Harris, 2008; Dierker, Nargiso, Wiseman, \& Hoff, 2001), substance abuse (Dierker et al., 2001), traumarelated symptom severity (Chasson et al., 2008), and/or with at least one Axis IV stressor (Miller et al., 2008) are at an increased risk of leaving therapy prematurely. The literature also suggests that children with a clinical diagnosis are more likely to leave therapy prematurely (Peters, Calam, \& Harrington, 2005), including an adjustment disorder diagnosis (de Haan et al., 2013; Miller et al., 2008). Those with comorbid psychiatric disorders (Lock, Courturier, Bryson, \& Agras, 2006) and a greater number of diagnoses (de Haan et al., 2013) might be especially at risk for treatment attrition. 
Other child problems leading to higher rates of attrition include: More caregiver-reported total problems (de Haan et al., 2013), lower functioning per caregiver report (Warnick et al., 2012), and overall risk for psychiatric problems (Dierker et al., 2001); taking psychotropic medication (de Haan et al., 2013); reasons for referral (de Haan et al., 2013, Dierker et al., 2001); and more contact with deviant peers (de Haan et al., 2013). However, while many studies suggest that increased psychiatric impairment and diagnoses put children at a greater risk of psychotherapy attrition, others have found that premature terminators and completers were equally psychiatrically impaired (Armbruster \& Fallon, 1994) or that those with a diagnosis may actually be less likely to terminate therapy prematurely (Lai, Pang, Wong, Lum, \& Low, 1998).

Caregiver and family variables. The literature suggests that caregiver and family demographics may predict attrition from child and adolescent therapy. For example, child and adolescent clients with younger mothers (de Haan et al., 2013; Luk et al., 2001); with less educated caregivers (Luk et al., 2001; McCabe, 2002); and from a lower socioeconomic status (SES; Armbruster \& Fallon, 1994; de Haan et al., 2013; Garcia \& Weisz, 2002; Nock \& Kazdin, 2001; Peters et al., 2005), who are homeless (de Haan et al., 2013), or who received state-funded, low-income insurance support (Armbruster \& Fallon, 1994; Warnick et al., 2012) tend to be more likely to leave therapy prematurely than those with older mothers, more educated caregivers, and higher SES. The findings on SES, however, are not consistent, with some findings suggesting that SES is not a significant predictor of attrition (Johnson et al., 2009; McCabe, 2002).

Children from single caregiver households, specifically those without the father in the home (de Haan et al., 2013), those living with a non-biological head of the household (de Haan et al., 2013; Warnick et al., 2012), and those living with a greater number of siblings (Johnson et 
al., 2009) may be more likely to leave therapy prematurely. Caregiver psychiatric problems, including depression, have also been found to predict attrition, with children and adolescents of caregivers with more psychiatric problems or psychopathology being more likely to leave therapy prematurely than those whose caregivers have fewer or no diagnoses (de Haan et al., 2013; Johnson et al., 2009; Nock \& Kazdin, 2001; Venable \& Thompson, 1998; Warnick et al., 2012). Parenting practices also predict treatment attrition, with those reporting the use of poorer parenting practices being more likely to leave therapy prematurely (de Haan et al., 2013).

Caregivers who reported experiencing more negative life events (de Haan et al., 2013), more parenting stress (Nock \& Kazdin, 2001), and who perceived their children as more difficult (Friars \& Mellor, 2007) were more likely to leave therapy prematurely. The lack of maternal knowledge of the child's diagnosis also predicted attrition (de Haan et al., 2013).

Treatment and therapist variables. Various therapist variables, treatment variables, and treatment participation barriers have been found to significantly predict treatment attrition. In fact, therapist and treatment variables have been found to predict attrition more strongly than even child or family variables (de Haan et al., 2013). Treatment-related variables that have been frequently examined include client barriers to treatment participation, attitudes about and expectations of therapy, satisfaction with treatment, ratings of therapeutic alliance, perceptions of their therapist's general and cultural competencies, and client-therapist matching.

Client-therapist match. The effects of ethnic and gender match between the therapist and child or adolescent clients on treatment attrition are mixed. Results of a meta-analysis on attrition in child and adolescent therapies suggested that a lack of gender match between the child and therapist predicts attrition (de Haan et al., 2013). Yeh, Eastman, and Cheung (1994) found that lack of ethnic match between the child and the therapist also significantly predicted attrition after 
just one therapy session in African-, Asian-, and Mexican-American adolescents. However, the effect of ethnic match was no longer significant when language match was controlled for (Yeh, Eastman, \& Cheung, 1994). Armbruster and Fallon (1994) also examined the effects of childtherapist ethnic match, in a sample of Mexican-American families seeking mental health treatment. Findings suggest that ethnic match was a predictor of attrition only when a minority therapist was matched with a nonminority caregiver.

Therapist cultural competence. Though client-therapist ethnic match does not seem to affect attrition, other research has examined the effect of therapist cultural competence on attrition. There is a paucity of research focused on therapist cultural competencies, treatment outcomes, and attrition and the results of the existing research have been mixed. Owen, Leach, Wampold, and Rodolfa (2011) found that client ratings of therapist multicultural competencies did not account for variability in therapy outcomes. However, in a review of previous reviews of cultural competence, Truong, Paradies, and Priest (2014) found moderate evidence to suggest that interventions to improve cultural competencies lead to improvements in health care access and utilization by clients.

Therapist general competence. Therapist competence in other areas, including therapist adherence to the treatment model, flexibility, and ability to structure treatment, on treatment attrition has been more frequently studied. Results of a study of cognitive behavioral treatment (CBT) in the National Institute of Mental Health Treatment of Depression Collaborative Research Program suggested a modest effect of therapist competence on treatment outcome (Shaw et al., 1999). Therapist ability to structure treatment well was the CBT component most highly related to outcome (Shaw et al., 1999). Interestingly, in another study of adolescents and their families who were being provided either CBT or multidimensional family therapy, when 
therapeutic alliance was controlled for, treatment competence no longer predicted treatment outcome (Hogue, Henderson, Dauber, Barajas, Fried, \& Liddle, 2008). Similarly, Barber, Connolly, Crits-Cristoph, Gladys, and Siqueland (2006) found that therapist adherence did not affect treatment outcomes for clients with a strong therapeutic alliance. Kendall and Chu (2000) measured therapist process variables via retrospective self-reports and found that the only variable that significantly affected treatment outcomes was flexibility when applying a manualized treatment.

Therapeutic alliance. Caregiver-therapist or family-therapist alliance has also been well studied and consistently found to be an important predictor of attrition. The literature suggests that therapeutic alliance in early, middle, and late stages of treatment, as well as over the course of treatment is associated with positive outcomes (Muran \& Barber, 2010). In a study of 344 youth in outpatient treatment, therapeutic relationship problems accounted for most of the variance distinguishing treatment completers from premature terminators (Garcia \& Weisz, 2002). A strong therapist-caregiver and adolescent-therapist alliance early on (Pereira, Lock, \& Oggins, 2006; Robbins, Liddle, Turner, Dakof, Alexander, \& Kogan, 2006), a strong therapistfamily relationship throughout treatment (Stevens, Kelleher, Ward-Estes, \& Hayes, 2006), and caregiver satisfaction with the therapist (Prinz \& Miller, 1994) have been found to prevent attrition or increase the likelihood of treatment completion. There is even some evidence to suggest that the therapeutic relationship may contribute even more to the change process than do specific therapeutic techniques. When clients emphasize the use of certain techniques, they tend to find those techniques less pleasant and to associate them with the perception that the therapist is less competent and less likable (Horvath \& Greenberg, 1994). 
In treatment modalities in which the child or adolescent is old enough to actively participate in treatment, balanced caregiver-child alliances are also important for treatment completion. In one study, though individual caregiver-therapist and adolescent-therapist alliances were not significant predictors of attrition, premature terminators tended to have greater imbalances in alliances than completers (e.g., the caregiver-therapist alliance was rated as much stronger than the adolescent-therapist alliance; Robbins, Turner, Alexander, \& Perez, 2003). Flicker, Turner, Waldron, Brody, and Ozechowski (2008) replicated this finding but found that ethnicity moderated the effect so that Hispanic families who reported a greater imbalance in alliance were more likely to leave therapy prematurely, while Anglo families with an alliance imbalance were not. Stronger therapeutic alliance has also been found to predict greater family participation in treatment, fewer cancellations and no-shows, and greater therapist agreement with the family's decision to terminate therapy (Hawley \& Weisz, 2005).

Caregiver-therapist agreement on therapy termination. Though stronger therapeutic alliance can increase the likelihood, caregiver-therapist agreement about therapy termination tends to be uncommon. In fact, client and family decisions to leave therapy are usually made unilaterally and against the recommendations of the therapist. Because of this, therapists are often not fully aware of client dissatisfaction, termination reasons, or perceptions of improvement (Westmacott, Hunsley, Best, Rumstein-McKean, \& Schindler, 2009). In fact, the literature suggests that therapists underestimate the rate of client attrition and typically expect clients to continue in treatment for considerably longer than the service mean (Pulford, Adams, $\&$ Sheridan, 2008). Though high rates of attrition are pervasive across treatment modalities, settings, and populations, therapists and agencies do not always follow up with clients after they 
leave treatment; and it is difficult to improve services without feedback from those who decide to leave treatment.

Caregiver satisfaction with treatment. Caregivers who are dissatisfied with the intervention (Prinz \& Miller, 1994) or treatment services (Luk et al., 2001), who do not find treatment helpful or effective (Yeh, McCabe, Hough, Dupuis, and Hazen, 2003) or strategies to be useful (Friars \& Mellor, 2007), who perceived the relevance of treatment to be low (Stevens et al., 2006), and who perceived treatment to be less organized (Luk et al., 2001) were also more likely to leave therapy prematurely. In a retrospective, qualitative study of client satisfaction with treatment, Rhodes, Hill, Thompson, and Elliott (1994) found evidence to suggest that clients' perception of a good therapeutic relationship, a flexible therapist, and willingness to assert negative feelings when they feel misunderstood may maintain their satisfaction with treatment even in the event of a misunderstanding. Clients who were more satisfied were more likely to stay in treatment (Rhodes et al., 1994).

Alternatively, some clients might choose to leave therapy prematurely because they are satisfied with treatment, find it useful, and feel that they have benefitted enough without having to complete treatment. In a sample of individuals receiving treatment for an eating disorder, half of the clients left therapy prematurely. However, of those who left before completing treatment, $75 \%$ felt they had improved. In fact, almost $50 \%$ of those who left treatment prematurely improved so much that they no longer met criteria for anorexia or bulimia; the percentage of those who met criteria decreased from $62 \%$ to $33 \%$ (Button, Marshall, Shinkwin, Black, \& Palmer, 1997).

Caregiver attitudes and expectations of treatment. In addition to caregiver satisfaction mid- and posttreatment, pretreatment caregiver expectations of and attitudes about therapy are 
also important predictors of attrition (Baker-Ericzén, Jenkins, \& Brookman-Frazee, 2010). In fact, "attitudinal barriers" have been found to be among the most powerful predictors of attrition in some populations (e.g., Mexican Americans; McCabe, Yeh, Garland, Lau, \& Chavez, 2005). In a study of 372 Latino families of a child with mental or behavioral health needs (Yeh et al., 2003), $64 \%$ of the participating families reported that concerns about what might happen in therapy (e.g., therapist would not keep information confidential) affected their decision to seek treatment. Other reported barriers to participating in treatment were concerns about the effectiveness of services (45\%), that characteristics of the therapist would not meet their needs $(45 \%)$, and that participating in treatment may negatively affect their family (e.g., fear of what others will say or think; 43\%). Of those who do seek treatment, the literature suggests that caregivers with pre-treatment expectancies that their child will recover quickly are more likely to leave therapy prematurely (McCabe, 2002) and do so early on in treatment (Nock \& Kazdin, 2001). Clients' expectations about the time and effort treatment will require may also affect attrition. For instance, clients may not "buy in" to the need for homework and research suggests that homework compliance may be associated with low ratings of therapeutic alliance and with attrition (Dunn, Morrison, \& Bentall, 2006; Helbig, \& Fehm, 2004). Other clients may feel concerned that they are letting their therapist down and experience feelings of shame, humiliation and embarrassment if they fail to complete homework, which may affect attrition (Petry, 2005).

Low caregiver confidence of doing well in treatment also predicted attrition (de Haan et al., 2013). Results from Gunnarsdottir, Njardvik, Olafsdottir, Craighead, \& Bjarnason (2001) and McCabe (2002) suggest that caregivers who reported feeling that they should be able to overcome their child's emotional and behavioral problems using increased discipline or that they 
should have been able to handle their child's problems on their own were more likely to leave therapy prematurely than caregivers who did not. On the other hand, caregivers who understood their own role in the management of their child's behavior (Peters et al., 2005) and who credited strategies they learned in therapy for increasing their relationship with their child (Friars \& Mellor, 2007) were more likely to complete treatment. Not only do caregiver expectancies for treatment predict treatment attendance and attrition, they also predict subsequent barriers to treatment participation such that caregivers with lower expectancies for therapy report experiencing greater barriers to treatment (Nock, Phil, \& Kazdin, 2001). Interestingly, caregivers with very low or very high expectancies were the least likely to leave therapy prematurely and attended the greatest number of therapy sessions (Nock et al., 2001).

Barriers to treatment participation. In addition to attitudes about and expectations of therapy, several other logistical barriers to treatment participation significantly predict treatment attrition (de Haan et al., 2013; McCabe, 2002). Barriers to treatment have also been found to moderate the risk of attrition so that even if families are at risk for leaving therapy prematurely due to other pre-treatment predictors, not experiencing barriers can reduce the risk of attrition and vice versa. Specific barriers to treatment participation that have been found to significantly predict attrition in previous research are: perceived low relevance of treatment, therapist rating of the treatment as more demanding, more caregiver-reported stressors-obstacles, and more therapist-reported stressors-obstacles (de Haan et al., 2013), including situational reasons or logistical or environmental obstacles related to their current life situation (Prinz \& Miller, 1994). Yeh and colleagues (2003) also found that financial, language, and other practical barriers discouraged Latino families from even seeking treatment. Many barriers to treatment 
participation can be quite personal and they are often kept private. So, therapists may not always be aware of or fully understand all of the barriers to treatment each of their clients experiences.

\section{Parent-Child Interaction Therapy}

The sample for the current study includes families provided one specific evidence-based treatment, Parent-Child Interaction Therapy (PCIT), in community settings. PCIT (Eyberg \& Funderburk, 2011; McNeil \& Hembree-Kigin, 2010) is an evidence-based treatment for 2.5- to 7-year-olds and their families. The manualized parent training intervention was developed to treat disruptive behavior and has also been used with families who have experienced or are at risk for physical abuse. The two main treatment goals for PCIT are: 1) to improve caregiverchild relationships and 2) to reduce externalizing behavior problems like tantrums and other aggressive, noncompliant, and oppositional behavior. Caregivers who participate in PCIT are coached in play therapy and discipline skills used to improve the quality of the caregiver-child relationship and to decrease negative behavior and increase positive behavior. Though adaptations of PCIT are currently being implemented in various settings, classic PCIT was designed to be an office-based intervention and PCIT is still largely provided as outpatient therapy. PCIT therapy rooms include a therapy room, observation room, and backup room. The therapist observes the caregiver-child interaction from the observation room, using a two-way mirror, and uses an ear piece to communicate with and coach the caregiver in their interactions with their child. There are two phases of PCIT: 1) Child Directed Interaction (CDI) and 2) Parent Directed Interaction (PDI). In CDI, the goal is to improve the caregiver-child relationship by increasing positive caregiver behaviors and supporting social interaction. In PDI, discipline techniques and other skills (e.g., giving correct commands, using limit-setting, implementing consequences like timeout) are introduced to decrease noncompliant and disruptive behavior. 
The PDI phase is meant to result in continued caregiver-child bonding and a strong relationship as well as reductions in negative child behaviors. With increased use of appropriate discipline techniques, PDI has also been found to result in the use of fewer harsh discipline tactics.

During each phase of treatment, caregiver skills are assessed during the first five minutes of each session to examine the caregiver's progress toward mastery of the skills. The CDI and PDI phases of treatment are delivered consecutively, with progress to PDI being dependent on CDI skill mastery and graduation and completion of the PCIT program being dependent upon PDI skill mastery. Neither phase has a fixed number of sessions, but the CDI phase usually lasts about four weeks and the PDI phase usually lasts about six weeks. The average length of treatment is between 12 and 14 weeks (McNeil \& Hembree-Kigin, 2010). CDI mastery criteria include the caregiver using 3 or fewer commands, questions, and criticisms and ten or more of each of three positive verbalizations: behavior descriptions, reflections, and labeled praises. Thought the treatment protocol indicates that moving on to the PDI phase is contingent upon mastery of CDI skills, this is not always the case. Therapists must sometimes balance treatment fidelity with the best interest of the child and use their clinical judgment and experience to decide whether or not to move forward without one or both caregivers meeting mastery. The PDI phase ends in PCIT graduation and treatment completion, contingent on meeting PDI mastery criteria. They include: (a) caregiver report of child behavior problems as in the normal range, (b) the caregiver implementation of at least four commands; at least $75 \%$ "effective," (c) using $75 \%$ correct follow-throw, and (d) successful use of the specific PCIT time-out procedure.

\section{Predictors of Attrition in Parent-Child Interaction Therapy}

Similar to other behavioral and mental health interventions, attrition among families receiving PCIT is an ongoing challenge. Four previous published studies of attrition in PCIT 
have identified attrition rates ranging from $33 \%$ to $69 \%$ as well as predictors at caregiver-, family-, and therapist-levels. Findings suggest that the following variables affect attrition in PCIT: low SES (Harwood \& Eyberg, 2004; Lanier, Kohl, Benz, Swinger, \& Drake, 2011; Werba, Eyberg, Boggs, \& Algina, 2006), poorer therapist rating of caregiver psychosocial and occupational functioning (Lanier et al., 2011), lower maternal IQ (Werba et al., 2006), greater parenting stress (Werba et al., 2006), being placed on a waiting list (Werba et al., 2006), and more caregiver cancellations and no-shows (Lyon \& Budd, 2010). Other variables found to affect attrition were more caregiver-reported barriers to treatment participation (Lyon \& Budd, 2010), more inappropriate parenting behavior at pre-treatment (Werba et al., 2006), and therapist verbalizations/therapy style and a good therapeutic alliance early in treatment (Harwood \& Eyberg, 2004). Additionally, families who had a referral for treatment were more likely to terminate PCIT prematurely than those who were self-referred (Lyon \& Budd, 2010) as were caregivers who felt that treatment was progressing too slowly, who had to wait longer for treatment to begin, and who were slightly less satisfied with therapy (Lyon \& Budd, 2010).

\section{The Pilot Study}

A fifth study of predictors of attrition in PCIT was my thesis study (Liebsack, Herschell, McNeil, \& Genzler, 2016), for which the current study will serve as a follow-up. In this pilot study, we examined patterns and predictors of attrition in a sample of 134 families receiving PCIT in various community settings across one state, with the aim to replicate and expand upon previous studies of attrition in child and adolescent therapies, and PCIT specifically. Of the 134 families, 98 (73\%) terminated PCIT prematurely and 36 families (37\%) graduated. Of the families who left therapy prematurely, 14\% dropped out after an assessment session, $10 \%$ after the CDI teach, $61 \%$ after a CDI coach, $2 \%$ after a PDI teach, and 13\% after a PDI coach. 
Findings supported previous studies indicating that families were most likely to drop out of treatment early on. Families were more likely to drop out during the CDI coach phase. Sixteen percent of families left after attending their second CDI coach session and the fourth CDI coach session was the last session attended by the majority (53\%) of families.

The pilot study examined child gender, minority status, externalizing behavior severity, caregiver symptoms of depression, and therapist satisfaction with PCIT, none of which significantly predicted attrition. However, caregiver-to-child ratio, SES, wait time for treatment, caregiver-reported life stressors and obstacles, and caregiver satisfaction with PCIT were all significant predictors of attrition. So, families with a lower caregiver-child ration (e.g., more children and fewer caregivers) and lower SES at pretreatment, families who waited longer between their PCIT intake session and CDI Teach session, families who reported experiencing more obstacles to participating in treatment and life stressors, and families who reported being less satisfied with PCIT services were all more likely to leave PCIT before graduating.

Therapists were asked to share their impressions about each family's progress in treatment, issues that may have had a negative impact on treatment outcomes and the overall course of treatment, and why PCIT services ended. Therapist reports were collected for all families at the time of discharge, whether they graduated or left prematurely. The top five family issues most endorsed by therapists as having a negative impact on PCIT were: family being too busy (54.2\% of families), marital discord/conflict (27.3\%), caregiver mental health problems (20.5\%), residential instability (e.g., moves, no phone; $18.2 \%)$, and "other" issues (26.5\%). "Other" negative impacts on treatment included logistical barriers such as lack of transportation, the birth of a new baby, or caregiver incarceration; caregivers' lack of commitment or resistance to PCIT (e.g., unresponsiveness to coaching, cancellations, no-shows); and PCIT not being an 
appropriate course of treatment for the individual child (e.g., caregiver does not have behavior concerns, child has limited speech).

Therapists also indicated that they believed that $15.9 \%$ of the families they had worked with experienced conflict with an outside family member or friends, that $12.1 \%$ of families' PCIT services were interfered with because of involvement in other treatment programs, that limited caregiver cognitive skills impacted PCIT negatively for $12.1 \%$ of families, and that PCIT was negatively impacted by caregiver anger or hostility in $7.6 \%$ of families treated. Other issues that had a negative impact on PCIT as reported by therapists included: parent out of the home (6.8\%), drug/alcohol problems (6.1\%), limited child cognitive skills (5.3\%) and child out of the home $(3.8 \%)$, having to "childline" a family or report suspected abuse to child welfare $(3.0 \%)$ and living in a dangerous community $(0.8 \%)$.

Therapists were also asked to report why PCIT services ended. Therapists reported that PCIT ended for $37.3 \%$ of families seen because of no-shows, $32.1 \%$ of families or caregivers were perceived as being disinterested in PCIT or having low motivation, $26.3 \%$ of families left PCIT because of clinical improvements or because problems got better, cancellations contributed to PCIT ending for $25.4 \%$ of families, and $23.1 \%$ of families chose to end PCIT because they felt they no longer need PCIT services. For $17.3 \%$ of families, the therapist also felt that PCIT services were no longer needed. Non-compliance with PCIT by patient and/or family during sessions was indicated as a reason for the end of PCIT for $16.4 \%$ of families, as were schedule conflicts $(16.4 \%)$. Therapists reported that $6.0 \%$ of families moved or were no longer available to participate in PCIT, that $3.8 \%$ of families did not like therapy, the therapy, or other aspects of PCIT services, and that the problem got worse for $3.7 \%$ of families. The other therapist reported reasons for ending PCIT were legal problems that prevented family’s participation $(2.2 \%)$; 
insurance company or policy constraints/issues $(2.2 \%)$; child removed from the home $(0.7 \%)$; other reasons $(23.3 \%)$; or, of course, because the client graduated from treatment $(27.6 \%)$.

Finally, therapists were asked about the discharge recommendations they gave to each family they worked with. Therapists referred $29.1 \%$ of their families to outpatient treatment, $21.6 \%$ to wraparound services or Behavioral Health Rehabilitation Services (BHRS), 14.9\% to intensive case management and resource coordination with face-to-face meetings, $7.5 \%$ to community support services, $6.7 \%$ to family-based services, $3.7 \%$ to family therapy, and $2.2 \%$ to administrative case management without face-to-face meetings or partial hospitalization or day treatment.

\section{Development of the Current Study}

Following the completion of the pilot study, we began discussing the opportunity to conduct a follow-up study. Because of the scope of the pilot study, the nature of the analyses used, and the use of archival data from a larger parent study, not all variables of interest were examined. Additionally, though the results had important implications for research and clinical practice, a better understanding of how and why certain predictors significantly affected attrition (e.g., caregiver-child ratio, caregiver satisfaction with treatment, experiencing more obstacles to treatment and life-stressors) was important. Also, while therapist beliefs, perceptions, and reasons why families left therapy prematurely were explored in the pilot study, families' reasons for ending treatment were not, which is problematic. Therapists are often only partly aware of client termination reasons, including dissatisfaction or perceived improvements, because clients and families often decide to leave therapy unilaterally and against the recommendations of the therapist (Westmacott et al., 2009). Thus, it was clear that a follow-up with the pilot study sample of PCIT families was needed. The intricacies of families' experiences, perspectives, and 
interpretations are important to assess when it comes to seeking client feedback about treatment and reasons for attrition.

At the thesis defense meeting on October 26, 2016, committee members discussed ideas and suggestions for variables to include in a follow-up study; the current study. The committee was interested in learning more about the effects of family engagement and commitment to treatment on attrition; about how the therapist explained PCIT to the family and whether or not the family understood the therapist description and what to expect in treatment; and whether the number of PCIT cases a therapist had on his or her caseload, the therapists' level of treatment fidelity, and other therapist variables affected attrition. The committee also expressed interest in the therapeutic alliance and how the strength of the therapist-caregiver alliance may have affected family attrition. Finally, committee members were interested in learning more about why caregiver-child ratio might have been a predictor of attrition, in distilling which specific obstacles to treatment participation and life stressors most strongly predicted families leaving therapy prematurely (e.g., childcare, transportation); and whether there may be a way to "triage" families into outpatient or in-home PCIT services based on two or three variables most likely to distinguish premature terminators from completers at pretreatment.

On February 15, 2017, I presented an overview of the pilot study findings as well as didactic information on increasing client engagement and decreasing attrition to a group of West Virginia University (WVU) clinical and clinical child faculty and graduate students, and asked for feedback on what they would be interested to learn in a follow-up study on attrition. Faculty and students in attendance were largely interested in learning why families sought treatment, what their goals were for treatment, whether they felt PCIT was a "good fit" for their family or 
how satisfied they were with PCIT, and when during the course of treatment they formed positive or negative views about PCIT.

Finally, Dr. Herschell and I presented the findings of the pilot study at a Pennsylvania PCIT Implementation Statewide Steering Committee, which was developed as part of the large parent study. Attendees included research team members from the parent study as well as representatives from the school system (e.g., school administrator); a managed care organization (e.g., president and CEO, senior director); community agencies (e.g., executive director, vice president of clinical services, coordinator of PCIT); the Bureau of Children's and Behavioral Health; faith-based community settings; a statewide Evidence-based Prevention and Intervention Support Center; and consultants (e.g., statewide child psychiatric consultant, statewide administration and implementation policy development and advocacy consultant, county consultant to Department of Human Services).

Attendees were interested in the effects of social determinants of health and other pretreatment family factors or barriers to treatment, family engagement in and satisfaction with PCIT, and therapist competence and therapeutic alliance on attrition from PCIT. Specifically, stakeholders expressed interest in learning from families who had left PCIT prematurely whether or not their basic social and economic needs were being met, whether or not they were experiencing other significant life stressors, and how that affected their treatment. They were also interested in any possible differences in barriers to treatment between families living in urban and rural areas (e.g., transportation). Because family definitions of treatment success and the graduation criteria in PCIT may not always be consistent, one stakeholder was interested in learning how families defined success in PCIT, and whether families left treatment prematurely because they felt they had learned enough or because their child's behavior had improved 
enough. Others were interested in learning more about why families initiated services in the first place and whether they felt that their concerns had been addressed in treatment. Additionally, stakeholders were interested in families' motivation for and engagement in PCIT and whether levels of motivation or engagement affected their decision to leave prematurely.

Other stakeholders argued that motivation is not a prerequisite for treatment and that family perceptions of therapist and agency variables would be important to assess. They were interested in whether families felt valued in treatment and whether or not, during the course of families' involvement with the agency from referral to leaving therapy, anyone asked about their satisfaction with and the utility of PCIT for them and their child. Finally, stakeholders expressed interest in learning more about the therapist skill and competence and therapeutic alliance. One stakeholder suggested that it would be important to assess any cultural barriers families may have experienced, as the majority of the therapists in the parent study (91\%) were white and the families were more racially and ethnically diverse (71\% white). Stakeholders hypothesized that caregiver perceptions of therapist cultural competence and general competence as well as therapeutic alliance would be related to family completion or attrition.

\section{Aims of the Current Study}

The current study is a correlational study which aimed to examine the association between caregiver factors, therapist factors, treatment characteristics, and treatment participation variables and family attrition from PCIT. Retrospective caregiver-report measures were used to examine additional variables that were not examined in the pilot study and to conduct a more indepth examination of certain variables that were significant predictors of attrition in the pilot study. Another aim was to compare therapist- and caregiver-reported negative impacts on treatment and reasons why treatment ended and to assess individual treatment experiences and 
additional reasons why premature terminators chose to end treatment. Specific research questions and corresponding hypotheses are presented in the temporal order in which the dependent variables were measured.

Research question 1: Factors associated with attrition. Do certain caregiver factors, therapist factors, treatment characteristics, and/or treatment participation variables and barriers predict attrition in PCIT? Are caregiver attitudes toward treatment, caregiver expectations of treatment, satisfaction with PCIT, ratings of therapist PCIT competence, therapeutic alliance, therapist cultural competence, and caregiver commitment to PCIT associated with attrition from treatment?

Hypothesis 1. It was hypothesized that more negative caregiver attitudes towards treatment as measured by total score on the Therapy Attitudes Questionnaire would be significantly associated with attrition. Therapy expectations as measured by the Therapy Expectations Questionnaire were also hypothesized to be associated with attrition, such that premature terminators would retrospectively report more barriers to treatment at pre-treatment and pretreatment expectations that their child would recover quickly and that the therapist would not be highly directive. Satisfaction with PCIT treatment components and higher ratings of therapist competency in PCIT as measured by the Treatment Satisfaction and Therapist Competency Questionnaire was hypothesized to be associated with treatment completion, as were a stronger therapeutic alliance and higher ratings of cultural competency, as measured by the Therapeutic Alliance Scale for Caregivers and Parents and Perceived Cultural Competency Scale, respectively. Finally, greater treatment commitment, as assessed by the Treatment Summary Report—Parent version, was hypothesized to be associated with treatment completion. Open ended questions asking what caregivers liked or did not like about PCIT, feedback they 
would give to their PCIT therapist or agency, and reasons for leaving treatment were also included. These items are exploratory in nature and caregiver responses will be reported.

Research question 2: Caregiver-therapist agreement on reasons for attrition. To what degree do therapist impressions about treatment completion, progress made in treatment, and reasons PCIT services were ended reflect caregiver reports?

Hypothesis 2. It was hypothesized that caregiver-therapist agreement on reasons of attrition may be low in general. However, research question 2 was exploratory in nature, so there were no additional, more specific, hypotheses.

\section{Research question 3: Family compliance with post-treatment therapist}

recommendations. To what degree did families comply with therapist post-treatment recommendations? Did families seek other services after graduating from or leaving PCIT prematurely? Were premature terminators more likely to seek other services or seek different services than completers?

Hypothesis 3. Research question 3 was exploratory in nature. Families were asked about any additional treatment received since ending PCIT to identify patterns and examine whether or not families complied with therapist post-treatment recommendations.

\section{Method}

\section{Parent Study}

Participants for the current study were recruited from families who participated in a large study (R01 MH095750; A Statewide Trial to Compare Three Training Models for Implementing an EBT; PI: Herschell). The RO1 was a National Institute of Mental Health (NIMH) funded statewide implementation trial testing the effectiveness of three different training models for training therapists in PCIT. The parent study ended on December 31, 2017 and tested three 
commonly used training models (i.e., learning collaborative, cascading, and distance education) in order to learn about training, implementation, and client outcomes. Data for the current study was collected as part of the larger parent study. A modification made to the original protocol to add the measures used in the current study and to update the payment schedule was approved by the University of Pittsburgh Institutional Review Board (IRB). Data collection was completed between August 3, 2017 and November 9, 2017. Data collection procedures are further detailed below. A Data Use Agreement was completed between the University of Pittsburgh and West Virginia University. The current data were analyzed at West Virginia University after a protocol to complete secondary analysis was approved by the West Virginia University IRB.

In order to answer some of the research questions (e.g., caregiver-therapist agreement), therapist report data from the parent study was also used. Demographic information collected in the current study (e.g., caregiver email address, child birth date, caregiver birth date, child race/ethnicity) was used to match their current data with their previous data from the parent study.

\section{Procedure}

Recruitment and consent. The researchers attempted to contact and re-consent all family participants who had previously consented to and participated in at least one time point of the parent study (see Figure 1 for a flow chart detailing the recruitment process; Appendix A for contact instructions used). Of the 398 families recruited by therapists who participated in the parent study, 228 families consented to the parent study. Of those, 36 later withdrew from the parent study or neglected to complete assessments at any of the four time points (e.g., baseline, three-, six-, or 12-month follow-up). Of the 192 remaining families, the researchers attempted to contact all by phone and left voicemails when able (see Appendix B for the phone script for 
voicemails). The researchers attempted to call families during hours which caregivers had previously indicated were "good times to call" if possible, and always between 9AM and 7PM in the family's time zone. If reached, the researcher followed a phone script (see Appendix C) to introduce the caregiver to study changes including the additional time point, added measures, and new payment schedule and to assess interest in participating. If interested, the caregiver was read the consent form, asked for verbal consent, and the researcher completed a Verification of Explanation form (Appendix C).

It was not possible to leave voicemails or reach 59 of the families by phone due to a variety of reasons including that the phone number on record had changed (e.g., the number listed in a family's contact information was now a "wrong number" according to the individual who answered or the number was no longer in service), the voicemail box was not set up or could not accept messages, or the number rang but did not lead to a voicemail or messaging service. Of the 192 families available for re-consent, 111 were also contacted by email. Twenty families were also contacted by text message, if they had previously given permission to be texted and if the researchers were certain that they had the correct phone number for the identified caregiver (e.g., they had previously spoken on the phone, the voicemail message included that caregiver's name).

Seventy-six families were re-consented and given the choice to complete the caregiverreport measures online, over the phone, or by mail. Sixty-eight families completed the assessments by the end-date of the study, seven by mail, seven by phone, and 54 online. One family's data (online) was removed from analyses due to an inconsistent pattern of reporting (e.g., rating all items on an assessment " 1 " even when there were reverse-scored items included) and a relatively short completion time which suggested he/she may have hurried through the 
assessments. Of those who were not re-consented, three refused participation and the remainder were impossible to contact, did not respond to the researcher's attempts to contact them, or were difficult to connect with after several attempts including those made at various times of the day on both week days and weekend days. Matched therapist-reported data were available for 55 of the 67 families who completed the current study $(82.10 \%)$.

Payment. Incentive for study participation was a $\$ 40$ prepaid debit card. The family’s addressed was verified during the consent process and an inactive debit card was mailed to the participating caregiver by the end of the next business day, including instructions on how to activate the card once received. One research assistant mailed out all debit cards, tracked card numbers, activated cards when contacted by participants, and loaded payment to cards upon notification that the participant had completed the assessments.

Data collection. Caregivers were asked their preferred mode of completing the assessments. If participants preferred to complete assessments online, they were emailed a link to the assessment on Qualtrics within 24 hours (see Appendix D for email). The first page of the Qualtrics survey system gave instructions on how to complete the questionnaires and the last page thanked the caregiver for their participation, included contact information for the researcher, and encouraged the caregiver to contact the researcher by phone or email with any questions or concerns. If participants preferred a hard copy of the assessments be mailed to their home, the assessments were mailed with a cover letter (Appendix E) and a stamped return envelope by the end of the next business day. Finally, if participants preferred to complete the assessment over the phone, the researcher attempted to complete the assessment immediately or scheduled a one-hour phone call to do so (see procedure in Appendix F). Completion of online 
and mailed assessment was checked twice daily and the research assistant was notified when assessments had been completed and debit cards could be loaded with payment.

Follow-up reminders. Families were followed up with two times a week using each consented to form of communication (phone call/voicemail, email, text message) for a total of up to six times per week for eight weeks. Contact attempts were documented in a call log (Appendix $\mathrm{G)}$.

Concluding procedures. If families expressed interest in returning to therapy to complete PCIT or asked for other therapy referrals, they were read, mailed, and/or emailed a referral sheet including local agencies at which PCIT and other treatments were offered.

\section{Participants}

Child demographics. The children in the study were approximately 5.35 years old when beginning PCIT and approximately 8.20 years old at the time the caregivers participated in the current study. The majority of children were male (73.1\%), Caucasian (76.1\%), and not Hispanic or Latino (81.3\%; Table 1).

Caregiver and family demographics. Caregivers were 32.82 years old on average when PCIT started and were 35.24 years old when they completed the current study. The majority of caregivers were female (98.5\%), Caucasian (76.1\%), not Hispanic/Latino (87.7\%), and were biological mothers (92.5\%; Table 1). Most families in the current sample included those from 2adult (48.5\%), 2-child (40.9\%) homes. Caregivers tended to be single (56.1\%), have completed at least a high school degree or GED (92.5\%), be employed full-time (45.3\%), and most families had a household income of $\$ 14,999$ or less per year (44.6\%; Tables 1 \& 2).

The point at which each family ended treatment differed according to which wave of the parent study they were a part of and their PCIT treatment process, including whether they left 
PCIT prematurely or graduated from treatment. Nine families were in Wave $1(13.4 \%), 28$ in Wave $2(41.8 \%), 15(22.4 \%)$ in Wave 3, and $15(22.4 \%)$ in Wave 4. Thus, the length of time between families' date of intake, end of treatment, and participation in the current study varied. Number of months between the completion of their first assessment in the parent study (at pretreatment) and participation in the current study ranged from 16.67 to 52.77 months ( $M=$ 33.89, $S D=8.74$; Table 2). Table 3 includes therapist information and demographics. The 67 families in the current study had 39 different therapists from 25 agencies in 19 counties across the Commonwealth of PA. Most agencies (36\%) treated one family in the current sample and most therapists (50\%) had one family from the current sample on their caseload. Therapists were largely white (96.9\%) women (88.2\%) with a Master's degree (97.0\%). They had 11.52 years of experience, on average, and about half (48.5\%) were professionally licensed. Families were included across all therapist training conditions in the parent study, including 34 (50.7\%) who were trained using learning collaborative, 21 (31.3\%) cascading, and 12 (17.9\%) distance learning. Percentages of families across study waves and conditions in the current study were commensurate with those in the parent study.

\section{Measures}

All consented participants completed caregiver-report measures online, over the phone, or by mail. Caregiver-report measures were used to collect data on variables hypothesized to be associated with attrition and not examined in the parent study and to collect additional in-depth information on variables that were found to significantly predict attrition in the pilot study. Measured variables included caregiver perceptions of treatment, the therapist, the therapeutic alliance, treatment completion, progress made in treatment, and reasons why their PCIT services ended. Caregiver reasons for leaving therapy prematurely were compared with the reasons 
therapists cited in the pilot study and the agreement between families and therapists was examined. The current study aimed to replicate findings of previous studies of attrition to a new, relatively large sample of premature terminators of PCIT and to learn about any PCIT-specific reasons for attrition, based on caregiver-report. Families were asked about any additional treatment they had received since ending PCIT to identify any patterns or differences between premature terminators and completers and to examine whether or not families complied with follow-up recommendations reported by therapists.

A list of the constructs assessed, measures used, and approximate time to complete each measure can be found in Appendix H. Minor edits were made to the language of each measure to orient the participant to the period of time they were asked to report on retrospectively. The measures can be found in Appendix I.

Demographic Questionnaire. The Demographic Questionnaire was used to assess the limited caregiver and child demographic information needed to match their current data with their previous data from the parent study (e.g., caregiver email address, child birth date, caregiver birth date, child race/ethnicity). Mailing addresses were also collected for payment purposes.

Therapy Attitudes Questionnaire (TAQ; McCabe, 2002). The TAQ was used to assess caregiver attitudes towards entering therapy. The 30-item caregiver-report was originally developed to assess Latino caregiver attitudes towards therapy for their young child upon therapy entry. It asks about caregiver perceptions that their child could improve without treatment, feelings of responsibility for their child's problems, perceptions of whether or not discipline is the best way to handle their child's problems, and how much stigma they associate with mental and behavioral health problems. Questions were developed using a literature review and focus 
groups of Latino caregivers and the measure has been updated and used with other diverse samples (Yeh et al., 2003). The TAQ includes 10 subscales: family/self-reliance, guilt feelings, reliance on discipline, stigma, family attitudes, mistrust of therapist, other general attitudes, religion, use of alternative treatments, and medications. Two items on the use of alternative treatments subscale are specific to Hispanic and Latino cultures (e.g., use of egg cleansing, lettuce baths) and so were not included for the purposes of the current study. One item on the mistrust of therapist subscale asks about the preference to work with a Latino therapist. For the purposes of the current study, "Latino" was changed to "from my/my child's culture." All other items were retained. The current sample was asked to retrospectively report on their attitudes towards therapy upon beginning PCIT.

Therapy Expectations Questionnaire (TEQ; McCabe, 2002). The TEQ, a 24-item caregiver-report measure, was used to assess caregivers' expectations for treatment. Like the TAQ, the TEQ was developed by McCabe (2002) for use with Latino families, and later used with more diverse samples. The five subscales include caregiver expectations of therapist directiveness (e.g., the extent to which the therapist will offer advice and ask the caregiver to actively participate in treatment), concerns and perceived barriers to treatment (e.g., financial barriers, lack of transportation), speed of recovery (e.g., how quickly the caregiver expects the child to improve in treatment), caregiver assertiveness (e.g., how likely the caregiver is to communicate dissatisfaction to the therapist), and other expectations for treatment (e.g., who from the family will be involved). The TEQ also includes two questions to assess caregiver expectations about frequency and length of treatment. Similar questions were also included on another measure used, so those two items were removed for the purposes of the current study. 
Treatment Satisfaction and Therapist Competency Questionnaire (TSTCQ). The

TSTCQ was developed for the purposes of the current study and was used to assess caregiver satisfaction with certain key features of PCIT as well as therapist competencies related to the key factors. Key factors of PCIT, according to McNeil and Hembree-Kigin (2010), include: 1) Working with the Parent and Child Together, 2) Direct Coaching of Parent-Child Interactions, 3) Using Data to Guide Treatment, 4) Sensitivity to Developmental Concerns, 5) Intervening Early, 6) Targeting a Range of Behavior Problems, 7) Specialized Space and Equipment, 8) Targeting Patterns of Interaction Rather than Discrete Behaviors, and 9) Positive, Non-judgmental Philosophy. Items for factors 4, 5, 6, 8, and 9 were not included. Though they are all important factors of PCIT, many caregivers participating in PCIT may have less insight into these aspects of treatment and have difficulty commenting on them. Items were added to assess satisfaction with and therapist competency in working with the caregiver and the child together (e.g., caregiver active participation in treatment), direct coaching, using data to guide treatment (e.g., tracking and sharing Eyberg Child Behavior Inventory [ECBI] scores weekly), and specialized space and equipment, as well as satisfaction with the two phases of treatment, with special playtime, and with timeout (on the chair and in the backup room) and an alternative discipline technique to time out, called swoop-and-go, in which the caregiver quickly collects all the toys and leaves the room if the child is noncompliant.

Skill and satisfaction subscale scores were used in current analyses, because while the two subscales are highly correlated, caregiver perception and ratings of therapist skill and ratings of their satisfaction with PCIT components are two unique constructs that may affect family attrition differently. Caregivers were not asked to rate perceived therapist skill or their satisfaction with components of treatment they did not participate in or experience, thus an 
average score for completed questions was calculated and these average scores were used as predictor variables.

Therapeutic Alliance Scale for Caregivers and Parents (TASCP; Accurso, Hawley, \& Garland, 2012). The TASCP is a 12-item caregiver-report measure used to assess perceived therapeutic alliance. It assesses the extent to which the caregiver and therapist collaborated throughout treatment and their personal relationship. Caregivers rate items on a four-point Likert scale ranging from "Not true" to "Very much true." The TASCP has high internal consistency across four time points in treatment (four, eight, 12, and 16 months), with Cronbach's alphas ranging from .85 to .88 . Temporal stability of caregiver-therapist alliance between four and 12 months is moderate and between months 12 and 16 is high. The TASCP also shows high convergent and predictive validity, with caregiver-reported alliance being significantly associated with therapist-reported alliance $(\mathrm{r}=.67, p<.0001)$ at 4 months and also significantly associated with variables like number of sessions attended, satisfaction with improvements, caregiver reports of wanting to end treatment, and endorsing disliking the therapist as one of the main reasons for attrition (Accurso, Hawley, \& Garland, 2012). The scale was made available for public research use via the PsycTESTS database.

Perceived Cultural Competency Scale (PCCS; Lucas, Michalopoulou, Falzarano, Menon, \& Cunningham, 2008). The Perceived Cultural Competency Scale is a nine-item clientreport measure that assesses perceptions of health care provider cultural knowledge, awareness, and skill. Caregivers rated items on a seven-point Likert scale ranging from "Not at all" to “Knows a lot." Higher scores indicate greater perceived competence. The three-factor model has been supported, with evidence that the three latent factors (e.g., skill, knowledge, awareness) are distinct and all predict a general higher order cultural competency latent factor $(p<.001$; Lucas 
et al., 2008). The measure also demonstrates convergent and incremental validity with measures of discrimination, trust, and satisfaction (Lucas et al., 2008). The scale was made available for public research use via the PsycTESTS database.

Treatment Summary Report—Parent Version (TSR-P). The TSR-P was designed for the purposes of the current study and edited from a therapist-completed treatment summary report used in the parent study. The TSR-P included a list of possible reasons for ending treatment, negative impacts on treatment, and other services utilized after ending PCIT and caregivers were asked to indicate all that applied to them. The TSR-P also assessed treatment participation and progress. Edits from the therapist-reported version included slight changes in the language used and the addition of questions regarding the caregivers' expectations of, commitment to, and opinions of treatment. Caregiver motivation for treatment was assessed using one item on which caregivers rated their motivation for the child to participate in treatment before their family started PCIT on a five-point Likert scale ranging from "Very Low" to "Very High". Caregivers were asked to rate their commitment to treatment before beginning PCIT, after the CDI teach session (because families are most likely to leave treatment during CDI), and at their last PCIT session using a five-point Likert scale ranging from "Very Low" to "Very High." Because caregiver commitment remained relatively stable across time points, with some slight changes for some families, an average commitment score over the course of treatment was calculated and used as the predictor variable.

\section{Results}

\section{Preliminary Analyses}

PASW Statistics Version 21.0 (IBM Corp., 2012) was used for statistical analyses of the caregiver-report measures. All variables were inspected for normal distributions, homogeneity of 
variance, multicollinearity, and univariate and bivariate outliers. Missing data were examined for meaningful patterns. Appropriate data transformations and imputations were made (Tabachnik \& Fidell, 2013). An unconditioned model of the variation of attrition was created in which variation in family attrition between therapists and agencies was predicted using a one-way analysis of variance. Agency and therapist were entered into the model predicting attrition, without any other variables included. In effect, the variance of the dependent variable, attrition, was partitioned in terms of therapist variance and agency variance. Results indicated that there were not significant nesting effects of family within therapist within agency, thus Hierarchical Linear Modeling was not necessary and Logistic Regression was used. Before conducting logistic regression analyses, variables were also inspected for linearity and independence of errors.

\section{Variable Choice}

In order to have sufficient power, because the nature of the analyses used, and the number of participants; four of the seven predictor variables of interest were examined. In order to choose which variables to include, first the distribution of each variable was examined. A ztest was applied for normality testing using skewness. Ratings of therapist skill, satisfaction with PCIT, and therapeutic alliance all had a skew variable greater than 3.29 (Kim, 2013), suggesting that the majority of participating caregivers rate their therapists as highly skilled, were highly satisfied with PCIT, and had positive alliances with their therapists. Thus, those variables were eliminated from analyses. The final variables included: attitudes toward treatment, expectations of treatment, perceived cultural competence, and commitment to treatment. Variables examined in the current study are described in Table 4. Correlations between predictors are described in Table 5 .

\section{Reliability}


Caregiver attitudes towards entering therapy were assessed using the TAQ. The scale had a questionable level of internal consistency, as determined by a Cronbach's alpha of 0.63 , overall (DeVellis, 2012; Table 6). Levels of internal consistency were acceptable for the family/selfreliance ( $\alpha=0.79)$, use of alternative treatments $(\alpha=0.77)$, and guilt feelings subscales $(\alpha=$ $0.73)$; questionable for the reliance on discipline ( $\alpha=0.67)$, stigma $(\alpha=0.67)$, and mistrust of therapist ( $\alpha=0.67)$ subscales; and poor for the medication $(\alpha=0.59)$, family attitudes $(\alpha=0.57)$, and religion $(\alpha=0.57)$ subscales.

The TEQ was used to measure caregivers' expectations for treatment. The scale had a Cronbach's alpha of 0.53 and a poor level of internal consistency overall (Table 6). The subscales assessing expectations of therapist directiveness $(\alpha=0.71)$, caregiver concerns and perceived barriers to treatment $(\alpha=0.71)$, and expectations about the speed of recovery $(\alpha=$ 0.77) had acceptable levels of internal consistency while the subscale measuring caregiver assertiveness had a questionable level of internal consistency $(\alpha=0.56)$.

Caregiver ratings of therapist PCIT skill and satisfaction with PCIT components was measured using the TSTCQ, which was developed for the current study. The scale had an excellent level of internal consistency, as determined by a Cronbach's alpha of 0.95 , overall (Table 6). Levels of internal consistency were good $(\alpha=0.84)$ and excellent $(\alpha=0.94)$ for ratings of therapist skill and caregiver satisfaction with PCIT, respectively (Table 8).

Caregivers' perceived therapeutic alliance was measured using the TASCP. A Cronbach's alpha of 0.77 suggests an acceptable level of internal consistency (Table 6).

Finally, caregiver perceptions of therapist cultural knowledge, awareness, and skill were assessed using the PCCS. The scale had an excellent level of internal consistency, as determined by a Cronbach's alpha of 0.95 (Table 6). 


\section{Factors Associated with Attrition}

A binomial logistic regression was performed to ascertain the effects of caregiver attitudes toward treatment, expectations of treatment, ratings of therapist cultural competence, and commitment to PCIT on the likelihood that families left PCIT prematurely. Linearity of the continuous variables with respect to the logit of the dependent variable was assessed via the BoxTidwell (1962) procedure. A Bonferroni correction was applied using 8 terms in the model resulting in statistical significance being accepted when $p<.00625$ (Tabachnick \& Fidell, 2013). Based on this assessment, all continuous independent variables were found to be linearly related to the logit of the dependent variable. The logistic regression model was statistically significant, $X^{2}(4)=20.42, p<.001$. The model explained $36.1 \%\left(\right.$ Nagelkerke $\left.R^{2}\right)$ of the variance in attrition and correctly classified $73.1 \%$ of cases. Sensitivity was $83.7 \%$, specificity was $54.2 \%$, positive predictive value was $76.6 \%$, and negative predictive value was $65.0 \%$. The area under the ROC curve was .82, 95\% CI [.72, .92], which is an excellent level of discrimination according to Hosmer et al. (2013; Figure 2). Of the four predictor variables, ratings of treatment expectations $(p=0.04)$ and self-reported level of commitment to PCIT over the course of treatment $(p=.002)$ added significantly to the model/prediction (as shown in Table 7). Less realistic expectations of treatment (e.g., more barriers to treatment at pre-treatment and pretreatment expectations that their child would recover quickly and that the therapist would not be highly directive) and lower reported levels of commitment was associated with an increased likelihood of leaving PCIT prematurely.

\section{Caregiver-Therapist Agreement on Treatment Characteristics}

Treatment Completion. Fleiss' kappa was run to determine if there was agreement between caregivers and therapists on whether families completed and graduated from PCIT or 
not. According to guidelines from Altman (1999) for assessing how good the strength of agreement is when based on the value of Cohen's kappa coefficient, caregiver-therapist agreement was good, though lower than would be expected, $\mathrm{K}=.63,95 \%$ CI [.37, .89], $p<.001$. Descriptive statistics were examined to further understand differences in caregiver-therapist agreement on ratings of treatment completion. In the 56 families for which both the caregiver and therapist reported on treatment completion, impressions between the two reporters differed for 10 families. Ninety percent of those caregivers reported that they had graduated while their therapists reported that they had not; One family had met mastery and graduated PCIT according to their therapist but reported they had not. Because the current study largely focused on caregiver-reported data and because the caregiver-reported data on treatment completion was more complete than the therapist report of treatment completion, caregiver reports were used for the remainder of analyses.

Treatment progress. Caregivers were asked how much progress they thought their family had made in PCIT overall (Table 8). Families tended to feel they made more progress in PCIT than therapists, with $43.3 \%$ of the total 66 families reporting feeling that they had made a lot of progress compared to $36.4 \%$ of the total 55 families' therapists (for which therapist reports were available) feeling that families had made a lot of progress. Of families who reported completing and graduating from PCIT, most caregivers $(58.1 \%)$ and therapists $(52.8 \%)$ reported feeling that completing families made "a lot" of progress. Alternatively, of families who reported leaving treatment prematurely, most caregivers (41.7\%) reported making "some" progress and most therapists $(42.1 \%)$ reported the families who did not complete and graduate from treatment made no progress. Fleiss' kappa was run to determine if there was agreement between caregivers and therapists on ratings of progress made in PCIT. Using the five item Likert scale with 1 being 
"None" and 5 being "A lot" of progress, there was poor caregiver-therapist agreement, $\mathrm{K}=.04$, $95 \%$ CI $[-.10, .19], p=.56$. Progress was recoded so that caregiver-therapist agreement on whether families made either a moderate to a lot of progress or less (e.g., none, a little, some). Caregiver-therapist agreement remained poor, $\mathrm{K}=.11,95 \% \mathrm{CI}[-.15, .38], p=.40$ (Table 8).

Why PCIT Ended. Caregivers and therapists were each asked to report why PCIT services ended (Table 9). For the remainder of the results section, items endorsed by at least $15 \%$ of participants will be reported in the text and the remaining results can be found in the tables for each research question. Forty-three (65.2\%) caregivers reported that they completed and graduated from PCIT. Of those who reported graduating, 11 (25.6\%) also reported ending treatment because their therapist felt that PCIT services were no longer needed and nine (20.9\%) reported ending treatment because problems got better or they saw a clinical improvement. Of those families who terminated PCIT prematurely, six (26.1\%) reported ending treatment because they moved, five $(21.7 \%)$ because they had limited resources or were unable to attend due to time, transportation, or finances; and four $(17.4 \%)$ because the therapist felt PCIT services were no longer needed.

Of the families who reported completing PCIT, therapists reported that 26 families (70.3\%) also ended treatment because problems got better or they saw a clinical improvement; $21(56.8 \%)$ because the therapist felt that PCIT services were no longer needed; $20(54.1 \%)$ because the caregiver felt that PCIT services were no longer needed; and seven (18.9\%) because of a high frequency of no-shows. Therapist reported reasons for ending PCIT tended to differ for families who did not complete treatment. Therapists reported that treatment ended for 12 families (63.2\%) who terminated PCIT prematurely because of frequent no-shows; $10(52.6 \%)$ because of frequent cancellations; eight $(42.1 \%)$ because of noncompliance with PCIT during sessions; 
eight $(42.1 \%)$ due to low caregiver motivation for or interest in treatment; four $(21.1 \%)$ because of scheduling conflicts; and three $(15.8 \%)$ because of limited time, transportation, or financial resources. Fleiss' kappa was run to determine the level of agreement between each of the caregiver and therapist reported reasons for PCIT ending. Caregiver-therapist agreement on PCIT ending because the family moved was fair $(\mathrm{\kappa}=.24,95 \% \mathrm{CI}[-.03, .50], p=.08)$. Agreement for each other reason endorsed was poor (Table 9).

Caregivers were also asked about six specific reasons why they may have ended PCIT (Table 10). Over a quarter of caregivers who had completed PCIT $(12,28.6 \%)$ reported ending treatment because they felt they got enough out of it and met their treatment goals. Of the caregivers who left PCIT prematurely, almost half $(11,45.8 \%)$ reported that life got in the way (e.g., transportation, child care, too busy, other commitments), five (20.8\%) left treatment because they did not think PCIT would work for them and their child, and four (16.7\%) reported leaving because PCIT was too much for them and their child at that time in their lives.

Finally, one open-ended question was used to assess any other caregiver reasons for ending PCIT. Most caregivers of families who had completed PCIT reported ending PCIT because they had graduated (82.8\% of caregivers), as expected (Table 11). Consistent themes reported by caregivers of families who had left PCT prematurely included: the family moved $(21.0 \%)$, transportation issues $(16.8 \%)$, the therapist left the agency or the PCIT program ended (16.8\%), and scheduling issues (16.8\%; Table 12). Please see Tables 11 and 12 for additional reasons caregivers indicated for leaving PCIT.

Barriers to Treatment. Caregivers and therapists were asked to indicate which, if any, of a list of situations or events had a negative impact on the overall course or outcome of PCIT for their child and family (Table 13). Caregivers who reported graduating from PCIT were most 
likely to report that scheduling conflicts had a negative impact on the overall course and outcome of PCIT for their family (25.6\%). Therapists agreed that scheduling conflicts was the most common issue affecting PCIT for families who had graduated, and that it seemed to have an impact for 17 families (48.6\%). Therapists also reported that marital problems or conflict may have affected treatment for 10 families $(27.8 \%)$ and that caregiver mental health may have impacted nine $(25.0 \%)$.

The most common barriers reported by caregivers who left PCIT prematurely differed slightly. Seven (30.4\%) caregivers reported that their own or their partners' mental health problems negatively impacted their PCIT progress and/or outcome, six (26.1\%) that marital conflict or discord, six $(26.1 \%)$ that scheduling conflicts, and four $(17.4 \%)$ that their own or their partners' high level of anger or hostility had an impact on the overall course and outcome of PCIT. Of the families who indicated that they had left PCIT prematurely, therapists indicated that for 10 families $(52.6 \%)$ scheduling conflicts seemed to have had a negative impact on family treatment as did caregiver mental health for seven (36.8\%), residential instability for six (31.6\%), conflict with an outside family member or friend for six (31.6\%), marital problems or conflict for five $(26.3 \%)$, and limited caregiver cognitive skills for three families (15.8\%; Table 13).

Fleiss' kappas were conducted to examine levels of agreement between caregiver and therapist reported barriers to treatment. Caregiver-therapist agreement on caregiver mental health problems having a negative impact on the overall course and outcome of PCIT was fair $(\mathrm{K}=.29$, 95\% CI $[.02, .56], p=.03)$. Agreement for each other possible negative impact endorsed was poor (Table 13).

Caregivers were asked what, specifically, got in the way of treatment in the form of an open-ended question. According to most caregivers of families who completed PCIT, nothing 
got in the way of treatment (84.4\%; Table 14). The four most common themes among caregivers who left PCIT prematurely were: 1$)$ transportation difficulties $(43.8 \%)$, the family moved $(25.0 \%), 3)$ scheduling issues (e.g., work schedules, care for other children; $25.0 \%$ ), and 4) the therapist left the agency or the PCIT program ended (18.8\%; Table 15). Please see Tables 14 and 15 for additional barriers to treatment reported by caregivers.

Other Caregiver Feedback. Caregivers were also asked four additional open-ended questions about why they started treatment (e.g., "Why did you start PCIT? What were your goals for treatment?"), what they liked and disliked about PCIT (e.g., "What was particularly helpful about PCIT?," "What was particularly frustrating about PCIT or what was not very helpful?'), and any advice they might give to others providing or receiving PCIT services (e.g., "If you had a chance to give advice to your therapist, others at the agency, or other parents in PCIT, what advice would you give?"). Common themes are reported below and in Tables 16 23).

For completers, common goals for treatment included improving child behavior (70.0\%), better understanding their child and reasons for his/her behavior (22.5\%), and/or because PCIT was recommended by a medical or mental health professional (15.0\%; Table 16). Goals reported by premature terminators included better child behavior and/or increased caregiver skill in controlling child behavior (69.6\%) and improving the caregiver-child relationship (21.7\%; Table 17).

Many caregivers provided positive feedback about PCIT and their experiences. Caregivers of families who had completed PCIT reported that the components that were most helpful about PCIT were the use of positive attention and special playtime (30.8\%); therapist patience, expertise, and coaching (28.2\%); improving caregiver-child communication, including 
the use of labeled praises $(23.1 \%)$; learning appropriate discipline techniques $(15.4 \%)$; and improved child behavior (15.4\%; Table 18). While some caregivers (18.2\%) who left PCIT prematurely reported that "nothing" was particularly helpful about PCIT, the outcome most appreciated was improved caregiver-child interactions (40.9\%; Table 19).

When asked what was frustrating for them about PCIT or their treatment experience, the most common answers given by treatment completers were "nothing" $(42.1 \%)$ and dealing with child noncompliance (15.8\%; Table 20). Caregivers who left PCIT prematurely were also most likely to report that "nothing" about treatment was frustrating or unhelpful (22.7\%), though some did report frustration with the time commitment required, including the time it took to reach mastery and move on in treatment (18.2\%; Table 21$)$.

When asked what advice they would offer to other parents or their therapists, $19.4 \%$ of the caregivers who had completed PCIT reported that they would recommend other parents try PCIT and $38.7 \%$ reported that they would advise other parents to persist in treatment, take their time, and remain patient as change can take time (Table 22). Premature terminators also recommended PCIT to others $(28.6 \%)$ and offered the same advice to other parents receiving PCIT; to persist in treatment and remain patient (35.7\%; Table 23).

\section{Family Compliance with Post-Treatment Therapist Recommendations}

An examination of descriptive statistics was also conducted to better understand what kinds of services were referred by therapists and sought by families after PCIT ended (Table 24). Sixty-six families reported on which services they used after ending PCIT. Of the 43 families who reported they completed and graduated from treatment, 18 (41.9\%) reported seeking out additional outpatient treatment after ending PCIT, nine (20.9\%) enrolled in BHRS or wraparound services, and eight (18.6\%) received family-based services. Of the 23 families who reported 
leaving PCIT prematurely, nine $(39.1 \%)$ reported seeking out additional outpatient treatment after ending PCIT and five (21.7\%) reported enrolling in BHRS or wraparound services.

There was therapist-reported data on treatment recommendations after ending PCIT for $55(83.33 \%)$ of the families in the current sample. For families who reported completing PCIT, therapists reported recommending outpatient treatment for 10 families $(27.8 \%)$, BHRS or wraparound services for seven (18.9\%), and intensive case management and resources coordination for six (16.2\%). Therapists also reported recommending continued outpatient treatment for six $(31.6 \%)$ and BHRS services for three $(15.5 \%)$ of the families who left PCIT prematurely.

Fleiss' kappas were conducted to examine family compliance with post-treatment therapist recommendations. Caregivers' likelihood of participating in intensive case management after being referred by their PCIT therapist was fair $(\mathrm{K}=.29,95 \% \mathrm{CI}[.03, .56], p=.03)$. Participation in each of the other therapist-referred services was low (Table 24).

\section{Discussion}

The hypothesis that caregivers' attitudes and expectations of treatment, ratings of perceived therapist cultural competency, and self-reported commitment to PCIT over the course of treatment would significantly predict attrition was partially supported. According to the model tested, caregiver commitment and therapy expectations were the only significant contributors to the model predicting attrition. Though results suggest that the model correctly classified almost three-fourths of the cases, other important variables were not included in the model, either because they had already been studied in the pilot study or because they were skewed in the current study (e.g., ratings of therapist skill in PCIT, satisfaction with PCIT components, therapeutic alliance). Previous findings from the pilot study suggest that a smaller caregiver-to- 
child ratio, lower socioeconomic status, longer wait time for treatment, greater caregiverreported life stressors and obstacles, and lower caregiver satisfaction with PCIT outcomes predicted attrition (Liebsack, Herschell, McNeil, \& Gentzler, 2016). It seems that a combination of pretreatment and treatment factors interact to ultimately predict attrition.

Therapy Attitudes. It was hypothesized that if caregivers reported having negative attitudes about treatment, they and their child would be more likely to leave PCIT prematurely. However, according to current findings, caregivers' treatment attitudes did not affect attrition as expected. One possible explanation is that treatment attitudes may change over the course of treatment so that pretreatment levels do not significantly affect treatment progress or outcomes. Though the literature suggests that "attitudinal barriers" are among the most powerful predictors of attrition in some populations (McCabe et al., 2005) they also affect families' decision to seek treatment (Yeh et al., 2003). Perhaps, if families begin treatment those attitudinal barriers can be overcome.

It is possible that caregiver attitudes did not affect attrition in the current sample because, even if attitudes were negative before treatment started, once families met their therapist, learned more about PCIT, and began treatment their attitudes quickly shifted. The content and structure of the CDI teach, the second PCIT session and first treatment session after the intake, includes extensive and helpful information about the treatment plan and process (Eyberg \& Funderburk, 2011; McNeil \& Hembree-Kigin, 2010) and may help facilitate an attitude shift. Previous treatment experience may also greatly impact attitudes toward treatment, however information about participants' treatment history was not examined in the present study. It may also be the case that, because PCIT differs from traditional individual therapy in many ways, most families' pre-treatment negative attitudes changed once they started treatment. Finally, sometimes families 
may receive PCIT services after trying various other strategies, treatments, and/or forms of discipline. Due to the interaction of this experience, which may be a long and stressful one, and the difficulty of managing disruptive behavior, caregivers seeking PCIT may be less likely than other individuals seeking treatment to have positive attitudes about treatment.

It is also possible that reported pre-treatment attitudes may have been affected by the use of retrospective reporting. Finally, there is evidence to suggest that, though there was variance in ratings of pre-treatment attitudes, they likely did change throughout the course of treatment, as ratings of treatment satisfaction were high overall. In the current study, the measure of treatment satisfaction (TSTCQ) used specifically assessed caregivers' satisfaction with the components of PCIT (e.g., coaching, use of timeout). Previous studies of attrition in PCIT, including the pilot study, have used the Therapy Attitude Inventory (TAI; Brestan, Jacobs, Rayfield, \& Eyberg, 1999) which measures satisfaction with treatment outcomes. Findings could not be compared across measures because the measure of satisfaction with treatment components was skewed positively, such that caregivers were very satisfied overall.

Therapy Expectations. It was hypothesized that if caregivers reported having unrealistic expectations for treatment, they and their child would be more likely to leave PCIT prematurely. Pretreatment therapy expectations were a significant predictor of the model predicting attrition. This finding replicates those found in previous studies which have also found that pre-treatment expectancies tend to affect attrition (McCabe, 2002), especially early on in treatment (Nock \& Kazdin, 2001). Unrealistic expectations include those that their child will recover quickly, that the time and effort required for treatment will be less than they typically are, and/or that they are not going to do well in treatment or that it will not be helpful (de Haan et al., 2013), among others. 
Cultural Competence. Cultural competence was considered especially important to assess in the current study because the majority of the therapists $(96.9 \%)$ were white and the families were more racially and ethnically diverse (45.5\% minorities). It was hypothesized that lower caregiver ratings of therapist cultural competence would predict PCIT attrition. However, it was not a significant contributor to the model predicting attrition. It is possible that the effects of cultural competence were impacted by the high overall ratings of therapeutic alliance in the current study as the two were moderately correlated $(\mathrm{r}=0.56, p<.001)$. It is also possible that, because the PCIT treatment manual is very structured, the focus of treatment is largely on child behavior, the nature of the caregiver-therapist relationship in parent training tends to be unique, and caregiver-therapist interaction largely occurs when the therapist is in a separate room and through a bug-in-the-ear device (Eyberg \& Funderburk, 2011; McNeil \& Hembree-Kigin, 2010), therapist cultural competence has less of an impact on treatment in PCIT than it might in individual therapy or other treatment modalities. It is also possible that caregiver perceptions of therapist skill in PCIT may weigh more heavily into families' decision to leave or to stay in treatment than cultural competency.

Commitment to Treatment. Caregiver self-reported commitment to PCIT over the course of treatment was a significant contributor to the model predicting attrition. Perhaps commitment interacts with the other predictor variables in order to predict attrition, such that it buffers the impact of negative attitudes, poor therapist cultural competency, and other barriers to treatment. For example, a caregiver could have relatively negative attitudes towards treatment but also be incredibly committed to treatment and helping his/her child. In this instance, his/her commitment may overcome his/her negative attitudes even just enough that he/she attends one or two sessions and through those has the opportunity to learn more about treatment and readjust 
his/her attitudes. In addition to attitudinal barriers to treatment and therapist cultural competence, caregivers also reported significant logistical and other barriers to treatment. Similarly, high levels of commitment may buffer the effect of those barriers so that families are more likely to continue and complete treatment.

Caregiver-Therapist Agreement. Caregiver-therapist agreement on whether or not families had completed and graduated from PCIT or left prematurely was low, with several caregivers reporting that they believed they had graduated from treatment when the therapist reported they had not. Additionally, of the 24 caregivers who indicated that they did not graduate from PCIT, half felt that they did not "drop out" from treatment because they had not wanted to end treatment but felt they had to at that time or because the decision to end PCIT was not, in fact, theirs. This low agreement on treatment completion status could be because those caregivers had limited knowledge of the treatment process and mastery criteria. If so, this suggests that PCIT therapists need to better explain the treatment process, including the necessity to meet mastery, and the mastery criteria early in treatment and to remind caregivers of it throughout treatment. It could also be the case that caregivers felt they graduated from PCIT because they met their treatment goals and saw an improvement, even if they did not meet mastery criteria.

There was poor caregiver-therapist agreement on treatment progress, with caregivers feeling they made more progress than therapists. This may be especially important to note, as families may be more likely to leave treatment when they feel they have seen an improvement and/or met their personal treatment goals, even if the therapist does not agree it is an appropriate time to end treatment (Westmacott et al., 2009). Caregiver-therapist agreement on reasons for ending treatment were also poor for the most part, though there was fair agreement on one reason 
for ending treatment: because the family moved away. This suggests that therapists are not good at deciphering why families leave therapy and, though rarely done, it is important to ask the client or caregiver directly why they are leaving or have left treatment. Caregiver-therapist agreement on barriers to treatment participation encountered by families also tended to be low, though there was fair agreement on whether or not caregiver mental health affected PCIT. This highlights the importance of therapists assessing barriers throughout treatment so that they can help problem solve any situations or events that may be negatively impacting the overall course and outcome of PCIT.

Finally, results suggest low caregiver compliance with most post-treatment therapy recommendations, though compliance with seeking intensive case management services was fair. Perhaps this low compliance was due to the caregiver and family experiencing continued barriers to treatment which were not or could not be addressed in PCIT. It may also be the case that caregivers did not feel that certain referrals were appropriate for their families and chose not to pursue them.

Overall, these findings suggest that therapists' ability to understand why families leave PCIT tends to be low; that reasons for attrition vary greatly across individuals and families, and include pre-treatment and treatment variables and family, therapist, and treatment process factors; and that attrition is complicated to predict.

\section{Limitations}

The current study had some limitations of note. The first is the use of retrospective reporting. Because the current study is a follow-up to the parent and pilot studies, caregivers were asked to retrospectively report their reasons for leaving treatment prematurely, involvement in and satisfaction with PCIT, and interactions with their therapist and therapeutic alliance. 
However, though retrospective data can be less accurate than observational or immediately selfreported data for assessing objective variables (e.g., behavior counts), they can be appropriate for many other research questions, are widely used, and can be both reliable and valid measures (Lam \& Beng, 2003). They have been used to assess a number of important variables in previous research, including subjective experiences and relationship phenomena (Metts, Sprecher, \& Cupach, 1991), interactions and personal relationships (Huston, Surra, Fitzgerald, \& Cate, 1981), and to assess childhood psychopathology (Johansson et al., 2005),

There are some issues with using retrospective data which are worth noting. Retrospective reports may suffer if caregivers experience recall problems, which can vary based on the length of time since the event or experience being asked about and the salience of the information being collected (Metts et al., 1991). Other issues include those encountered when using any type of self-report data. One potential threat to the validity of caregiver-reports is limited caregiver insight or introspection. Caregiver-reported data may also be impacted by social desirability or other cognitive biases.

Attempts to limit these types of issues and mitigate the threats to validity were made in the current study. It was stressed that, while a follow-up to the parent study, the current study was in fact separate from the parent study and that their responses would be kept confidential, particularly from their PCIT therapists. The current study was referred to as the "PCIT Experiences and Family Feedback Study" in an attempt to elicit both positive and critical feedback from caregivers about their PCIT experience and therapist. The use of vaguely worded questions were limited to decrease response error and Likert scales were used to limit response choices. There were some open-ended questions included which might have been interpreted as slightly ambiguous, however prompts were used to offer anchor points as appropriate, to 
minimize any participant confusion about what is being asked or which period of time they were being asked to report on.

Though the researcher attempted to re-consent all participants of the parent study, it is important to note that the current sample is self-selected; it includes families who chose to take time to complete an additional assessment and it is reasonable to assume that those who enjoyed PCIT and participated in it longer may be more likely to do so. Another possible limitation is that other variables that may have affected attrition, including therapist training condition, were not examined in the current study. The effect of training condition on attrition will be further examined in the parent study. It was also not possible to examine the effect of specific treatment process variables (e.g., number of timeouts in therapy) and other treatment modality features that are specific to PCIT, largely due to the sample size. Caregivers rated their PCIT therapists' skill, their own satisfaction with PCIT, and their alliance with their therapists high overall, which is a positive outcome, but made it impossible to examine their effects on attrition because they were highly skewed. The limited variance in therapist skill may be partly due to it being based on caregiver ratings, which may or may not be a reliable measure of actual therapist skill level, with the ideal being a behavioral observation of therapist behavior in session.

Finally, due to the imperfect rate of caregiver-therapist agreement on ratings of treatment completion, a decision rule was used to determine which raters' reports would be used to separate completers from premature terminators for additional analyses. The decision to use caregiver report was made because of two main reasons: 1) caregiver reports were used on all other measures in the study (except for the data from the parent study used as a comparison) and 2) the caregiver reported data was more complete than the therapist reported data (e.g., 66 cases versus 56 cases). This definition of attrition, however, differs from that used in the pilot study 
and some of the other research in the literature, which may make it difficult to compare results directly with other studies which define treatment completion based on therapist report or in other ways.

\section{Strengths}

Though there are limitations to the current study, there are also several strengths. First, the parent study is a large, state-wide effectiveness and implementation study of PCIT. Thus, study conditions and inclusion criteria were less restricted and participants included therapists from various real-world community settings and a diverse sample of children and families throughout an entire state. Another important strength is the size and breadth of the current study. Because of the size and scope of the parent study, the current study also includes a relatively diverse sample of children, families, and therapists from 25 different agencies across an entire state. Thus, results of the current study may be more easily generalizable to other PCIT populations. Though the response rate may seem somewhat low, families were contacted an average of almost three years after they started treatment and many families had changed their phone numbers or moved in the interim. Considering this, a sample of 67 families seems reasonable. Additionally, findings of the current study are current and relevant as it is an active study rather than a chart review.

Because this is a follow-up study, another strength is the availability of additional data from the parent study and the ability to match and compare family data between caregivers and therapists. Other studies have not included perceptions of barriers from multiple sources. Previous studies on attrition in PCIT have also largely focused on caregiver and family characteristics. Another strength of the current study is that it also examines treatment participation barriers, treatment characteristics, and therapist factors. 
Though there are some limitations related to using retrospective reports, there are also some strengths. Prospective studies of attrition are important because identifying predictors can allow therapists to recognize them and preempt attrition. Previous prospective studies have largely focused on pretreatment client and family factors. However, Kazdin, Holland, Crowley, and Breton (1997) suggest that therapist characteristics, treatment process variables, and family experiences of barriers to treatment participation play a significant role in treatment attrition and can be assessed before, during, and after treatment. Retrospective studies of attrition allow for relationship histories and therapeutic events and their consequences (e.g., client or caregiver decision to leave treatment) to be assessed and may help researchers and therapists better understand client's, caregivers', and therapists' subjective experiences and perceptions of treatment and why it may have ended prematurely. Additionally, these experiences might include specific therapeutic or relationship events or turning points (e.g., perceived therapist cultural competence throughout treatment, decisions to leave treatment prematurely) that cannot be assessed before or during treatment because they cannot be reported until they have been experienced. Thus, retrospective studies of attrition like the current study are also imperative.

\section{Future Research}

Because the current study was not able to, future research should examine the effects of therapist skill level and other important variables that may affect attrition. Additionally, though the current study examined therapeutic alliance, previous research suggests that caregivertherapist relationship very early on in treatment is related to early attrition (Harwood \& Eyberg, 2004). It would also be interesting to examine the separate effects of specific PCIT treatment components on attrition and the impact of other PCIT process variables. For example, the use 
and frequency of the timeout procedure and the timeout room may independently affect attrition in some families.

Though the current study collected some qualitative information about specific logistical barriers experienced, future research should examine the impact of specific barriers such as lack of childcare, lack of transportation, illness, pregnancy, and bad weather. The current findings provide some evidence that caregivers perceive these types of barriers to greatly affect their ability to complete treatment, thus conducting research in which these barriers are better understood is an important next step. One recent project has examined whether incentivizing treatment might increase attendance, reduce attrition, and increase outcomes in PCIT (Quetsch, 2018) and found that the low-cost incentives used did not significantly affect treatment attendance of family outcomes. Studies on the effects of other types of incentives including providing childcare, transportation, and reducing other barriers in PCIT should also be conducted. The provision of in-home behavioral health treatment reduces several of logistical barriers for families. Another recent study has examined the implementation of an adaptation of PCIT provided by bachelor's level clinicians (i.e., therapeutic support staff) as part of a homebased service program, BHRS. Results suggest decreases in children's disruptive behavior and improvements in the quality of the parent-child relationship after receiving this PCIT-informed treatment (Wallace, Quetsch, Robinson, McCoy, \& McNeil, 2018). Future research should examine attrition in home-based PCIT and compare rates of attrition across community- and home-based PCIT services.

As commitment to PCIT significantly predicted attrition, another area for further PCIT research is to examine which factors affect commitment to treatment and how to improve or maintain it over the course of treatment. Therapy expectations also significantly predicted 
attrition. There is a movement to destigmatize mental health services, thus additional research examining what types of treatment expectations most affect both clients' decisions to seek treatment or not and their decisions to continue treatment or not is an important next step.

\section{Implications and Clinical Recommendations}

The results of the current study support the use of certain clinical recommendations and engagement strategies. Commitment was a significant predictor of attrition and remained fairly consistent over time. So, strategies to elicit engagement and commitment early in therapy may be especially useful. Caregivers' therapy expectations also predicted attrition, such that caregivers with more appropriate expectations for treatment were more likely to complete PCIT. One method which may address and improve therapy expectations is role induction (Barrett et al., 2008). Role induction is a method used at the beginning of treatment, either before treatment begins or during an early therapy session, to educate new therapy clients on the treatment plan (e.g., duration, process) and to address their expectations for treatment. Research has suggested that the use of in-person and videotaped role induction can reduce attrition and improve overall treatment attendance (Reis \& Brown, 1999). Role induction may be a particularly feasible and helpful way to decrease attrition through increased commitment to treatment and improved therapy expectations. Though some role induction strategies tend to occur during the first therapy session of PCIT, the CDI teach, it may be important to discuss treatment components (e.g., PDI, treatment progression being contingent upon mastery criteria) in even more detail so that caregivers have appropriate expectations..

Some families indicated that the time it took to complete PCIT could be daunting and that caregiver work schedules, family schedules and being too busy for treatment often negatively affected the overall progress and outcome of treatment. Due to time constraints it may be helpful 
to implement and study time-limited or ultra-brief applications of PCIT. These intensive versions of PCIT but may be good solutions for families who find it difficult to attend the traditional 12 to 14 weekly, 50-minute PCIT therapy sessions. Graziano and colleagues (2015) examined the feasibility of intensive PCIT and results suggest that an intensive, two week adaptation of PCIT was effective and that all 11 families completed treatment. Shapiro and colleagues (2003) also found that ultra-brief treatments can be as effective as longer-term weekly therapy, particularly for clients with less severe symptoms. Perhaps rates of attrition in PCIT will decrease if its duration is adapted to be more in line with families' actual, shorter-term usual use of services. The use of time-limited therapy may be an effective way to do so as it tends to have lower attrition rates than long-term treatment (Sledge, Moras, Harley, \& Levine, 1990).

Finally, commitment to or motivation for treatment seems to be an important component for treatment completion. Perhaps it would be helpful to assess client commitment to treatment throughout treatment so that decreases in commitment can be addressed and problem-solving can occur. One way to enhance caregiver motivation for PCIT may be by directly addressing it each session and using motivational interviewing techniques (Swift and Greenberg, 2012). Motivational Interviewing (Miller \& Rollnick, 1991) focuses on clients' ambivalent feelings toward treatment and the use of internal motivation for change to help them understand and resolve those feelings. The use of motivational interviewing has been examined in PCIT previously. Chaffin and colleagues (2009) found that use of a motivational orientation in PCIT with a child welfare population decreased treatment attrition and led to reduced recidivism (Chaffin et al., 2009). However, findings suggest that selective use of motivational interview may be more helpful than using motivational interviewing with all PCIT families. When more closely examined, Chaffin and colleagues (2009) actually found that the motivation orientation 
had negative effects for families who began PCIT with high motivation. They found that motivational interviewing specifically benefited families whose initial levels of motivation were low to moderate.

\section{Conclusion}

Attrition continues to be a significant problem in psychotherapy in general, and PCIT specifically. PCIT is highly effective in treating 2.5 to 7 -year-olds with disruptive behavior disorders. However, attrition reduces the effectiveness of PCIT and various other treatments. The current study suggests that lower levels of self-reported commitment to PCIT and less realistic expectations of PCIT predict attrition and that retrospectively reported caregiver-therapist agreement on reasons PCIT ended, negative impacts on treatment, and even whether or not the family graduate from treatment is low. Future research should focus on predicting and reducing attrition in PCIT, improving caregiver-therapist communication throughout treatment, and how to measure and improve or maintain levels of commitment to treatment. Increases in treatment retention may help to improve therapy outcome even more than additional efficacy studies or developing new treatments. 


\section{References}

Accurso, E. C., Hawley, K. M., \& Garland, A. F. (2012). Psychometric properties of the therapeutic alliance scale for caregivers and parents. Psychological Assessment, 25, 244252.

Aebi, M., Plattner, B., Metzke, C. W., Bessler, C., \& Steinhausen, H.-C. (2013). Parent- and selfreported dimensions of oppositionality in youth: Construct validity, concurrent validity, and the prediction of criminal outcomes in adulthood. Journal of Child Psychology and Psychiatry, 54, 942-949.

Altman, D. G. (1999). Practical statistics for medical research. New York, NY: Chapman \& Hall/CRC Press.

Armbruster, P., \& Fallon, T. (1994). Clinical, sociodemographic, and systems risk factors for attrition in a children's mental health clinic. American Journal of Orthopsychiatry, 64, $577-585$.

Bados, A., Balaguer, G., \& Saldana, C. (2007). The efficacy of cognitive-behavioral therapy and the problem of drop-out. Journal of Clinical Psychology, 63, 585-592.

Baker-Ericzén, M. J., Jenkins, M. M., \& Brookman-Frazee, L. (2010). Clinician and parent perspectives on parent and family contextual factors that impact community mental health services for children with behavior problems. Child Youth Care Forum, 39, 397419.

Barber, J. P., Connolly, M. B., Crits-Cristoph, P., Gladys, L., Siqueland, L. (2000). Alliance predicts patients' outcome beyond in-treatment change in symptoms. Journal of Consulting and Clinical Psychology, 68, 1027-1032. 
Barrett, M. S., Chua, W.-J., Crits-Christoph, P., Gibbons, M. B., Casiano, D., \& Thompson, D. (2008). Early withdrawal from mental health treatment: Implications for psychotherapy practice. Psychotherapy (Chic), 45, 247-267.

Baruch, G., Vrouva, I., \& Fearon, P. (2009). A follow-up study of characteristics of young people that dropout and continue psychotherapy: Service implications for a clinic in the community. Child and Adolescent Mental Health, 14, 69-75.

Boggs, S. R., Eyberg, S. M., Edwards, D. L., Rayfield, A., Jacobs, J., Bagner, D., \& Hood, K. K. (2004). Outcomes of Parent-Child Interaction Therapy: A comparison of treatment completers and study dropouts one to three years later. Child \& Family Behavior Therapy, 26, 1-22.

Box, G. E. P., \& Tidwell, P. W. (1962). Transformation of the independent variables. Technometrics, 4, 531-550.

Brestan, E., Jacobs, J., Rayfield, A., \& Eyberg, S. M. (1999). A consumer satisfaction measure for parent-child treatments and its relationship to measures of child behavior change. Behavior Therapy, 30, 17-30.

Button, E. J., Marshall, P., Shinkwin, R., Black, S. H., \& Palmer, R. (1997). One hundred referrals to an eating disorder service: Progress and service consumption over a 2-4 year period. European Eating Disorders Review, 5, 47-63.

Chaffin, M., Valle, L. A., Funderburk, B., Gurwitch, R., Silovsky, J., Bard, D., McCoy, C., \& Kees, M. (2009). A motivational intervention can improve retention in PCIT for lowmotivation child welfare clients. Child Maltreatment, 14, 356-368. 
Chasson, G. S., Vincent, J. P., \& Harris, G. E. (2008). The use of symptom severity measured just before termination to predict child treatment dropout. Journal of Clinical Psychology, 64, 891-904.

Copeland, W. E., Shanahan, L., Costello, J. E., \& Angold, A. (2009). Childhood and adolescent psychiatric disorders as predictors of young adult disorders. Archives of General Psychiatry, 66, 764-772.

Costello, J. E., Copeland, W. E., \& Angold, A. (2011). Trends in psychopathology across the adolescent years: What changes when children become adolescents, and when adolescents become adults? Journal of Child Psychology and Psychiatry, 52, 1015-1025.

de Haan, A. M., Boon, A. E., de Jong, J. T. V. M., Hoeve, M., \& Vermeiren, R. R. J. M. (2013). A meta-analytic review on treatment dropout in child and adolescent outpatient mental health care. Clinical Psychology Review, 33, 698-711.

DeVellis, R. F. (2012) Scale development: Theory and applications. Los Angeles, CA: Sage Publications.

Dierker, L., Nargiso, J., Wiseman, R., \& Hoff, D. (2001). Factors predicting attrition within a community initiated system of care. Journal of Child and Family Studies, 10, 367-383.

Dunn, H., Morrison, A. P., \& Bentall, R. P. (2006). The relationship between patient suitability, therapeutic alliance, homework compliance, and outcome in cognitive therapy for psychosis. Clinical Psychology \& Psychotherapy, 13, 145-152.

Eyberg, S. \& Funderburk, B. (2011). Parent-Child Interaction Therapy protocol. Gainesville, FL: PCIT International Publishing. 
Fernandez, E., Salem, D., Swift, J. K., \& Ramtahal, N. (2015). Meta-analysis of dropout from Cognitive Behavioral Therapy: Magnitude, time, and moderators. Journal of Consulting and Clinical Psychology, 83, 1108-1122.

Flicker, S. M., Turner, C. W., Waldron, H. B., Brody, J. L., \& Ozechowski, T. J. (2008). Ethnic background, therapeutic alliance, and treatment retention in functional family therapy with adolescents who abuse substances. Journal of Family Psychology, 22, 167-170.

Friars, P. M., \& Mellor, D. J. (2007). Drop out from behavioral management training programs for ADHD: A prospective study. Journal of Child and Family Studies, 16, 427-441.

Garcia, J. A., \& Weisz, J. R. (2002). When youth mental health care stops: Therapeutic relationship problems and other reasons for ending youth outpatient treatment. Journal of Consulting and Clinical Psychology, 70, 439-443.

Garfield, S. L. (1994). Research on client variables in psychotherapy. In A. E. Bergin \& S. L. Garfield. (Eds.), Handbook of psychotherapy and behavior change (pp. 190-228). New York, NY: Wiley.

Graziano, P. A., Bagner, D. M., Slavec, J., Hungerford, G., Kent, K., Babinski, D., Derefinko, K., \& Pasalich, D. (2014). Feasibility of intensive parent-child interaction therapy (IPCIT): Results from an open trial. Journal of Psychopathology and Behavioral Assessment, 37, 38-49.

Gunnarsdottir, T., Njardvik, U., Olafsdottir, A. S., Craighead, L. W., \& Bjarnason, R. (2011). The role of parental motivation in family-based treatment for childhood obesity. Pediatric Obesity, 19, 1654-1662. 
Harwood, M. D., \& Eyberg, S. M. (2004). Therapist verbal behavior early in treatment: Relation to successful completion of Parent-Child Interaction Therapy. Journal of Clinical Child and Adolescent Psychology, 33, 601-612.

Hawley, K. M., \& Weisz, J. R. (2005). Youth versus parent working alliance in usual clinical care: Distinctive associations with retention, satisfaction, and treatment outcome. Journal of Clinical Child \& Adolescent Psychology, 34, 117-128.

Helbig, S., \& Fehm, L. (2004). Problems with homework in CBT: Rare exception or rather frequent? Behavioral and Cognitive Psychotherapy, 32, 291-301.

Hogue, A., Henderson, C. E., Dauber, S., Barajas, P. C., Fried, A., \& Liddle, H. A. (2008). Treatment adherence, competence, and outcome in individual and family therapy adolescent behavior problems. Journal of Consulting and Clinical Psychology, 76, 544555.

Horvath, A. O., \& Greenberg, L. S. (Eds.). (1994). The working alliance: Theory, research, and practice. New York, NY: John Wiley \& Sons, Inc.

Hosmer, D. W., Jr., Lemeshow, S., \& Sturdivant, R. X. (2013). Applied logistic regression (3 ${ }^{\text {rd }}$ ed.). Hoboken, NJ: Wiley.

Huston, T. L., Surra, C. A., Fitzgerald, N. M., \& Cate, R. M. (1981). From courtship to marriage: Mate selection as an interpersonal process. In S. Duck \& R. Gilmour (Eds.), Personal relationships 2: Developing personal relationships (pp. 53-90). New York, NY: Academic Press.

Johansson, P., Kerr, M., \& Andershed, H. (2005). Linking adult psychopathy with childhood hyperactivity-impulsivity-attention problems and conduct problems through retrospective self-reports. Journal of Personality Disorders, 19, 94-101. 
Johnson, E., Mellor, D., \& Brann, P. (2009). Factors associated with dropout and diagnosis in child and adolescent mental health services. Australian and New Zealand Journal of Psychiatry, 43, 431-437.

Kataoka, S. H., Zhang, L., \& Wells, K. B. (2002). Unmet need for mental health care among US children: Variation by ethnicity and insurance status. American Journal of Psychiatry, $159,1548-1555$.

Kazdin, A. E., Holland, L., Crowley, M., \& Breton, S. (1997). Barriers to treatment participation scale: Evaluation and validation in the context of child outpatient treatment. Child Psychology \& Psychiatry \& Allied Disciplines, 38, 1051-1062.

Kazdin, A. E., \& Mazurick, J. L. (1994). Dropping out of child psychotherapy: Distinguishing early and late dropouts over the course of treatment. Journal of Consulting and Clinical Psychology, 62, 1069-1074.

Kazdin, A. E., \& Wassell, G. (1998). Treatment completion and therapeutic change among children referred for outpatient therapy. Professional Psychology: Research and Practice, $29,332-340$.

Kendall, P. C. \& Chu, B. C. (2010). Retrospective self-reports of therapist flexibility in a manual-based treatment for youths with anxiety disorders. Journal of Clinical Child Psychology, 29, 209-220.

Lai, K. Y. C., Pang, A. H. T., Wong, C. K., Lum, F., \& Lo, M. K. (1998). Characteristic of dropouts from a child psychiatry clinic in Hong Kong. Social Psychiatry and Psychiatric Epidemiology, 33, 45-48. 
Lam, T. C. M., \& Bengo, P. (2003). A comparison of three retrospective self-reporting methods of measuring change in instructional practice. American Journal of Evaluation, 24, 6580.

Lanier, P., Kohl, P. L., Benz, J., Swinger, D., Moussette, P., \& Drake, B. (2011). Parent-Child Interaction Therapy in a community setting: Examining outcomes, attrition, and treatment setting. Research on Social Work Practice, 1, 689-698.

Liebsack, B. K., Herschell, A. D., McNeil, C. B., \& Genzler, A. L. (2016). Attrition in ParentChild Interaction Therapy (Unpublished masters thesis). West Virginia University, Morgantown, WV.

Lock, J., Courturier, J., Bryson, S., \& Agras, S. (2006). Predictors of dropout and remission in family therapy for adolescent anorexia nervosa in a randomized clinical trail. International Journal of Eating Disorders, 39, 639-647.

Lucas, T., Michalopoulou, G., Falzarano, P., Menon, S., \& Cunningham, W. (2008). Healthcare provider cultural competency: Development and initial validation of a patient report measure. Health Psychology, 27, 185-193.

Luk, E. S. L., Staiger, P. K., Mathai, J., Wong, L., Birleson, P., \& Adler, R. (2001). Children with persistent conduct problems who dropout of treatment. European Child \& Adolescent Psychiatry, 10, 28-36.

Lyon, A. R., \& Budd, K. S. (2010). A community mental health implementation of Parent-Child Interaction Therapy (PCIT). Journal of Child and Family Studies, 19, 654-668.

McCabe, K. M. (2002). Factors that predict premature termination among Mexican-American children in outpatient psychotherapy. Journal of Child and Family Studies, 11, 347-359. 
McCabe, K. M., Yeh, M., Garland, A. F., Lau, A. S., \& Chavez, G. (2005). The GANA program: A tailoring approach to adapting parent child interaction therapy for Mexican Americans. Education and Treatment of Children, 28, 111-129.

McNeil, C. B., \& Hembree-Kigin, T. L. (2010). Parent-Child Interaction Therapy (2 ${ }^{\text {nd }}$ ed.), New York: Springer.

Metts, S., Sprecher, S., \& Cupach, W. R. (1991). Retrospective self-reports. In Montgomery, B. M., \& Duck, S. (Eds), Studying interpersonal interaction (pp. 162-178). New York: NY: The Guilford Press.

Miller, W., \& Rollnick, S. (1991). Motivational interviewing: Preparing people to change addictive behaviors. New York: Guilford Press.

Miller, L. M., Southam-Gerow, M. A., \& Allin Jr., R. B. (2008). Who stays in treatment? Child and family predictors of youth client retention in a public mental health agency. Child Youth Care Forum, 37, 153-170.

Muran, J. C., \& Barber, J. P. (Eds.). (2010). The therapeutic alliance: An evidence-based guide to practice. New York, NY: The Guildford Press.

Nock, M. K., \& Kazdin, A. E. (2001). Parent expectancies for child therapy: Assessment and relation to participation in treatment. Journal of Child and Family Studies, 10, 155-180.

Nock, M. K., Phil, M., \& Kazdin, A. E. (2001). Parent expectancies for child therapy: Assessment and relation to participation in treatment. Journal of Child and Family Studies, 10 , 155-180.

Owen, J., Leach, M. M., Wampold, B. \& Rodolfa, E. (2011). Client and therapist variability in clients' perceptions of their therpists' multicultural competencies. Journal of Counseling Psychology, 58, 1-9. 
Pereira, T., Lock, J., \& Oggins, J. (2006). Role of therapeutic alliance in family therapy for adolescent anorexia nervosa. International Journal of Eating Disorders, 39, 677-684.

Peters, S., Calam, R., \& Harrington, R. (2005). Maternal attributions and expressed emotion as predictors of attendance at parent management training. Journal of Child Psychology and Psychiatry, 46, 436-448.

Petry, N. M. (2005). Stages of change in treatment-seeking pathological gamblers. Journal of Consulting and Clinical Psychology, 73, 312-322.

Prinz, R. J., \& Miller, G. E. (1994). Family-based treatment for childhood antisocial behavior: Experimental influences on dropout and engagement. Journal of Consulting and Clinical Psychology, 62, 645-650.

Pulford, J., Adams, P., \& Sheridan, J. (2008). Therapist attitudes and beliefs relevant to client dropout revisited. Community Mental Health Journal, 44, 181-186.

Quetsch, L. B. (2018). A Randomized Controlled Trial of Parent-Child Interaction Therapy with and without Incentives in a Community Mental Health Setting. (Unpublished doctoral dissertation). West Virginia University, Morgantown, WV.

Reis, B. F., \& Brown, L. G. (1999). Reducing psychotherapy dropouts: Maximizing perspective convergence in the psychotherapy dyad. Psychotherapy, 36, 123-136.

Rhodes, R. H., Hill, C. E., Thompson, B. J., \& Elliott, R. (1994). Client retrospective recall of resolved and unresolved misunderstanding events. Journal of Counseling Psychology, 41, 473-483.

Robbins, M. S., Liddle, H. A., Turner, C. W., Dakof, G. A., Alexander, J. F., \& Kogan, S. M. (2006). Adolescent and parent therapeutic alliances as predictors of dropout in Multidimensional Family Therapy. Journal of Family Psychology, 20, 108-116. 
Robbins, M. S., Turner, C. W., Alexander, J. F., \& Perez, G. A. (2003). Alliance and dropout in family therapy for adolescents with behavior problems: Individual and systematic effects. Journal of Family Psychology, 17, 534-544.

Shapiro, C. J., Prinz, R. J., \& Sanders, M. R. (2012). Facilitators and barriers to implementation of an evidence-based parenting intervention to prevent child maltreatment: The triple ppositive parenting program. Child Maltreatment, 17, 86-95.

Shaw, B. F., Elkin, I., Yamaguchi, J., Olmsted, M., Vallis, T. M., Dobson, K. S., ... Imber, S. D. (1999). Therapist competence ratings in relation to clinical outcome in cognitive therapy of depression. Journal of Consulting and Clinical Psychology, 67, 837-846.

Sledge, W. H., Moras, K., Hartley, D., \& Levine, M. (1990). Effect of time-limited psychotherapy on patient dropout rates. The American Journal of Psychiatry, 147, 13411347.

Stevens, J., Kelleher, K. J., Ward-Estes, J., \& Hayes, J. (2006). Perceived barriers to treatment and psychotherapy attendance in child community mental health centers. Community Mental Health Journal, 42, 449-458.

Swift, J. K., Callahan, J., \& Levine, J. C. (2009). Using clinically significant change to identify premature termination. Psychotherapy Theory, Research, Practice, Training, 46, 328335.

Swift, J. K., \& Greenberg, R. P. (2012). Premature discontinuation in adult psychotherapy: A meta-analysis. Journal of Consulting and Clinical Psychology, 80, 547-559.

Tabachnik, B. G., \& Fidell, L. S. (2013). Using multivariate statistics (6 ${ }^{\text {th }}$ ed.). Boston, MA: Pearson Education. 
Truong, M., Paradies, Y., \& Priest, M. (2014). Interventions to improve cultural competency in healthcare: A systematic review of reviews. BMC Health Services Research, 14, 1-17.

Venable, W. M., \& Thompson, B. (1998). Caretaker psychological factors predicting premature termination of children's counseling. Journal of Counseling \& Development, 76, 286293.

Wallace, N. M., Quetsch, L. B., Robinson, C., McCoy, K., \& McNeil, C. B. (2018). Infusing parent-child interaction therapy principles into community-based wraparound services: An evaluation of feasibility, child behavior problems, and staff sense of competence. Children and Youth Services Review, 88, 675-581.

Warnick, E. M., Gonzalez, A., Weersing, V. R., Scahill, L., \& Woolston, J. (2012). Defining dropout from youth psychotherapy: How definitions shape the prevalence and predictors of attrition. Child and Adolescent Mental Health, 17, 76-85.

Werba, B. E., Eyberg, S. M., Boggs, S. R., \& Algina, J. (2006). Predicting outcome in ParentChild Interaction Therapy: Success and attrition. Behavior Modification, 30, 618-646.

Westmacott, R., Hunsley, J., Best, M., Rumstein-McKean, O., \& Schindler, D. (2009). Client and therapist views of contextual factors related to termination from psychotherapy: A comparison between unilateral and mutual terminators. Psychotherapy Research, 20, 423-435.

Yeh, M., Eastman, K., \& Cheung, M. K. (1994). Children and adolescents in community health centers: Does the ethnicity or the language of the therapist matter? Journal of Community Psychology, 22, 153-163. 
Yeh, M., McCabe, K., Hough, R. L., Dupuis, D., \& Hazen, A. (2003). Racial/ethnic differences in parental endorsement of barriers to mental health services for youth. Mental Health Services Research, 5, 65-77. 


\section{Tables}

Table 1

Demographics for Children and Caregivers

\begin{tabular}{|c|c|c|c|c|c|c|}
\hline & \multicolumn{3}{|c|}{ Child } & \multicolumn{3}{|c|}{ Caregiver } \\
\hline & \multicolumn{2}{|c|}{ Frequency } & \multirow[t]{2}{*}{ Percent } & \multicolumn{2}{|c|}{ Frequency } & Percent \\
\hline \multicolumn{6}{|l|}{ Gender } & \\
\hline Male & 49 & & $73.1 \%$ & & 1 & $1.5 \%$ \\
\hline Female & 18 & & $26.9 \%$ & & 57 & $98.5 \%$ \\
\hline Race & & & & & 19 & \\
\hline Caucasian & 51 & & $75.0 \%$ & & 1 & $76.0 \%$ \\
\hline African American & 23 & & $33.8 \%$ & & 6 & $24.0 \%$ \\
\hline $\begin{array}{c}\text { American Indian or } \\
\text { Alaska Native }\end{array}$ & 1 & & $1.5 \%$ & & 1 & $1.5 \%$ \\
\hline Unknown/Unreported & 0 & & $0 \%$ & & 0 & $0 \%$ \\
\hline Asian & 0 & & $0 \%$ & & 0 & $0 \%$ \\
\hline $\begin{array}{c}\text { Native Hawaiian or } \\
\text { Pacific Islander }\end{array}$ & 0 & & $0 \%$ & & 0 & $0 \%$ \\
\hline Multiracial & 9 & & $13.2 \%$ & & 3 & $4.5 \%$ \\
\hline \multicolumn{7}{|l|}{ Ethnicity } \\
\hline Hispanic/Latino & 8 & & $18.7 \% \%$ & & 3 & $12.3 \%$ \\
\hline \multicolumn{7}{|l|}{ Minority Status } \\
\hline No & 36 & & $54.5 \%$ & & 4 & $66.7 \%$ \\
\hline \multirow[t]{2}{*}{ Yes } & 30 & & $45.5 \%$ & & 2 & $33.3 \%$ \\
\hline & \multicolumn{3}{|c|}{$\mathrm{M}$} & \multicolumn{3}{|c|}{$\mathrm{SD}$} \\
\hline Number of Adults in Home & \multicolumn{3}{|c|}{1.82} & \multicolumn{3}{|c|}{0.84} \\
\hline \multirow[t]{2}{*}{ Number of Children in Home } & \multicolumn{3}{|c|}{2.03} & \multicolumn{3}{|c|}{1.04} \\
\hline & \multicolumn{3}{|c|}{ Child } & \multicolumn{3}{|c|}{ Caregiver } \\
\hline Age & $M$ & $\mathrm{SD}$ & Range & M & $\mathrm{SD}$ & Range \\
\hline Beginning PCIT & 5.35 & 1.66 & $2.02-9.85$ & 32.38 & 8.30 & $17.77-69.80$ \\
\hline Current study & 8.20 & 1.77 & $5.02-13.04$ & 35.24 & 8.41 & $19.71-73.61$ \\
\hline
\end{tabular}


Table 2

Demographics for Caregivers

\begin{tabular}{lcc}
\hline & Frequency & Percent \\
\hline Relationship to Child & & \\
Biological Mother & 63 & $92.6 \%$ \\
Adoptive Mother & 3 & $4.4 \%$ \\
Stepmother & 1 & $1.5 \%$ \\
Grandfather & 1 & $1.5 \%$ \\
Education & 3 & \\
< $7^{\text {th }}$ grade & 2 & $4.5 \%$ \\
Some High School & 27 & $3.0 \%$ \\
High School Graduate/GED & 13 & $40.3 \%$ \\
Some College & 10 & $19.4 \%$ \\
Associates Degree & 3 & $14.9 \%$ \\
Standard College Degree & 9 & $4.5 \%$ \\
Graduate/Professional Training & & $13.4 \%$ \\
Employment Status & 29 & \\
Full-Time & 11 & $44.6 \%$ \\
Part-Time & 23 & $16.9 \%$ \\
Unemployed & 2 & $35.4 \%$ \\
Retired & & $3.1 \%$ \\
Marital Status & 21 & \\
Married & 38 & $31.3 \%$ \\
Single & 3 & $56.7 \%$ \\
Divorced & 5 & $4.5 \%$ \\
Separated & & $7.5 \%$ \\
\hline
\end{tabular}


Table 3

Demographics for Therapists

\begin{tabular}{|c|c|c|c|}
\hline & M & SD & Range \\
\hline \multirow[t]{2}{*}{ Age (Beginning PCIT) } & 38.63 & 10.78 & $24.98-61.36$ \\
\hline & Frequency & & Percent \\
\hline \multicolumn{4}{|l|}{ Gender } \\
\hline Male & 4 & & $11.8 \%$ \\
\hline Female & 30 & & $88.2 \%$ \\
\hline \multicolumn{4}{|l|}{ Race } \\
\hline Caucasian & 31 & & $96.9 \%$ \\
\hline African American & 1 & & $3.1 \%$ \\
\hline \multicolumn{4}{|l|}{ American Indian or Alaska } \\
\hline Native & 0 & & $0 \%$ \\
\hline Asian & 0 & & $0 \%$ \\
\hline \multicolumn{4}{|l|}{ Native Hawaiian or Pacific } \\
\hline Islander & 0 & & $0 \%$ \\
\hline Multiracial & 0 & & $0 \%$ \\
\hline \multicolumn{4}{|l|}{ Ethnicity } \\
\hline Hispanic/Latino & 2 & & $6.1 \%$ \\
\hline Professionally Licensed & 16 & & $48.5 \%$ \\
\hline \multicolumn{4}{|l|}{ Condition } \\
\hline Learning Collaborative & 34 & & $50.7 \%$ \\
\hline Cascading & 21 & & $31.3 \%$ \\
\hline Distance Learning & 12 & & $17.9 \%$ \\
\hline Education/Degree & 33 & & \\
\hline Master's & 32 & & $97.0 \%$ \\
\hline \multirow[t]{2}{*}{ Doctoral } & 1 & & $3.0 \%$ \\
\hline & $\mathrm{M}$ & & SD \\
\hline Years Experience & 11.52 & & 9.03 \\
\hline
\end{tabular}


Table 4

Means and Standard Deviations for Variables Examined

\begin{tabular}{lccc}
\hline Variable & Frequency & \multicolumn{2}{c}{ Percent } \\
\hline Family Completion Status & & & \\
$\quad$ Premature Terminators & 43 & & $64.2 \%$ \\
$\quad$ Completers & 24 & & $35.8 .8 \%$ \\
\hline Variable & $\mathrm{M}$ & $\mathrm{SD}$ & Range (Possible range) \\
\hline Caregiver Therapy Attitudes & 59.12 & 8.10 & $37-74(28-140)$ \\
Caregiver Therapy Expectations & 56.24 & 6.82 & $40-69(24-120)$ \\
Therapist Cultural Competence & 48.67 & 12.76 & $9-63(7-63)$ \\
Caregiver Commitment & 1.93 & 0.86 & $1-4.33(1-5)$ \\
\hline
\end{tabular}


Table 5

Intraclass Correlations Between Logistic Regression Predictor Variables

\begin{tabular}{lllll}
\hline Measure & 1 & 2 & 3 & 4 \\
\hline 1. Caregiver Therapy Attitudes & - & & & \\
2. Caregiver Therapy Expectations & $0.39 * *$ & -- & & \\
3. Therapist Cultural Competence & 0.05 & -0.23 & -- & \\
4. Caregiver Commitment & 0.18 & $0.30 *$ & $-0.29 *$ & -- \\
\hline$* p<.05, * * p<.01$ & & & &
\end{tabular}


Table 6

Reliability of Measures Used

\begin{tabular}{lll}
\hline Measure/Subscale & Number of Items & Cronbach's Alpha \\
\hline TAQ & 27 & 0.63 \\
Family/Self-Reliance & 4 & 0.79 \\
Use of Alternative Treatments & 2 & 0.77 \\
Guilt Feelings & 2 & 0.73 \\
Reliance on Discipline & 2 & 0.67 \\
Stigma & 5 & 0.67 \\
Mistrust of Therapist & 4 & 0.67 \\
Medication & 3 & 0.59 \\
Family Attitudes & 2 & 0.57 \\
Religion & 2 & 0.57 \\
Other & 1 & -- \\
TEQ & 22 & 0.53 \\
Speed of Recovery & 2 & 0.77 \\
Therapist Directiveness & 6 & 0.71 \\
Concerns/Perceived Barriers & 9 & 0.71 \\
Caregiver Assertiveness & 2 & 0.56 \\
Other & 3 & -- \\
TSTCQ Total & 19 & 0.95 \\
Skill Subscale & 6 & 0.84 \\
Satisfaction Subscale & 13 & 0.94 \\
TASCP & 12 & 0.77 \\
PCCS & 9 & 0.95 \\
\hline
\end{tabular}


Table 7

Logistic Regression Predicting Likelihood of Attrition Based on Treatment Attitudes, Expectations, Perceived Cultural Competence, and Commitment.

\begin{tabular}{lcccccccc}
\hline & & & & & & \multicolumn{3}{c}{$95 \%$ CI for Odds } \\
& & & & & & \multicolumn{2}{c}{ Odds } & \multicolumn{2}{c}{ Ratio } \\
& & & & & & & & \\
Ratio & Lower & Upper \\
\hline Therapy Attitudes & -.002 & .04 & .002 & 1 & .97 & 1.00 & .92 & 1.08 \\
Therapy Expectations & -.05 & .05 & 1.02 & 1 & .004 & .95 & .86 & 1.05 \\
Perceived Cultural Competence & .03 & .03 & 1.37 & 1 & .24 & 1.03 & .98 & 1.08 \\
Commitment to Treatment & -1.22 & .40 & 9.23 & 1 & .002 & .30 & .14 & .65 \\
Constant & 4.70 & 3.41 & 1.91 & 1 & .17 & 110.18 & & \\
\hline
\end{tabular}


Table 8

Caregiver and Therapist Impressions of Treatment Progress

\begin{tabular}{|c|c|c|c|c|c|c|c|c|c|}
\hline \multirow[b]{2}{*}{ Level of Progress } & \multicolumn{4}{|c|}{ Completers } & \multicolumn{4}{|c|}{ Premature Terminators } & \multirow[b]{2}{*}{ Kappa } \\
\hline & $\mathrm{N}$ & $\begin{array}{c}\text { Number of } \\
\text { Caregivers }(\%)\end{array}$ & $\mathrm{N}$ & $\begin{array}{c}\text { Number of } \\
\text { Therapists }(\%)\end{array}$ & $\mathrm{N}$ & $\begin{array}{c}\text { Number of } \\
\text { Caregivers }(\%)\end{array}$ & $\mathrm{N}$ & $\begin{array}{c}\text { Number of } \\
\text { Therapists }(\%)\end{array}$ & \\
\hline A little & 43 & $2(4.7 \%)$ & 36 & $2(5.6 \%)$ & 24 & $4(16.7 \%)$ & 19 & $4(21.1 \%)$ & 0.09 \\
\hline Some & 43 & $10(23.3 \%)$ & 36 & $4(13.9 \%)$ & 24 & $10(41.7 \%)$ & 19 & $5(26.3 \%)$ & -0.21 \\
\hline Moderate & 43 & $5(11.6 \%)$ & 36 & $9(25.0 \%)$ & 24 & $4(16.7 \%$ & 19 & $1(5.3 \%)$ & -0.004 \\
\hline None/A little/Some & 43 & $13(30.2 \%)$ & 36 & $8(18.6 \%)$ & 24 & $16(66.7 \%)$ & 19 & $17(89.5 \%)$ & .113 \\
\hline Moderate/A lot & 43 & $30(69.8 \%)$ & 36 & $28(65.1 \%)$ & 24 & $8(33.3 \%)$ & 19 & $2(10.5 \%)$ & .113 \\
\hline
\end{tabular}


Table 9

Why PCIT Services Ended

\begin{tabular}{|c|c|c|c|c|c|c|c|}
\hline \multirow[b]{2}{*}{ Reason } & \multirow[b]{2}{*}{$\mathrm{N}$} & \multicolumn{2}{|c|}{ Number of Caregivers $(\%)$} & \multirow[b]{2}{*}{$\mathrm{N}$} & \multicolumn{2}{|c|}{ Number of Therapists (\%) } & \multirow[b]{2}{*}{ Kappa } \\
\hline & & $\begin{array}{c}\text { Premature } \\
\text { Terminators }\end{array}$ & Completers & & $\begin{array}{l}\text { Premature } \\
\text { Terminators }\end{array}$ & Completers & \\
\hline Graduated from treatment & 66 & \multicolumn{2}{|c|}{$40(61.5 \%)$} & 56 & \multicolumn{2}{|c|}{$29(52.7 \%)$} & 0.63 \\
\hline \multirow[t]{2}{*}{ Therapist felt PCIT services were no longer needed } & 66 & \multicolumn{2}{|c|}{$15(22.7 \%)$} & 56 & \multicolumn{2}{|c|}{$22(39.3 \%)$} & -0.02 \\
\hline & & $4(17.4 \%)$ & $11(25.6 \%)$ & & $1(5.3 \%)$ & $21(56.8 \%)$ & \\
\hline \multirow[t]{2}{*}{ Problems got better/clinical improvement } & 66 & \multicolumn{2}{|c|}{$11(16.7 \%)$} & 56 & \multicolumn{2}{|c|}{$28(50.0 \%)$} & 0.12 \\
\hline & & $2(8.7 \%)$ & $9(20.9 \%)$ & & $2(10.5 \%)$ & $26(70.3 \%)$ & \\
\hline \multirow{2}{*}{$\begin{array}{l}\text { Caregiver/family felt PCIT services were no longer } \\
\text { needed }\end{array}$} & 66 & \multicolumn{2}{|c|}{$7(10.6 \%)$} & 56 & \multicolumn{2}{|c|}{$22(39.3 \%)$} & 0.07 \\
\hline & & $3(13.0 \%)$ & $4(9.3 \%)$ & & $2(10.5 \%)$ & $20(54.1 \%)$ & \\
\hline \multirow[t]{2}{*}{ Family or child moved/no longer available/missing } & 66 & \multicolumn{2}{|c|}{$7(10.6 \%)$} & 56 & \multicolumn{2}{|c|}{$1(1.8 \%)$} & 0.24 \\
\hline & & $6(26.1 \%)$ & $1(2.3 \%)$ & & $1(5.3 \%)$ & $0(0 \%)$ & \\
\hline \multirow{2}{*}{$\begin{array}{l}\text { Limited resources/unable to attend due to time, } \\
\text { Transportation, or money }\end{array}$} & 66 & \multicolumn{2}{|c|}{$7(10.6 \%)$} & 56 & \multicolumn{2}{|c|}{$5(8.9 \%)$} & -0.10 \\
\hline & & $5(21.7 \%)$ & $2(4.7 \%)$ & & $3(15.8 \%)$ & $2(5.4 \%)$ & \\
\hline \multirow[t]{2}{*}{ Schedule conflicts } & 66 & \multicolumn{2}{|c|}{$5(7.6 \%)$} & 56 & \multicolumn{2}{|c|}{$8(14.3 \%)$} & -0.11 \\
\hline & & $3(13.0 \%)$ & $2(4.7 \%)$ & & $4(21.1 \%)$ & $4(10.8 \%)$ & \\
\hline \multirow[t]{2}{*}{ Problem got worse/clinical deterioration } & 66 & \multicolumn{2}{|c|}{$5(7.6 \%)$} & 56 & \multicolumn{2}{|c|}{$0(0 \%)$} & -0.03 \\
\hline & & $3(13.0 \%)$ & $2(4.7 \%)$ & & $0(0 \%)$ & $0(0 \%)$ & \\
\hline \multirow[t]{2}{*}{ Disinterest in PCIT/low motivation } & 66 & \multicolumn{2}{|c|}{$3(4.5 \%)$} & 55 & \multicolumn{2}{|c|}{$10(17.9 \%)$} & -0.12 \\
\hline & & $1(4.3 \%)$ & $2(4.7 \%)$ & & $8(42.1 \%)$ & $2(5.4 \%)$ & \\
\hline Cancellations & 66 & $3(4$ & $5 \%)$ & 56 & $14(2$ & $.0 \%)$ & 0.10 \\
\hline & & $2(8.7 \%)$ & $1(2.3 \%)$ & & $10(52.6 \%)$ & $4(10.8 \%)$ & \\
\hline Do not like therapy (i.e., PCIT), therapist, or other & 66 & $2(3$ & $0 \%)$ & 56 & $1(1$ & $3 \%)$ & -0.03 \\
\hline aspects of the service & & $1(4.3 \%)$ & $1(2.3 \%)$ & & $1(5.3 \%)$ & $0(0 \%)$ & \\
\hline Insurance company or policy constraints/issues & 66 & $1(1$ & $5 \%)$ & 56 & & $\%)$ & -- \\
\hline & & $0(0 \%)$ & $1(2.3 \%)$ & & -- & -- & \\
\hline Non-compliance with PCIT by patient and/or & 66 & $1(1$ & $5 \%)$ & 56 & $9(1$ & $1 \%)$ & -0.10 \\
\hline family during sessions & & $0(0 \%)$ & $1(2.3 \%)$ & & $8(42.1 \%)$ & $1(2.7 \%)$ & \\
\hline
\end{tabular}




\begin{tabular}{|c|c|c|c|c|c|c|c|}
\hline \multirow{2}{*}{$\begin{array}{l}\text { Major crises or family emergency, including } \\
\text { serious illness }\end{array}$} & \multirow[t]{2}{*}{66} & \multicolumn{2}{|c|}{$1(1.5 \%)$} & 56 & \multicolumn{2}{|c|}{$2(3.6 \%)$} & \multirow[t]{2}{*}{-0.02} \\
\hline & & $1(4.3 \%)$ & $0(0 \%)$ & & $2(10.5 \%)$ & $0(0 \%)$ & \\
\hline \multirow[t]{2}{*}{ No-shows } & 66 & \multicolumn{2}{|c|}{$0(0 \%)$} & 56 & \multicolumn{2}{|c|}{$19(33.9 \%)$} & -0.20 \\
\hline & & $0(0 \%)$ & $0(0 \%)$ & & $12(63.2 \%)$ & $7(18.9 \%)$ & \\
\hline Legal problems that prevent family's participation & 66 & & & 56 & & & -- \\
\hline Child removed from home & 66 & & & 56 & & & -- \\
\hline \multirow[t]{2}{*}{ Therapist left } & 66 & \multicolumn{2}{|c|}{$6(9.1 \%)$} & -- & \multirow{2}{*}{\multicolumn{2}{|c|}{--}} & -- \\
\hline & & $3(13.0 \%)$ & $3(7.0 \%)$ & & & & \\
\hline
\end{tabular}


Table 10

Caregiver Reasons for Ending PCIT

\begin{tabular}{|c|c|c|c|c|}
\hline \multirow[b]{2}{*}{ Reasons } & \multicolumn{2}{|r|}{ Completers } & \multicolumn{2}{|c|}{ Premature Terminators } \\
\hline & $\mathrm{N}$ & $\begin{array}{c}\text { Number of } \\
\text { Caregivers (\%) }\end{array}$ & $\mathrm{N}$ & $\begin{array}{c}\text { Number of } \\
\text { Caregivers (\%) }\end{array}$ \\
\hline I did not think it would work for my child and I & 42 & $4(9.5 \%)$ & 24 & $5(20.8 \%)$ \\
\hline I felt like I got enough out of it and met my treatment goals & 42 & $12(28.6 \%)$ & 24 & $2(8.3 \%)$ \\
\hline I did not like my therapist & 42 & $1(2.3 \%)$ & 24 & $1(4.2 \%)$ \\
\hline $\begin{array}{l}\text { Life got in the way (e.g., transportation, child care, too busy, other } \\
\text { commitments) }\end{array}$ & 43 & $2(4.7 \%)$ & 24 & $11(45.8 \%)$ \\
\hline It was a bigger commitment than I was expecting & 43 & $2(4.7 \%)$ & 24 & $3(12.5 \%)$ \\
\hline It was too much for my child and I at that time in our lives & 43 & $1(2.3 \%)$ & 24 & $4(16.7 \%)$ \\
\hline
\end{tabular}




\section{Table 11}

Completer Reported Reasons for Ending PCIT Services

\begin{tabular}{lccc}
\hline & \multicolumn{3}{c}{ Number of } \\
Reason & $\mathrm{N}$ & Families & Percent \\
\hline Graduated & 43 & 36 & $82.8 \%$ \\
Therapist indicated not appropriate/needed & 43 & 2 & $4.6 \%$ \\
Therapist left agency & 43 & 1 & $2.3 \%$ \\
Caregiver found it unhelpful & 43 & 1 & $2.3 \%$ \\
Insurance issues & 43 & 1 & $2.3 \%$ \\
Caregiver had baby & 43 & 1 & $2.3 \%$ \\
\hline
\end{tabular}


Table 12

Premature Terminator Reported Reasons for Ending PCIT Services

\begin{tabular}{lccc}
\hline & \multicolumn{3}{c}{ Number of } \\
Reason & N & Families & Percent \\
\hline Family moved & 24 & 5 & $21.0 \%$ \\
Transportation issues & 24 & 4 & $16.8 \%$ \\
Therapist left agency/PCIT program closed & 24 & 4 & $16.8 \%$ \\
Scheduling difficulties & 24 & 4 & $16.8 \%$ \\
Families felt they finished the program & 24 & 2 & $8.4 \%$ \\
Family issues/Medical issues & 24 & 2 & $8.4 \%$ \\
Caregiver did not see improvement & 24 & 1 & $4.2 \%$ \\
Caregiver disliked therapist & 24 & 1 & $4.2 \%$ \\
Child needed medication & 24 & 1 & $4.2 \%$ \\
Child not willing to participate & 24 & 1 & $4.2 \%$ \\
Therapist felt PCIT not appropriate & 24 & 1 & $4.2 \%$ \\
\hline
\end{tabular}


Table 13

Negative Impacts on Overall Course and Outcome of Treatment

\begin{tabular}{|c|c|c|c|c|c|c|c|}
\hline \multirow[b]{2}{*}{ Impact } & \multirow[b]{2}{*}{$\mathrm{N}$} & \multicolumn{2}{|c|}{ Number of Caregivers $(\%)$} & \multirow[b]{2}{*}{$\mathrm{N}$} & \multicolumn{2}{|c|}{ Number of Therapists (\%) } & \multirow[b]{2}{*}{ Kappa } \\
\hline & & $\begin{array}{c}\text { Premature } \\
\text { Terminators }\end{array}$ & Completers & & $\begin{array}{c}\text { Premature } \\
\text { Terminators }\end{array}$ & Completers & \\
\hline \multirow[t]{2}{*}{ Marital discord/conflict } & \multirow[t]{2}{*}{66} & \multicolumn{2}{|c|}{$11(16.7 \%)$} & \multirow[t]{2}{*}{55} & \multicolumn{2}{|c|}{$15(27.3 \%)$} & \multirow[t]{2}{*}{0.04} \\
\hline & & $5(11.6 \%)$ & $6(26.1 \%)$ & & $10(27.8 \%)$ & $5(26.3 \%)$ & \\
\hline \multirow{2}{*}{$\begin{array}{l}\text { Family involvement in other treatment that } \\
\text { interfered with PCIT services }\end{array}$} & \multirow{2}{*}{66} & \multicolumn{2}{|c|}{$4(6.1 \%)$} & \multirow{2}{*}{55} & \multicolumn{2}{|c|}{$6(10.9 \%)$} & \multirow[t]{2}{*}{-0.09} \\
\hline & & $1(2.3 \%)$ & $3(13.0 \%)$ & & $4(11.1 \%)$ & $2(10.5 \%)$ & \\
\hline \multirow[t]{2}{*}{ Conflict with an outside family member or friend } & \multirow[t]{2}{*}{66} & \multicolumn{2}{|c|}{$2(3.0 \%)$} & 55 & \multicolumn{2}{|c|}{$9(16.4 \%)$} & \multirow[t]{2}{*}{-0.10} \\
\hline & & $1(2.3 \%)$ & $1(4.3 \%)$ & & $3(8.3 \%)$ & $6(31.6 \%)$ & \\
\hline \multirow[t]{2}{*}{ Conflict with work and family schedules/too busy } & \multirow[t]{2}{*}{66} & \multicolumn{2}{|c|}{$17(25.8 \%)$} & 54 & \multicolumn{2}{|c|}{$27(50.0 \%)$} & \multirow[t]{2}{*}{-0.07} \\
\hline & & $11(25.6 \%)$ & $6(26.1 \%)$ & & $17(48.6 \%)$ & $10(52.6 \%)$ & \\
\hline \multirow[t]{2}{*}{ Family living in a dangerous community } & \multirow[t]{2}{*}{66} & \multicolumn{2}{|c|}{$1(1.5 \%)$} & 55 & \multicolumn{2}{|c|}{$4(7.3 \%)$} & -0.04 \\
\hline & & $0(0.0 \%)$ & $1(4.3 \%)$ & & $2(5.6 \%)$ & $2(10.5 \%)$ & \\
\hline Caregiver anger/hostility & 66 & $7(10$ & $6 \%)$ & 54 & $2(3$ & $7 \%)$ & 0.19 \\
\hline & & $3(7.0 \%)$ & $4(17.4 \%)$ & & $0(0.0 \%)$ & $2(10.5 \%)$ & \\
\hline Caregiver drug/alcohol problems & 66 & 0( & $\%)$ & 55 & $3(5$ & $5 \%)$ & -0.03 \\
\hline & & $0(0.0 \%)$ & $0(0.0 \%)$ & & $2(5.6 \%)$ & $1(5.3 \%)$ & \\
\hline Caregiver mental health problems & 66 & $12(1$ & $.2 \%)$ & 55 & $16(2$ & $.1 \%)$ & 0.29 \\
\hline & & $5(11.6 \%)$ & $7(30.4 \%)$ & & $9(25.0 \%)$ & $7(36.8 \%)$ & \\
\hline Limited caregiver cognitive skills & 66 & $2(3$ & $0 \%)$ & 55 & $4(7$ & $3 \%)$ & -0.06 \\
\hline & & $0(0 \%)$ & $2(8.7 \%)$ & & $1(2.8 \%)$ & $3(15.8 \%)$ & \\
\hline Residential instability (e.g., moves, no phone, etc.) & 66 & $2(3$ & $0 \%)$ & 55 & $8(1$ & $5 \%)$ & 0.15 \\
\hline & & $0(0 \%)$ & $2(8.7 \%)$ & & $2(5.6 \%)$ & $6(31.6 \%)$ & \\
\hline Child out of home & 66 & $1(1$ & $5 \%)$ & 55 & $3(5$ & $5 \%)$ & -0.03 \\
\hline & & $0(0 \%)$ & $1(4.3 \%)$ & & $2(5.6 \%)$ & $1(5.3 \%)$ & \\
\hline Caregiver out of home & 66 & $4(6$ & $1 \%)$ & 55 & $4(7$ & $3 \%)$ & 0.19 \\
\hline & & $3(7.0 \%)$ & $1(4.3 \%)$ & & $2(5.6 \%)$ & $2(10.5 \%)$ & \\
\hline
\end{tabular}




\begin{tabular}{|c|c|c|c|c|c|c|c|}
\hline \multirow{2}{*}{ Limited child cognitive skills } & \multirow[t]{2}{*}{66} & \multicolumn{2}{|c|}{$7(10.6 \%)$} & 55 & \multicolumn{2}{|c|}{$3(5.5 \%)$} & -0.09 \\
\hline & & $5(11.6 \%)$ & $2(8.7 \%)$ & & $2(5.6 \%)$ & $1(5.3 \%)$ & \\
\hline \multirow{2}{*}{ Involvement with child welfare } & 66 & \multicolumn{2}{|c|}{$2(3.0 \%)$} & 55 & \multicolumn{2}{|c|}{$2(3.6 \%)$} & -0.04 \\
\hline & & $0(0 \%)$ & $2(8.7 \%)$ & & $2(5.6 \%)$ & $0(0 \%)$ & \\
\hline \multirow[t]{2}{*}{ Domestic violence } & 66 & \multicolumn{2}{|c|}{$3(4.5 \%)$} & 55 & \multicolumn{2}{|c|}{$1(1.8 \%)$} & -0.04 \\
\hline & & $2(4.7 \%)$ & $1(4.3 \%)$ & & $0(0 \%)$ & $1(5.3 \%)$ & \\
\hline
\end{tabular}


Table 14

Completer Reported Barriers to PCIT

\begin{tabular}{|c|c|c|c|}
\hline Reason & $\mathrm{N}$ & $\begin{array}{c}\text { Number of } \\
\text { Families }\end{array}$ & Percent \\
\hline Nothing & 32 & 27 & $84.4 \%$ \\
\hline Slow progress/time consuming & 32 & 2 & $6.3 \%$ \\
\hline Caregiver disliked therapist & 32 & 1 & $3.1 \%$ \\
\hline Difficult child & 32 & 1 & $3.1 \%$ \\
\hline Insurance issues & 32 & 1 & $3.1 \%$ \\
\hline Parent conflict about whether treatment necessary & 32 & 1 & $3.1 \%$ \\
\hline Transportation difficulties & 32 & 1 & $3.1 \%$ \\
\hline
\end{tabular}


Table 15

Premature Terminator Reported Barriers to PCIT

\begin{tabular}{lccc}
\hline & & Number of \\
Reason & N & Families & Percent \\
\hline Transportation difficulties & 16 & 7 & $43.8 \%$ \\
Family moved & 16 & 4 & $25.0 \%$ \\
Scheduling issues (e.g., work, other children) & 16 & 4 & $25.0 \%$ \\
Therapist left/PCIT program ended & 16 & 3 & $18.8 \%$ \\
None & 16 & 2 & $12.5 \%$ \\
Caregiver did not feel PCIT was helpful & 16 & 1 & $6.3 \%$ \\
Child unwillingness to participate & 16 & 1 & $6.3 \%$ \\
Medical issues & 16 & 1 & $6.3 \%$ \\
Others in household not supportive of treatment & 16 & 1 & $6.3 \%$ \\
\hline
\end{tabular}


Table 16

Completer Reported Goals for Treatment

\begin{tabular}{lccc}
\hline & & Number of \\
Reason & $\mathrm{N}$ & Families & Percent \\
\hline Improve child behavior & 40 & 28 & $70.0 \%$ \\
Better understand child/reasons for child behavior & 40 & 9 & $22.5 \%$ \\
Recommended by medical or mental health professional & 40 & 6 & $15.0 \%$ \\
Improve caregiver-child relationship & 40 & 5 & $12.5 \%$ \\
Learn appropriate discipline techniques & 40 & 4 & $10.0 \%$ \\
Improve caregiver-child communication & 40 & 3 & $7.5 \%$ \\
Decrease parent stress & 40 & 2 & $5.0 \%$ \\
Improve child self-esteem & 40 & 1 & $2.5 \%$ \\
\hline
\end{tabular}




\section{Table 17}

Premature Terminator Reported Goals for Treatment

\begin{tabular}{lccc}
\hline & & Number of \\
Reason & $\mathrm{N}$ & Families & Percent \\
\hline Improve child behavior/caregiver skills & 23 & 16 & $69.6 \%$ \\
Improve caregiver-child relationship & 23 & 5 & $21.7 \%$ \\
To help child & 23 & 3 & $13.0 \%$ \\
Improve caregiver-child communication & 23 & 2 & $8.7 \%$ \\
Better understand child/reasons for child behavior & 23 & 1 & $4.3 \%$ \\
Recommended by medical or mental health professional & 23 & 1 & $4.3 \%$ \\
Improve child self-esteem & 23 & 1 & $4.3 \%$ \\
\hline
\end{tabular}


Table 18

Completer Reported Most Helpful Components of PCIT

\begin{tabular}{|c|c|c|c|}
\hline Component & $\mathrm{N}$ & $\begin{array}{c}\text { Number of } \\
\text { Families }\end{array}$ & Percent \\
\hline Use of positive attention/Special play time & 39 & 12 & $30.8 \%$ \\
\hline Therapist patience, expertise, coaching & 39 & 11 & $28.2 \%$ \\
\hline Improved communication, labeled praise & 39 & 9 & $23.1 \%$ \\
\hline Appropriate discipline techniques & 39 & 6 & $15.4 \%$ \\
\hline Improved child behavior & 39 & 6 & $15.4 \%$ \\
\hline Improved caregiver-child relationship & 39 & 4 & $10.3 \%$ \\
\hline Better understand child/reasons for child behavior & 39 & 2 & $5.1 \%$ \\
\hline Nothing & 39 & 1 & $5.1 \%$ \\
\hline
\end{tabular}


Table 19

Premature Terminator Reported Most Helpful Components of PCIT

\begin{tabular}{lccc}
\hline & \multicolumn{3}{c}{ Number of } \\
Reason & $\mathrm{N}$ & Families & Percent \\
\hline Use of positive attention/Special play time & 23 & 9 & $40.9 \%$ \\
Nothing & 23 & 4 & $18.2 \%$ \\
Improved communication, labeled praise & 23 & 4 & $18.2 \%$ \\
Appropriate discipline techniques & 23 & 2 & $9.1 \%$ \\
Better understand child/reasons for child behavior & 23 & 2 & $9.1 \%$ \\
Improved caregiver-child relationship & 23 & 2 & $9.1 \%$ \\
Therapist patience, expertise, coaching & 23 & 2 & $9.1 \%$ \\
\hline
\end{tabular}


Table 20

Completer Reported Most Frustrating Components of PCIT

\begin{tabular}{lccc}
\hline & & Number of \\
Component & $\mathrm{N}$ & Families & Percent \\
\hline Nothing & 38 & 16 & $42.1 \%$ \\
Child noncompliance & 38 & 7 & $15.8 \%$ \\
Generalization of caregiver skills/child behavior to home & 38 & 3 & $7.9 \%$ \\
Scheduling difficulties & 38 & 3 & $7.9 \%$ \\
Time to see results/meet mastery & 38 & 3 & $7.9 \%$ \\
Allowing the child to direct the interaction & 38 & 2 & $5.3 \%$ \\
High level of treatment structure/use of specific language & 38 & 2 & $5.3 \%$ \\
Use of time out & 38 & 2 & $5.3 \%$ \\
Ignoring child disruptive behavior & 38 & 1 & $2.6 \%$ \\
Insurance issues & 38 & 1 & $2.6 \%$ \\
PCIT not appropriate for child/family & 38 & 1 & $2.6 \%$ \\
Caregiver changing his/her own behavior & 38 & 1 & $2.6 \%$ \\
Caregiver disliked therapist & 38 & 1 & $2.6 \%$ \\
\hline
\end{tabular}


Table 21

Premature Terminator Reported Most Frustrating Components of PCIT

\begin{tabular}{|c|c|c|c|}
\hline Reason & $\mathrm{N}$ & $\begin{array}{l}\text { Number of } \\
\text { Families }\end{array}$ & Percent \\
\hline Nothing & 22 & 5 & $22.7 \%$ \\
\hline Time to see results/meet mastery & 22 & 4 & $18.2 \%$ \\
\hline PCIT not appropriate for child/family & 22 & 2 & $9.1 \%$ \\
\hline Therapist unhelpful & 22 & 2 & $9.1 \%$ \\
\hline Transportation difficulties & 22 & 2 & $9.1 \%$ \\
\hline Almost everything & 22 & 1 & $4.5 \%$ \\
\hline Caregiver changing his/her own behavior & 22 & 1 & $4.5 \%$ \\
\hline Child unwilling to participate & 22 & 1 & $4.5 \%$ \\
\hline High level of treatment structure/use of specific language & 22 & 1 & $4.5 \%$ \\
\hline Interruptions of treatment in the therapy room & 22 & 1 & $4.5 \%$ \\
\hline Other caregiver unwilling to participate & 22 & 1 & $4.5 \%$ \\
\hline Therapist left & 22 & 1 & $4.5 \%$ \\
\hline Use of time out & 22 & 1 & $4.5 \%$ \\
\hline
\end{tabular}


Table 22

Completer Recommendations for Other Caregivers and Therapists

\begin{tabular}{|c|c|c|c|}
\hline Recommendation & $\mathrm{N}$ & $\begin{array}{l}\text { Number of } \\
\text { Families }\end{array}$ & Percent \\
\hline \multicolumn{4}{|l|}{ Other Caregivers } \\
\hline Persist in treatment/remain patient & 31 & 14 & $45.2 \%$ \\
\hline Try PCIT & 31 & 6 & $19.4 \%$ \\
\hline Follow therapist recommendations & 31 & 3 & $9.7 \%$ \\
\hline Know that parent behavior is the focus of PCIT & 31 & 3 & $9.7 \%$ \\
\hline Confirm that insurance will cover PCIT & 31 & 1 & $3.2 \%$ \\
\hline Use skills at home as well as in session & 31 & 1 & $3.2 \%$ \\
\hline Recommended their specific therapist & 31 & 1 & $3.2 \%$ \\
\hline \multicolumn{4}{|l|}{ Therapists } \\
\hline Be more supportive/listen to caregivers more & 31 & 3 & $9.7 \%$ \\
\hline Personalize treatment to the child & 31 & 2 & $6.5 \%$ \\
\hline Provide regular follow-up sessions after graduation & 31 & 1 & $3.2 \%$ \\
\hline Better explain mastery criteria & 31 & 1 & $3.2 \%$ \\
\hline Continue providing PCIT & 31 & 1 & $3.2 \%$ \\
\hline Provide more toy options & 31 & 1 & $3.2 \%$ \\
\hline
\end{tabular}


Table 23

Premature Terminator Recommendations for Other Caregivers and Therapists

\begin{tabular}{lccc}
\hline Recommendation & N $\begin{array}{c}\text { Number of } \\
\text { Families }\end{array}$ & Percent \\
\hline Other Caregivers & & & \\
$\quad$ Persist in treatment/remain patient & 14 & 7 & $50.0 \%$ \\
$\quad$ Try PCIT & 14 & 5 & $35.7 \%$ \\
$\quad$ Confirm therapist will remain at agency & 14 & 1 & $7.1 \%$ \\
$\quad$ Use skills at home as well as in session & 14 & 1 & $7.1 \%$ \\
$\quad$ Communicate dissatisfaction or if treatment is not working & 14 & 1 & $7.1 \%$ \\
Therapists & & & \\
$\quad$ Be more supportive/listen to caregivers more & 14 & 2 & $14.3 \%$ \\
Continue providing PCIT & 14 & 2 & $14.3 \%$ \\
\hline
\end{tabular}




\section{Table 24}

Family Use of Other Services after PCIT and Compliance with Post-Treatment Therapy Recommendations

\begin{tabular}{|c|c|c|c|c|c|c|c|}
\hline \multirow[b]{2}{*}{ Service } & \multirow[b]{2}{*}{$\mathrm{N}$} & \multicolumn{2}{|c|}{ Number of Caregivers (\%) } & \multirow[b]{2}{*}{$\mathrm{N}$} & \multicolumn{2}{|c|}{ Number of Therapists (\%) } & \multirow[b]{2}{*}{ Kappa } \\
\hline & & $\begin{array}{c}\text { Premature } \\
\text { Terminators }\end{array}$ & Completers & & $\begin{array}{c}\text { Premature } \\
\text { Terminators }\end{array}$ & Completers & \\
\hline Outpatient treatment & 66 & \multicolumn{2}{|c|}{$27(40.9 \%)$} & 55 & \multicolumn{2}{|c|}{$16(29.1 \%)$} & -0.06 \\
\hline \multirow{3}{*}{ BHRS (wraparound) } & & $18(41.9 \%)$ & $9(39.1 \%)$ & & $10(27.8 \%)$ & $6(31.6 \%)$ & \\
\hline & 66 & \multicolumn{2}{|c|}{$14(21.2 \%)$} & 55 & \multicolumn{2}{|c|}{$10(18.2 \%)$} & 0.06 \\
\hline & & $9(20.9 \%)$ & $5(21.7 \%)$ & & $7(18.9 \%)$ & $3(15.8 \%)$ & \\
\hline \multirow{2}{*}{$\begin{array}{l}\text { Intensive case management/resource coordination } \\
\quad \text { (face-to-face) }\end{array}$} & 66 & \multicolumn{2}{|c|}{$3(4.5 \%)$} & 55 & \multicolumn{2}{|c|}{$7(12.7 \%)$} & 0.29 \\
\hline & & $1(2.3 \%)$ & $2(8.7 \%)$ & & $6(16.2 \%)$ & $1(5.3 \%)$ & \\
\hline \multirow[t]{2}{*}{ Community support services } & 66 & \multicolumn{2}{|c|}{$5(7.6 \%)$} & 55 & \multicolumn{2}{|c|}{$7(12.7 \%)$} & -0.07 \\
\hline & & $3(7.0 \%)$ & $2(87 \%)$ & & $5(13.5 \%)$ & $2(10.5 \%)$ & \\
\hline \multirow[t]{2}{*}{ Family-based services } & 66 & \multicolumn{2}{|c|}{$9(13.6 \%)$} & 55 & \multicolumn{2}{|c|}{$1(1.8 \%)$} & 0.06 \\
\hline & & $8(18.6 \%)$ & $1(4.3 \%)$ & & $0(0 \%)$ & $1(5.3 \%)$ & \\
\hline \multirow[t]{2}{*}{ Family therapy } & 66 & \multicolumn{2}{|c|}{$8(12.1 \%)$} & 55 & \multicolumn{2}{|c|}{$1(1.8 \%)$} & -0.10 \\
\hline & & $6(14.0 \%)$ & $2(8.7 \%)$ & & $0(0 \%)$ & $1(5.3 \%)$ & \\
\hline \multirow[t]{2}{*}{ Partial hospitalization or day treatment } & 66 & \multicolumn{2}{|c|}{$3(4.5 \%)$} & 55 & \multicolumn{2}{|c|}{$1(1.8 \%)$} & 0.09 \\
\hline & & $1(4.3 \%)$ & $2(4.7 \%)$ & & $1(2.7 \%)$ & $0(0 \%)$ & \\
\hline \multirow[t]{2}{*}{ Administrative case management (not face-to-face) } & 66 & \multicolumn{2}{|c|}{$1(1.5 \%)$} & 55 & \multicolumn{2}{|c|}{$1(1.8 \%)$} & -0.03 \\
\hline & & $0(0 \%)$ & $1(4.3 \%)$ & & $1(2.7 \%)$ & $0(0 \%)$ & \\
\hline \multirow[t]{2}{*}{ Support group } & 66 & \multicolumn{2}{|c|}{$6(9.1 \%)$} & 55 & \multicolumn{2}{|c|}{$1(1.8 \%)$} & -0.23 \\
\hline & & $5(11.6 \%)$ & $1(4.3 \%)$ & & $1(2.7 \%)$ & $0(0 \%)$ & \\
\hline \multirow{2}{*}{ Inpatient hospitalization or day treatment } & 66 & $1(1$ & $5 \%)$ & 55 & & & -0.09 \\
\hline & & $0(0 \%)$ & $1(4.3 \%)$ & & $0(0 \%)$ & $0(0 \%)$ & \\
\hline Residential treatment & 66 & $2(3$ & $0 \%)$ & 55 & & & -0.07 \\
\hline & & $0(0 \%)$ & $2(8.7 \%)$ & & $0(0 \%)$ & $0(0 \%)$ & \\
\hline
\end{tabular}




\section{Figures}

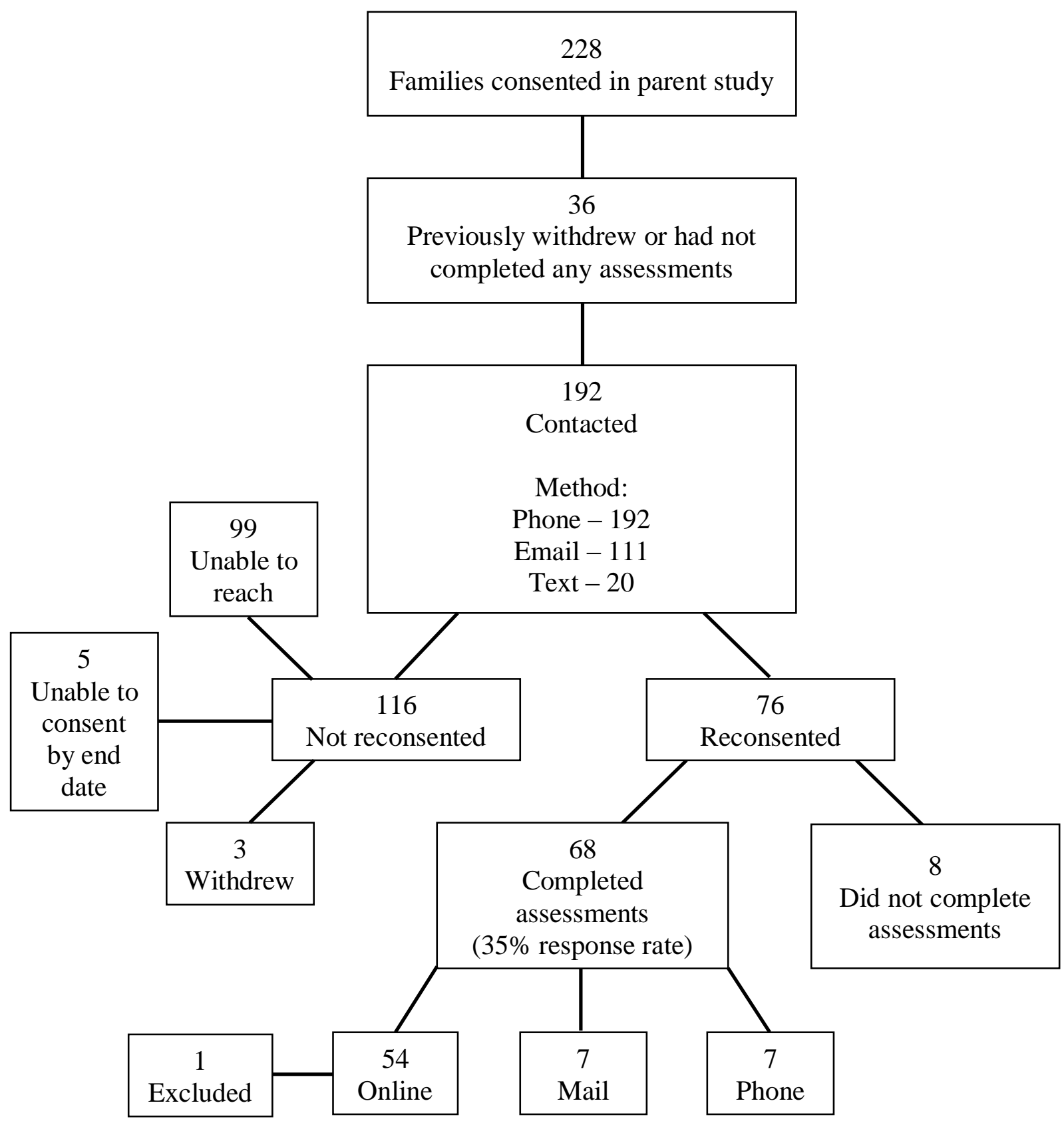

Figure 1. Flow chart showing participant re-consent 


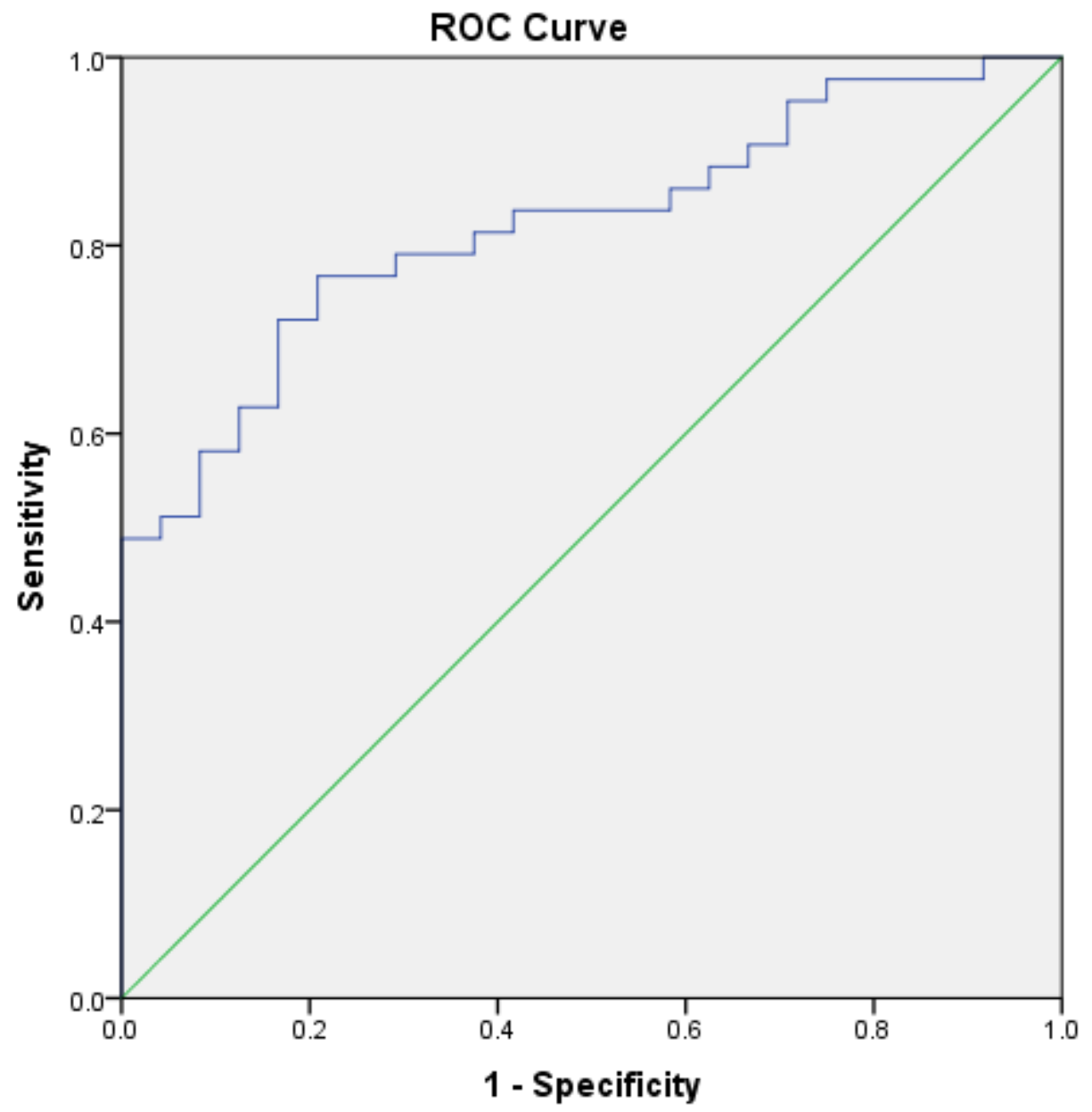

Figure 2. ROC curve for logistic regression 


\title{
Appendices
}

\author{
Appendix A
}

\section{Instructions for Calling Families to Re-Consent}

Have a printed copy of the 'Sample Telephone Script - PCIT Across PA: Re-consent for PCIT Family Experiences Questionnaires'

1) Open Family Management to access parent name, child name, and contact info

2) Try to call within the timeframe indicated next to the 'Good Time to Call' item

3) Follow the 'Sample Telephone Script' or 'Sample Voicemail Script'

a. Read the first three sections of the 'Sample Telephone Script'

b. "If you have a few minutes, I would like to tell you about the assessment, you can decide if you are interested, and I can receive your consent over the phone."

[Allow parent to respond]

i. If time, finish 'Sample Telephone Script'

ii. If not, "I can call back another time. When would be a good time?" [Get availability]

4) If they decide not to participate, thank them for their time and document on 'Call Log'

5) If they are re-consented:

a. Complete verification of explanation on 'Sample Telephone Script'

b. Get current mailing address in order to mail prepaid debit card

c. "We are so glad you are participating, thank you so much! The next step is to complete a few self-report assessments. There are three ways to do that: you can complete the assessment online via a link we can email or text you, we can mail you a paper version of the assessment for you to complete and mail back to us, or I can complete the assessment with you over the phone, which will take 40-60 minutes." (document preference, see A-C below)

A. Online: "Okay, you will receive an email with the link by the end of the day. Please go online at your earliest convenience and complete the questionnaire before November 9. I will receive a notification once you have completed the assessment and will load $\$ 40$ onto your prepaid debit card. You can call us at 412-337-2187, or email us at liebsackbk@umpc.edu if you have any further questions."

B. Mail: "Okay, I will mail you a paper version of the assessment measures right away. I will include a returnable envelope which you can use to return the assessment back to us free of charge. Please return it by November 9 and we will load $\$ 40$ onto your prepaid debit card when we receive it."

Enclose the following documents into a manila envelope: 
1. Prepaid debit card

2. 5. Cover letter for mailed questionnaires

3. 6. Questionnaires to mail

a. Family Information Form

b. Therapy Attitudes Questionnaire

c. Therapy Expectations Questionnaire

d. Treatment Satisfaction and Therapist Competency Questionnaire

e. Therapeutic Alliance Scale for Caregivers and Parents

f. Perceived Cultural Competency Scale

g. Treatment Summary Report-Parent

- Staple the assessment together

- Write the family's ID number on the top right corner of the assessment

- Prepare a returnable envelope by writing the department ID (WPICC-06163), your name, and your room number on the front.

*Document mailing and receiving assessments into the 'Call Log'.

C. Phone: "Okay, do you have time to do it right now?"

a. If yes, open a survey link to Qualtrics from the brittdissertation@gmail.com email and complete the assessments over the phone

i. Please "reply" to that email with the family ID number for tracking - so that Britt knows that link was used and so that you do not attempt to use the same link in the future

b. If no, ask "Can we make an appointment to complete it over the phone sometime this week?

i. Log on to brittdissertation@gmail.com (password: XXXXXXXX) and schedule a time during someone's availability

ii. Email that person to notify them 


\section{Appendix B}

\section{Phone Script for Voicemail}

"Hello, this message is for (first name of parent). My name is (your name) and I am calling from the University of Pittsburgh in regard to the PCIT across PA Project.

I am calling to talk to you about an opportunity to complete an additional assessment, about your expectations of and experiences in PCIT. You will be paid $\$ 40$ for the completion of the assessment. It should take about 1 hour and you can complete it online, by phone, or by mail before November 9.

If you are interested in learning more about this please call us back at the PCIT Across PA number (412) 337 - 2187 or at (412) 525 - PCIT (7248).” 


\section{Appendix C}

Phone Script for Re-consent

“Hello, may I please speak with (first name and last name).

Hello, my name is (your name) and I am calling from the University of Pittsburgh in regard to the PCIT across PA Project. How are you? Do you have a few minutes to talk right now?

We wanted to talk to you about a change in the assessment schedule for the study. If you continue participation in the study, in addition to the assessments you will complete or have completed for the study, we will ask you to answer questions about your experiences in PCIT between today (date) and November 9, 2017. This assessment will occur by phone, mail, or online. The time to complete this assessment should be about sixty (60) minutes. The assessment includes questions pertaining to the following:

o $\quad$ Your expectations of PCIT

o $\quad$ Your experiences in PCIT

You will not benefit directly from participating in this research. However, the information you give us may help us understand how to improve PCIT services and how to best offer PCIT services in the future to families like yours.

There is no cost for your participation in this study. You will be paid $\$ 40$ for the completion of this assessment.

This is a very low risk study, but you should be aware of potential risks. You may experience minimal stress or embarrassment associated with participation in a research study. One of the potential risks is that someone other than the research team might see your answers to the questions. To reduce this risk of breach of confidentiality, we will take several steps to ensure confidentiality including but not limited to assigning a study ID number to you so your name will not appear on the questionnaires you complete; keeping the list that has your name and the ID number assigned to you separate from the research records and your responses, and not revealing your identity in any description or publications of this research. The principal investigator and research staff members will do everything in their power to protect your privacy and the confidentiality of your records. Your data will not be shared with your PCIT therapist.

It is important for me to share that your decision to participate in this study is completely up to you. If you decide not to participate, you will not be affected in any way. Also, if you decide to participate now but as you complete the assessments you change your mind, it is ok and you can withdraw from the study at any time. If you decide not to participate, it will not affect you.

Do you have any questions about this change, the study or your participation?

Do you agree to continue participation in this research project or refuse to continue participation?" 


\section{VERIFICATION OF EXPLANATION}

I certify that I have carefully explained the change in this research protocol to the adult participant in appropriate language on (date) via phone or in person. He/she has had an opportunity to discuss it with me in detail. I have answered all of his/her questions and he/she freely agreed to participate in this research.

Printed Name of Person Obtaining Consent

Signature of Person Obtaining Consent
Role in Research Study

Date 


\section{Appendix D}

\section{Email for Re-consent}

Dear (first name of parent),

I am emailing you about your participation in the Parent-Child Interaction Therapy Across PA Project. There is an opportunity to complete an additional assessment, before November 9, about your expectations of and experiences in PCIT. You will be paid $\$ 40$ for the completion of the assessment. It should take about 1 hour and you can complete it online or by phone.

If you are interested in learning more about this please call us back at the PCIT Across PA number (412) $337-2187$ on weekdays or at (412) $525-7248$ on evenings or weekends at your earliest convenience.

Thank you for your participation!

Britt

$--$

Brittany K. Liebsack

liebsackbk@upmc.edu

(412) 525 - PCIT (7248) 


\section{Appendix E}

Cover Letter for Mailed Questionnaires

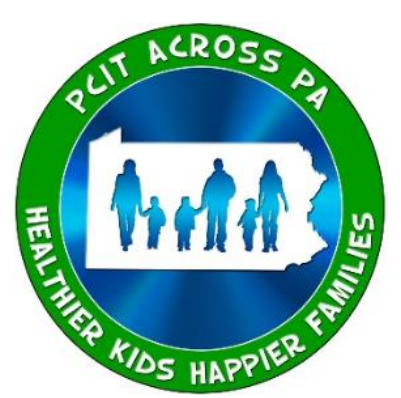

Thank you so much for your participation in the PCIT Family Experiences and Feedback Study!

Please complete the following assessments and mail them back to us using the stamped envelope that is enclosed. Please return them by Wednesday, November 1, 2017. When we receive your completed assessments, we will load $\mathbf{\$ 4 0}$ onto your prepaid debit card.

Your answers will remain private and will not be shared with your PCIT therapist or agency, so please share both positive and negative experiences with us, in an effort to improve services.

Please do not hesitate to call us at (412) 337-2187 or email us at liebsackbk@umpc.edu if you have any questions. 


\section{Appendix F}

Procedure for Administering Over the Phone Assessments to Families

When administering assessments to families over the phone, you will access the assessment online as if you were them.

1. Log on to Qualtrics

2. Enter the email address that is provided on the Family Management form

3. Read each question slowly and clearly and fill in the corresponding answers

After the assessment is complete, say:

"Thank you so much for taking the time to complete this assessment with me. I will now upload $\$ 40$ to your prepaid debit card. Do you still have this card?"

If yes: "Great! I will email you with a receipt once that transaction is completed."

If no: "No problem, I will be happy to send you a new one. Once you receive the new card in the mail, please call, email, or text me to let me know and I will transfer any remaining funds from your old card over to your new one and upload the $\$ 40$ from today on to it." 
Appendix G

Call Log

Researcher Call Log - Week: 05/05/1955 - 05/05/1955

Re-consent/Assessment Reminders

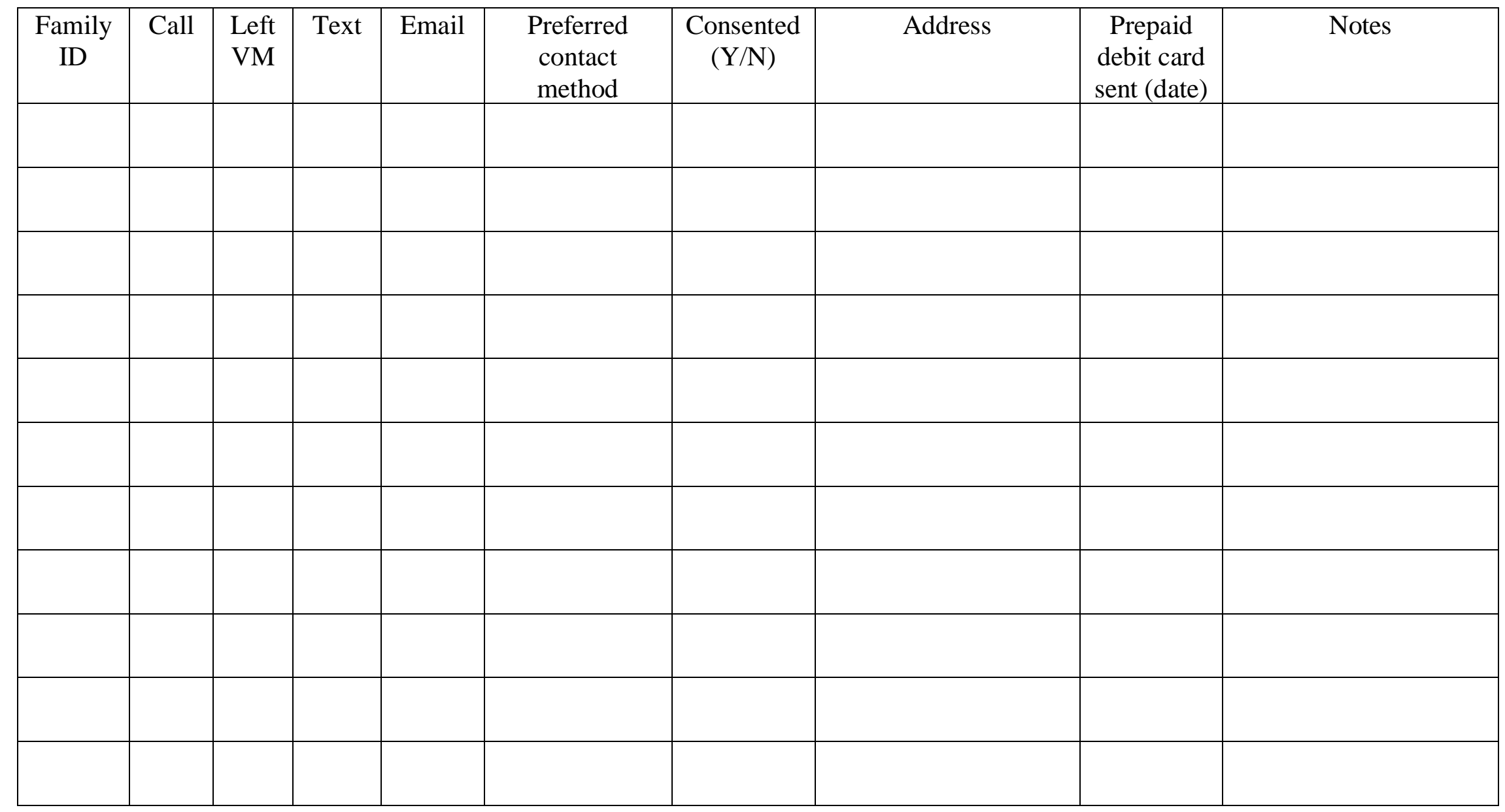


Appendix $\mathrm{H}$

Assessment Overview

Last Updated - April 29, 2017

\begin{tabular}{|c|c|c|c|c|}
\hline Measure & Construct & Admin (min) & \# items & Method \\
\hline Demographic Questionnaire & Demographic information & 5 & 7 & $\begin{array}{l}\text { Online } \\
\text { Mail } \\
\text { Phone }\end{array}$ \\
\hline Therapy Attitudes Questionnaire & Attitudes toward treatment participation & 10 & 28 & $\begin{array}{c}\text { Online } \\
\text { Mail } \\
\text { Phone }\end{array}$ \\
\hline Therapy Expectations Questionnaire & Expectations for treatment & 10 & 22 & $\begin{array}{c}\text { Online } \\
\text { Mail } \\
\text { Phone }\end{array}$ \\
\hline $\begin{array}{l}\text { Treatment Satisfaction and Therapist } \\
\text { Competency Questionnaire }\end{array}$ & $\begin{array}{l}\text { Satisfaction with key PCIT components } \\
\text { Perception of therapist PCIT competence }\end{array}$ & 10 & 18 & $\begin{array}{l}\text { Online } \\
\text { Mail } \\
\text { Phone }\end{array}$ \\
\hline $\begin{array}{l}\text { Therapeutic Alliance Scale for } \\
\text { Caregivers and Parents }\end{array}$ & Therapeutic alliance & 5 & 12 & $\begin{array}{l}\text { Online } \\
\text { Mail } \\
\text { Phone }\end{array}$ \\
\hline Perceived Cultural Competence Scale & Perception of therapist cultural competence & 5 & 9 & $\begin{array}{l}\text { Online } \\
\text { Mail } \\
\text { Phone }\end{array}$ \\
\hline Treatment Summary Report—Parent & $\begin{array}{l}\text { Expectations of, commitment to, and opinions of } \\
\text { treatment; reasons for ending treatment; and other } \\
\text { services used }\end{array}$ & 10 & 21 & $\begin{array}{l}\text { Online } \\
\text { Mail } \\
\text { Phone }\end{array}$ \\
\hline All Measures & & 55 & 117 & \\
\hline
\end{tabular}




\section{Appendix I}

Assessments

\section{Demographic Questionnaire}

Number \& Street Address

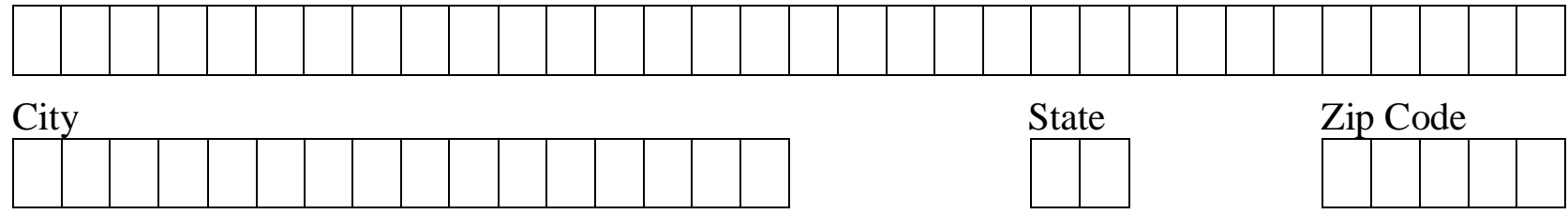

Email Address

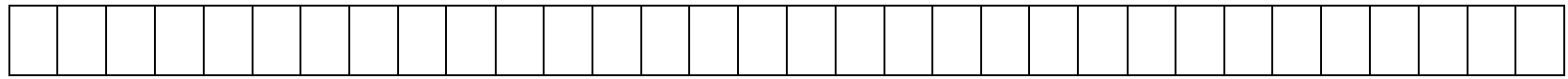

Caregiver's Date of birth:

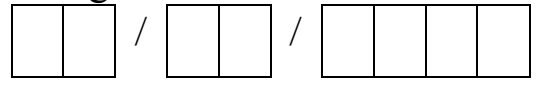

Child's Date of birth:

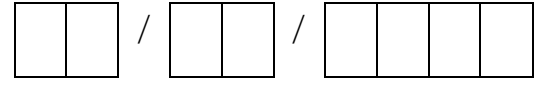

Child's Gender:

Male $\quad \square$ Female

Child's Ethnicity:

Hispanic or Latino

Not Hispanic or Latino

$\square$ Unknown

Child's Race:

$\square$ American Indian/Alaska native

Asian

$\square$ Native Hawaiian or Pacific Islander

$\square$ Black or African American

$\square$ White

$\square$ Unknown 
On a scale from 1 to 10, rate your child's (who participated in PCIT) ability to behave well and to listen to and obey you BEFORE BEGINNING PCIT:

\begin{tabular}{|cccccccccc|}
\hline$\square$ & $\square$ & $\square$ & $\square$ & $\square$ & $\square$ & $\square$ & $\square$ & $\square$ & $\square$ \\
1 & 2 & 3 & 4 & 5 & 6 & 7 & 8 & 9 & 10 \\
Poor & & & Average & & & & & Great \\
$\begin{array}{l}\text { My child did not } \\
\text { behave well or } \\
\text { listen at all }\end{array}$ & & & & & & & & & $\begin{array}{r}\text { My child always } \\
\text { behaved well and } \\
\text { listened }\end{array}$ \\
\hline
\end{tabular}

On a scale from 1 to 10, rate your child's (who participated in PCIT) ability to behave well and to listen to and obey you IMMEDIATELY AFTER ENDING PCIT:

\begin{tabular}{|lllllllllc|}
\hline$\square$ & $\square$ & $\square$ & $\square$ & $\square$ & $\square$ & $\square$ & $\square$ & $\square$ & $\square$ \\
1 & 2 & 3 & 4 & 5 & 6 & 7 & 8 & 9 & 10 \\
Poor & & & Average & & & & & Great \\
$\begin{array}{l}\text { My child did not } \\
\text { behave well or } \\
\text { listen at all }\end{array}$ & & & & & & & & & $\begin{array}{r}\text { My child always } \\
\text { behaved well and } \\
\text { listened }\end{array}$ \\
\hline
\end{tabular}

On a scale from 1 to 10, rate your child's (who participated in PCIT) ability to behave well and to listen to and obey you NOW (PAST TWO WEEKS):

\begin{tabular}{|cccccccccc|}
\hline$\square$ & $\square$ & $\square$ & $\square$ & $\square$ & $\square$ & $\square$ & $\square$ & $\square$ & $\square$ \\
1 & 2 & 3 & 4 & 5 & 6 & 7 & 8 & 9 & 10 \\
Poor & & & Average & & & & & Great \\
$\begin{array}{l}\text { My child does } \\
\text { not behave well } \\
\text { or listen at all }\end{array}$ & & & & & & & & $\begin{array}{r}\text { My child always } \\
\text { behaves well and } \\
\text { listens }\end{array}$ \\
\hline
\end{tabular}




\section{Therapy Attitudes Questionnaire}

Parents have many different thoughts and concerns when they decide to take their child to a counselor/therapist. Listed below are a few of those thoughts and concerns. Please circle one answer to indicate how much you agreed with each of the following statements BEFORE STARTING PCIT:

\section{Family/Self Reliance}

1. My child could overcome his/her problems without the help of a therapist if s/he tried hard enough.
1
Strongly
2
3
4
5
Disagree
Disagree
Neither Agree
Nor Disagree
Agree
Strongly
Agree

2. I could help my child overcome his/her problems without the help of a therapist if I tried hard enough.
1
2
3
4
5
Strongly
Disagree
Neither Agree
Agree
Strongly
Disagree
Nor Disagree
Agree

3. Children's behavioral or emotional problems would usually just go away by themselves if you gave them time.
1
Strongly
2
3
4
5
Disagree
Disagree
Neither Agree
Nor Disagree
Agree
Strongly
Agree

4. All problems with children's' emotions or behavior should be handled within the family.

$\begin{array}{ccccc}1 & 2 & 3 & 4 & 5 \\ \text { Strongly } & \text { Disagree } & \text { Neither Agree } & \text { Agree } & \text { Strongly } \\ \text { Disagree } & & \text { Nor Disagree } & & \text { Agree }\end{array}$

$\underline{\text { Guilt Feelings }}$

1. My child would not have problems if I were a better parent.

$\begin{array}{ccccc}1 & 2 & 3 & 4 & 5 \\ \text { Strongly } & \text { Disagree } & \text { Neither Agree } & \text { Agree } & \text { Strongly } \\ \text { Disagree } & & \text { Nor Disagree } & & \text { Agree }\end{array}$


2. Sometimes I thought it was my fault that my child had emotional/behavioral problems.

$\begin{array}{lcccc}1 & 2 & 3 & 4 & 5 \\ \text { Strongly } & \text { Disagree } & \text { Neither Agree } & \text { Agree } & \text { Strongly } \\ \text { Disagree } & & \text { Nor Disagree } & & \text { Agree }\end{array}$

$\underline{\text { Religion }}$

1. When a child has an emotional/behavioral problem, only God can help.
1
2
3
4
5
Strongly
Disagree
Neither Agree
Agree
Strongly
Nor Disagree
Agree

2. When a child has an emotinal/behavioral problem, the church should be involved in treatment.
1
2
3
4
5
Strongly
Disagree
Neither Agree
Nor Disagree
Agree
Strongly
Disagree

3. When a child has an emotional/behavioral problem, praying is the best thing you can do.

$\begin{array}{lcccc}1 & 2 & 3 & 4 & 5 \\ \text { Strongly } & \text { Disagree } & \text { Neither Agree } & \text { Agree } & \text { Strongly } \\ \text { Disagree } & & \text { Nor Disagree } & & \text { Agree }\end{array}$

\section{Reliance on Discipline}

1. Children developed emotional/behavioral problems because their parents didn't discipline them enough.
1
Strongly
2
3
4
5
Disagree
Disagree
Neither Agree
Nor Disagree
Agree
Strongly
Agree

2. If a child had emotional/behavioral problem, you should be extra strict with them.

$\begin{array}{ccccc}1 & 2 & 3 & 4 & 5 \\ \text { Strongly } & \text { Disagree } & \text { Neither Agree } & \text { Agree } & \text { Strongly } \\ \text { Disagree } & & \text { Nor Disagree } & & \text { Agree }\end{array}$




\section{$\underline{\text { Stigma }}$}

1. I would be embarrassed to talk about my child's emotional/behavioral problems with a therapist.
1
2
3
4
5
Strongly
Disagree
Neither Agree
Nor Disagree
Agree
Strongly
Agree

2. I would be embarrassed if my friends or neighbors knew I was taking my child to therapy.

$\begin{array}{ccccc}1 & 2 & 3 & 4 & 5 \\ \text { Strongly } & \text { Disagree } & \text { Neither Agree } & \text { Agree } & \text { Strongly } \\ \text { Disagree } & & \text { Nor Disagree } & & \text { Agree }\end{array}$

3. A child should not be taken to a therapist unless they have problems that are really serious.
1
Strongly
2
3
4
5
Disagree
$\begin{array}{ll}\text { Disagree } & \text { Neither Agree } \\ \text { Nor Disagree }\end{array}$
Agree
Strongly
Agree

4. Mental illness was a sign of a weak character.

$\begin{array}{ccccc}1 & 2 & 3 & 4 & 5 \\ \text { Strongly } & \text { Disagree } & \text { Neither Agree } & \text { Agree } & \text { Strongly } \\ \text { Disagree } & & \text { Nor Disagree } & & \text { Agree }\end{array}$

5. If a child is seeing a therapist, $\mathrm{s} / \mathrm{he}$ must be crazy.

$\begin{array}{lcccc}1 & 2 & 3 & 4 & 5 \\ \text { Strongly } & \text { Disagree } & \text { Neither Agree } & \text { Agree } & \text { Strongly } \\ \text { Disagree } & & \text { Nor Disagree } & & \text { Agree }\end{array}$

$\underline{\text { Use of Alternative Treatments }}$

1. I have treated my child's emotional/behavioral problems with special teas or herbs.
1
Strongly
2
3
4
5
Disagree
Disagree
Neither Agree
Nor Disagree
Agree
Strongly
Agree

2. I have treated my child's emotional/behavioral problems using other home remedies.

$\begin{array}{ccccc}1 & 2 & 3 & 4 & 5 \\ \text { Strongly } & \text { Disagree } & \text { Neither Agree } & \text { Agree } & \text { Strongly } \\ \text { Disagree } & & \text { Nor Disagree } & & \text { Agree }\end{array}$




\section{Medications}

1. Children should not be given medications for emotional/behavioral problems because they might become addicted.
Strongly
Disagree
2
3
4
5
Disagree
Neither Agree
Nor Disagree
Agree
Strongly
Agree

2. Children's emotional and behavioral problems should be treated by a physician.

$\begin{array}{ccccc}1 & 2 & 3 & 4 & 5 \\ \text { Strongly } & \text { Disagree } & \text { Neither Agree } & \text { Agree } & \text { Strongly } \\ \text { Disagree } & & \text { Nor Disagree } & & \text { Agree }\end{array}$

3. Children's emotional and behavioral problems should be treated with medications.
1
Strongly
2
3
4
5
Disagree
Disagree
Neither Agree
Nor Disagree
Agree
Strongly
Agree

Family Attitudes

1. Some members of my family would not approve of me taking my child to see a therapist.

$\begin{array}{ccccc}1 & 2 & 3 & 4 & 5 \\ \text { Strongly } & \text { Disagree } & \text { Neither Agree } & \text { Agree } & \text { Strongly } \\ \text { Disagree } & & \text { Nor Disagree } & & \text { Agree }\end{array}$

2. My child's other parent would not approve of my child going to therapy.

$\begin{array}{ccccc}1 & 2 & 3 & 4 & 5 \\ \text { Strongly } & \text { Disagree } & \text { Neither Agree } & \text { Agree } & \text { Strongly } \\ \text { Disagree } & & \text { Nor Disagree } & & \text { Agree }\end{array}$

Mistrust of Therapist

1. Therapists generally treat families with respect and understanding.

$\begin{array}{ccccc}1 & 2 & 3 & 4 & 5 \\ \text { Strongly } & \text { Disagree } & \text { Neither Agree } & \text { Agree } & \text { Strongly } \\ \text { Disagree } & & \text { Nor Disagree } & & \text { Agree }\end{array}$

2. I feared that my child's therapist will be judgmental and critical.

$\begin{array}{ccccc}1 & 2 & 3 & 4 & 5 \\ \text { Strongly } & \text { Disagree } & \text { Neither Agree } & \text { Agree } & \text { Strongly } \\ \text { Disagree } & & \text { Nor Disagree } & & \text { Agree }\end{array}$


3. I feared that my child's therapist would be racist or discriminate against me or my child.

$\begin{array}{ccccc}1 & 2 & 3 & 4 & 5 \\ \text { Strongly } & \text { Disagree } & \text { Neither Agree } & \text { Agree } & \text { Strongly } \\ \text { Disagree } & & \text { Nor Disagree } & & \text { Agree }\end{array}$

4. A therapist who is not from my cultural background would not be able to help my child.

$\begin{array}{ccccc}1 & 2 & 3 & 4 & 5 \\ \text { Strongly } & \text { Disagree } & \text { Neither Agree } & \text { Agree } & \text { Strongly } \\ \text { Disagree } & & \text { Nor Disagree } & & \text { Agree }\end{array}$

Other

1. Therapy can help emotional/ behavioral problems.

$\begin{array}{ccccc}1 & 2 & 3 & 4 & 5 \\ \text { Strongly } & \text { Disagree } & \text { Neither Agree } & \text { Agree } & \text { Strongly } \\ \text { Disagree } & & \text { Nor Disagree } & & \text { Agree }\end{array}$




\section{Therapy Expectations Questionnaire}

When parents decide to take their child to a counselor/therapist, they have different ideas about what therapy will be like and what will happen in therapy. Some of these ideas are listed below. Please circle one answer to indicate how much you agreed with each of the following statements BEFORE STARTING PCIT:

\section{Directiveness}

1. I expected the therapist to ask me to make changes or to do things differently at home.

$\begin{array}{ccccc}1 & 2 & 3 & 4 & 5 \\ \text { Strongly } & \text { Disagree } & \text { Neither Agree } & \text { Agree } & \text { Strongly } \\ \text { Disagree } & & \text { Nor Disagree } & & \text { Agree }\end{array}$

2. I expected my child's therapist to give me advice.

$\begin{array}{ccccc}1 & 2 & 3 & 4 & 5 \\ \text { Strongly } & \text { Disagree } & \text { Neither Agree } & \text { Agree } & \text { Strongly } \\ \text { Disagree } & & \text { Nor Disagree } & & \text { Agree }\end{array}$

3. I expected my child's therapist to use his/her authority to discipline my child.
1
2
3
4
5
Strongly
Disagree
Neither Agree
Agree
Strongly
Disagree
Nor Disagree
Agree

4. I expected my child's therapist to give me advice about how to discipline my child.

$\begin{array}{ccccc}1 & 2 & 3 & 4 & 5 \\ \text { Strongly } & \text { Disagree } & \text { Neither Agree } & \text { Agree } & \text { Strongly } \\ \text { Disagree } & & \text { Nor Disagree } & & \text { Agree }\end{array}$

5. I expected my child's therapist to give me assignments to do at home.
1
2
3
4
Strongly
Disagree
Neither Agree
Agree
5
Disagree
Nor Disagree
Strongly
Agree

6. I expected the therapist to decide what the goals for my child's therapy would be.

1

Strongly

Disagree
2

Disagree

ree

\begin{abstract}
Neither Agree
Nor Disagree
\end{abstract}

5

Agree

Strongly

Agree 


\section{Concerns/Perceived Barriers}

1. I was not sure that I would have time to go to therapy weekly.

$\begin{array}{ccccc}1 & 2 & 3 & 4 & 5 \\ \text { Strongly } & \text { Disagree } & \text { Neither Agree } & \text { Agree } & \text { Strongly } \\ \text { Disagree } & & \text { Nor Disagree } & & \text { Agree }\end{array}$

2. I was not sure that I would have a way to get to my appointment weekly.

$\begin{array}{ccccc}1 & 2 & 3 & 4 & 5 \\ \text { Strongly } & \text { Disagree } & \text { Neither Agree } & \text { Agree } & \text { Strongly } \\ \text { Disagree } & & \text { Nor Disagree } & & \text { Agree }\end{array}$

3. I was not sure if my insurance would cover the full cost of therapy.

$\begin{array}{ccccc}1 & 2 & 3 & 4 & 5 \\ \text { Strongly } & \text { Disagree } & \text { Neither Agree } & \text { Agree } & \text { Strongly } \\ \text { Disagree } & & \text { Nor Disagree } & & \text { Agree }\end{array}$

4. I was concerned that I would not be able to afford therapy.

$\begin{array}{ccccc}1 & 2 & 3 & 4 & 5 \\ \text { Strongly } & \text { Disagree } & \text { Neither Agree } & \text { Agree } & \text { Strongly } \\ \text { Disagree } & & \text { Nor Disagree } & & \text { Agree }\end{array}$

5. I was worried about having to sign forms that were difficult to understand.

$\begin{array}{ccccc}1 & 2 & 3 & 4 & 5 \\ \text { Strongly } & \text { Disagree } & \text { Neither Agree } & \text { Agree } & \text { Strongly } \\ \text { Disagree } & & \text { Nor Disagree } & & \text { Agree }\end{array}$

6. I was afraid that my therapist may tell others about what I said in therapy.
1
Strongly
2
Disagree
3
4
Disagree
Neither Agree
Agree
Agree

7. I was worried that seeing a therapist for my child would affect my immigration status.
1
2
3
4
Agree
5
Strongly
Disagree (N/A)
Disagree
Neither Agree
Nor Disagree
Strongly
Agree 
8. I was worried that my child's therapist would talk to Child Protective Services about me.

$\begin{array}{ccccc}1 & 2 & 3 & 4 & 5 \\ \text { Strongly } & \text { Disagree } & \text { Neither Agree } & \text { Agree } & \text { Strongly } \\ \text { Disagree } & & \text { Nor Disagree } & & \text { Agree }\end{array}$

9. I was worried that if my child saw a therapist, s/he would be teased and rejected by his/her classmates.

$\begin{array}{ccccc}1 & 2 & 3 & 4 & 5 \\ \text { Strongly } & \text { Disagree } & \text { Neither Agree } & \text { Agree } & \text { Strongly } \\ \text { Disagree } & & \text { Nor Disagree } & & \text { Agree }\end{array}$

\section{Speed of Recovery}

1. If my child seemed better after a few sessions, it would be time to stop therapy.

$\begin{array}{ccccc}1 & 2 & 3 & 4 & 5 \\ \text { Strongly } & \text { Disagree } & \text { Neither Agree } & \text { Agree } & \text { Strongly } \\ \text { Disagree } & & \text { Nor Disagree } & & \text { Agree }\end{array}$

2. If my child did not get better after a few sessions, then treatment was not working.

$\begin{array}{ccccc}1 & 2 & 3 & 4 & 5 \\ \text { Strongly } & \text { Disagree } & \text { Neither Agree } & \text { Agree } & \text { Strongly } \\ \text { Disagree } & & \text { Nor Disagree } & & \text { Agree }\end{array}$

\section{Assertiveness}

1. If I didn't like what my child's therapist was doing, I would tell him/her.

$\begin{array}{ccccc}1 & 2 & 3 & 4 & 5 \\ \text { Strongly } & \text { Disagree } & \text { Neither Agree } & \text { Agree } & \text { Strongly } \\ \text { Disagree } & & \text { Nor Disagree } & & \text { Agree }\end{array}$

2. If I were angry with my child's therapist, I would tell him/her.

1

Strongly

Disagree
2

Disagree

3

Neither Agree

Nor Disagree
4

Agree

5

Strongly

Agree 


\section{Other}

1. I expected both parents (father and mother) to participate in treatment.

$\begin{array}{ccccc}1 & 2 & 3 & 4 & 5 \\ \text { Strongly } & \text { Disagree } & \text { Neither Agree } & \text { Agree } & \text { Strongly } \\ \text { Disagree } & & \text { Nor Disagree } & & \text { Agree }\end{array}$

2. I expected extended family like siblings, grandparents, aunts and uncles to be part of treatment.

$\begin{array}{ccccc}1 & 2 & 3 & 4 & 5 \\ \text { Strongly } & \text { Disagree } & \text { Neither Agree } & \text { Agree } & \text { Strongly } \\ \text { Disagree } & & \text { Nor Disagree } & & \text { Agree }\end{array}$

3. I expected my therapist to help my child by playing with him/her.

$\begin{array}{ccccc}1 & 2 & 3 & 4 & 5 \\ \text { Strongly } & \text { Disagree } & \text { Neither Agree } & \text { Agree } & \text { Strongly } \\ \text { Disagree } & & \text { Nor Disagree } & & \text { Agree }\end{array}$


Did you attend one or more sessions of the first phase of PCIT (e.g., Child Directed Interaction phase [CDI], relationship-building, use of play therapy skills, child led play)? Yes

No

I don't know

Did you meet mastery and complete the first phase of PCIT (e.g., Child Directed Interaction phase [CDI], relationship-building, use of play therapy skills, child led play) and move to the second phase of PCIT?

Yes

I completed the first phase of treatment but did not move on to the second phase No

I don't know

Did you attend one or more sessions of the second, and final, phase of PCIT (e.g., Parent Directed Interaction [PDI], behavior management/discipline, use of commands, limit setting)?

Yes

No

I don't know 
Did you complete the second, and final, phase of PCIT (e.g., Parent Directed Interaction [PDI], behavior management/discipline, use of commands, limit setting) and graduate from PCIT?

Yes

I completed PCIT but did not graduate

No

I don't know

Was there someone in your or your child's life who encouraged you to attend and complete PCIT (e.g., family member, friend, case worker)?

No

Yes

If yes, who?

If you left PCIT before graduating, do you feel that you "dropped out" of treatment?

No

Yes

Why?

N/A (I graduated from PCIT) 
Treatment Satisfaction and Therapist Competency Questionnaire

\begin{tabular}{|c|c|c|c|c|c|}
\hline $\begin{array}{c}1 \\
\text { Very dissatisfied }\end{array}$ & $\begin{array}{c}2 \\
\text { Somewhat dissatisfied }\end{array}$ & $\begin{array}{c}3 \\
\text { Neutral }\end{array}$ & $\begin{array}{c}4 \\
\text { Somewhat satisfied }\end{array}$ & $\begin{array}{c}5 \\
\text { Very satisfied }\end{array}$ & $\begin{array}{c}6 \\
\text { N/A }\end{array}$ \\
\hline $\begin{array}{l}\text { I would have } \\
\text { strongly preferred } \\
\text { that my child meet } \\
\text { with a therapist } \\
\text { one-on-one }\end{array}$ & & & & $\begin{array}{l}\text { I enjoyed taking an } \\
\text { active part in my } \\
\text { child's treatment }\end{array}$ & $\begin{array}{l}\text { I did not participate } \\
\text { in PCIT with my } \\
\text { child }\end{array}$ \\
\hline \multicolumn{6}{|c|}{ 1b. I feel my PCIT therapist described the importance of my participation in treatment: } \\
\hline $\begin{array}{c}1 \\
\text { Very well }\end{array}$ & $\begin{array}{c}2 \\
\text { Slightly well }\end{array}$ & $\begin{array}{c}3 \\
\text { Neutral }\end{array}$ & $\begin{array}{c}4 \\
\text { Not very well }\end{array}$ & $\begin{array}{c}5 \\
\text { Not at all well }\end{array}$ & $\begin{array}{c}6 \\
\mathrm{~N} / \mathrm{A}\end{array}$ \\
\hline $\begin{array}{c}\text { My therapist } \\
\text { clearly explained to } \\
\text { me why it was } \\
\text { important that I } \\
\text { participate in PCIT }\end{array}$ & & & & $\begin{array}{l}\text { I was unsure why I } \\
\text { needed to } \\
\text { participate in PCIT/ } \\
\text { the therapist never } \\
\text { spoke about it }\end{array}$ & $\begin{array}{l}\text { I did not participate } \\
\text { in PCIT with my } \\
\text { child }\end{array}$ \\
\hline \multicolumn{6}{|c|}{ 2a. How satisfied were you that you received live coaching from your PCIT therapist during the session(s)?: } \\
\hline$\frac{1}{\text { Very dissatisfied }}$ & $\begin{array}{c}2 \\
\text { Somewhat dissatisfied }\end{array}$ & $\begin{array}{c}3 \\
\text { Neutral }\end{array}$ & $\begin{array}{c}4 \\
\text { Somewhat satisfied }\end{array}$ & $\begin{array}{c}5 \\
\text { Very satisfied }\end{array}$ & $\begin{array}{c}6 \\
\mathrm{~N} / \mathrm{A}\end{array}$ \\
\hline $\begin{array}{l}\text { I would have } \\
\text { strongly preferred } \\
\text { not to be coached }\end{array}$ & & & & $\begin{array}{l}\text { Live coaching was } \\
\text { very useful }\end{array}$ & $\begin{array}{c}\text { I was never } \\
\text { coached during } \\
\text { PCIT }\end{array}$ \\
\hline
\end{tabular}




\begin{tabular}{|c|c|c|c|c|c|}
\hline \multicolumn{6}{|c|}{ 2b. I feel my PCIT therapist was skilled and helpful during in-session coaching: } \\
\hline 1 & 2 & 3 & 4 & 5 & 6 \\
\hline Strongly disagree & Slightly disagree & Neutral & Slightly agree & Strongly agree & N/A \\
\hline $\begin{array}{l}\text { I did not find } \\
\text { his/her coaching } \\
\text { clear or helpful }\end{array}$ & & & & $\begin{array}{l}\text { The therapist was } \\
\text { very skilled and } \\
\text { helpful when } \\
\text { coaching }\end{array}$ & $\begin{array}{c}\text { I was never } \\
\text { coached during } \\
\text { PCIT }\end{array}$ \\
\hline \multicolumn{6}{|c|}{$\begin{array}{l}\text { 3a. My PCIT therapist collected and tracked my reports of my child's behaviors (e.g., ECBI, WACB), and reviewed and clearly } \\
\text { explained how the behavior scores changed over treatment: }\end{array}$} \\
\hline 1 & 2 & 3 & 4 & 5 & \\
\hline Never & A few times & Sometimes & Often & Every week & \\
\hline \multicolumn{6}{|c|}{$\begin{array}{l}\text { 3b. How satisfied were you with your PCIT therapist collecting, tracking, and reviewing with you your report of your child's } \\
\text { behavior score (e.g., ECBI, WACB)? }\end{array}$} \\
\hline 1 & 2 & 3 & 4 & 5 & 6 \\
\hline Very dissatisfied & Somewhat dissatisfied & Neutral & Somewhat satisfied & Very satisfied & N/A \\
\hline $\begin{array}{l}\text { It was not at all } \\
\text { helpful to see the } \\
\text { change in my } \\
\text { child's behavior } \\
\text { over time }\end{array}$ & & & & $\begin{array}{l}\text { It was very helpful } \\
\text { to see my child's } \\
\text { behavior over the } \\
\text { course of treatment }\end{array}$ & $\begin{array}{l}\text { My PCIT therapist } \\
\text { did not collect, } \\
\text { track, or review my } \\
\text { report of my } \\
\text { child's behavior }\end{array}$ \\
\hline
\end{tabular}




\begin{tabular}{|c|c|c|c|c|c|}
\hline \multicolumn{6}{|c|}{$\begin{array}{l}\text { 4a. My PCIT therapist's skill at observing my interactions with my child and coding for "mastery" of PCIT skills (e.g., during the } \\
\text { first five minutes of each PCIT session) and communicating the findings/goals for each session was: }\end{array}$} \\
\hline 1 & 2 & 3 & 4 & 5 & 6 \\
\hline Very poor & Poor & Fine & Good & Great & N/A \\
\hline $\begin{array}{l}\text { My therapist did } \\
\text { not do a good job } \\
\text { of coding at the } \\
\text { beginning of } \\
\text { sessions and/or } \\
\text { clearly explaining } \\
\text { the session goals }\end{array}$ & & & & $\begin{array}{l}\text { My therapist coded } \\
\text { at the beginning of } \\
\text { every session then } \\
\text { clearly explained } \\
\text { the session goals }\end{array}$ & $\begin{array}{l}\text { My therapist did } \\
\text { not code or set } \\
\text { goals for the } \\
\text { session at all }\end{array}$ \\
\hline \multicolumn{6}{|c|}{$\begin{array}{l}\text { 4b. How satisfied were you with your PCIT therapist observing your interactions with your child and coding for "mastery" of PCIT } \\
\text { skills? }\end{array}$} \\
\hline 1 & 2 & 3 & 4 & 5 & 6 \\
\hline Very dissatisfied & Somewhat dissatisfied & Neutral & Somewhat satisfied & Very satisfied & N/A \\
\hline $\begin{array}{l}\text { I would have } \\
\text { strongly preferred } \\
\text { not to be observed } \\
\text { and coded }\end{array}$ & & & & $\begin{array}{l}\text { Being coded was } \\
\text { useful and helped } \\
\text { me learn what I } \\
\text { needed to work on }\end{array}$ & $\begin{array}{c}\text { My therapist did } \\
\text { not code or set } \\
\text { goals for the } \\
\text { session at all }\end{array}$ \\
\hline \multicolumn{6}{|c|}{$\begin{array}{l}\text { 5a. How satisfied were you with the need to reach "mastery" of PCIT skills in the first phase of treatment (e.g., Child Directed } \\
\text { Interaction phase [CDI], relationship-building, use of play therapy skills, child led play) before moving on to the second phase of } \\
\text { treatment (e.g., Parent Directed Interaction [PDI], behavior management/discipline, use of commands, limit setting)?: }\end{array}$} \\
\hline 1 & 2 & 3 & 4 & 5 & 6 \\
\hline Very dissatisfied & Somewhat dissatisfied & Neutral & Somewhat satisfied & Very satisfied & N/A \\
\hline $\begin{array}{l}\text { I did not like that I } \\
\text { had to meet } \\
\text { mastery before } \\
\text { moving on to the } \\
\text { second phase }\end{array}$ & & & & $\begin{array}{l}\text { I agree that it was } \\
\text { best to move on } \\
\text { only after I met } \\
\text { mastery }\end{array}$ & $\begin{array}{l}\text { I did not participate } \\
\text { in the first phase of } \\
\text { treatment or did not } \\
\text { know I needed to } \\
\text { reach mastery }\end{array}$ \\
\hline
\end{tabular}




\begin{tabular}{|c|c|c|c|c|c|}
\hline \multicolumn{6}{|c|}{$\begin{array}{l}\text { 5b. I feel my PCIT therapist described the importance of meeting "mastery" in the first phase of treatment (e.g., Child Directed } \\
\text { Interaction phase [CDI], relationship-building, use of play therapy skills, child led play) before moving on to the second phase of } \\
\text { PCIT (e.g., Parent Directed Interaction [PDI], behavior management/discipline, use of commands, limit setting): }\end{array}$} \\
\hline 1 & 2 & 3 & 4 & 5 & 6 \\
\hline Not at all well & Not very well & Neutral & Slightly well & Very well & N/A \\
\hline $\begin{array}{l}\text { My therapist did } \\
\text { not explain why I } \\
\text { needed to meet } \\
\text { mastery before } \\
\text { moving on }\end{array}$ & & & & $\begin{array}{l}\text { My therapist } \\
\text { clearly explained to } \\
\text { me the importance } \\
\text { of meeting mastery } \\
\text { before moving on }\end{array}$ & $\begin{array}{l}\text { I did not participate } \\
\text { in the first phase of } \\
\text { treatment or did not } \\
\text { know I needed to } \\
\text { reach mastery }\end{array}$ \\
\hline \multicolumn{6}{|c|}{$\begin{array}{l}\text { 6a. How satisfied were you with the need to reach "mastery" in the second phase of treatment (e.g., Parent Directed Interaction } \\
\text { [PDI], behavior management/discipline, use of commands, limit setting) before graduating from PCIT?: }\end{array}$} \\
\hline 1 & 2 & 3 & 4 & 5 & 6 \\
\hline Very dissatisfied & Somewhat dissatisfied & Neutral & Somewhat satisfied & Very satisfied & N/A \\
\hline $\begin{array}{l}\text { I did not like that I } \\
\text { had to meet } \\
\text { mastery before } \\
\text { graduating and } \\
\text { ending PCIT }\end{array}$ & & & & $\begin{array}{l}\text { I agree that it was } \\
\text { best to graduate } \\
\text { and end treatment } \\
\text { only after I met } \\
\text { mastery }\end{array}$ & $\begin{array}{l}\text { I did not participate } \\
\text { in the second phase } \\
\text { of treatment or did } \\
\text { not know I needed } \\
\text { to reach mastery }\end{array}$ \\
\hline \multicolumn{6}{|c|}{$\begin{array}{l}\text { 6b. I feel my child's PCIT therapist/coach described the importance of meeting "mastery" of PCIT skills before graduating from } \\
\text { PCIT: }\end{array}$} \\
\hline 1 & 2 & 3 & 4 & 5 & 6 \\
\hline Not at all well & Not very well & Neutral & Slightly well & Very well & N/A \\
\hline $\begin{array}{l}\text { My therapist did } \\
\text { not explain why I } \\
\text { needed to meet } \\
\text { mastery before } \\
\text { graduating }\end{array}$ & & & & $\begin{array}{l}\text { My therapist } \\
\text { clearly explained to } \\
\text { me the importance } \\
\text { of meeting mastery }\end{array}$ & $\begin{array}{l}\text { I did not participate } \\
\text { in the second phase } \\
\text { of treatment or did } \\
\text { not know I needed } \\
\text { to reach mastery }\end{array}$ \\
\hline
\end{tabular}


7. How satisfied were you with the PCIT room setup (e.g., one-way mirror, PCIT therapist observing and coaching from a separate room, use of bug-in-the-ear/blue tooth/walkie-talkie device)?:

1

Very dissatisfied

I did not at all like

the therapist being

in another room,

the one-way mirror,

using the bug-in-

the-ear, etc.

\begin{tabular}{|c|c|c|c|c|}
\hline $\begin{array}{c}2 \\
\text { Somewhat dissatisfied }\end{array}$ & $\begin{array}{c}3 \\
\text { Neutral }\end{array}$ & $\begin{array}{c}4 \\
\text { Somewhat satisfied }\end{array}$ & $\begin{array}{c}5 \\
\text { Very satisfied }\end{array}$ & $\begin{array}{c}6 \\
\text { N/A }\end{array}$ \\
\hline & & & $\begin{array}{l}\text { I really liked how } \\
\text { the PCIT room was } \\
\text { set up and how } \\
\text { PCIT was delivered }\end{array}$ & $\begin{array}{l}\text { The therapist did } \\
\text { not coach from } \\
\text { another room, there } \\
\text { was no one-way } \\
\text { mirror, and/or I did } \\
\text { not use a bug-in- } \\
\text { the-ear device }\end{array}$ \\
\hline
\end{tabular}

8. How satisfied were you with the first phase of PCIT, overall (e.g., Child Directed Interaction phase [CDI], relationship-building, use of play therapy skills, child led play)?:

\begin{tabular}{|c|c|c|c|c|c|}
\hline $\begin{array}{c}1 \\
\text { Very dissatisfied }\end{array}$ & $\begin{array}{c}2 \\
\text { Somewhat dissatisfied }\end{array}$ & $\begin{array}{c}3 \\
\text { Neutral }\end{array}$ & $\begin{array}{c}4 \\
\text { Somewhat satisfied }\end{array}$ & $\begin{array}{c}5 \\
\text { Very satisfied }\end{array}$ & $\begin{array}{c}6 \\
\text { N/A }\end{array}$ \\
\hline $\begin{array}{l}\text { I did not like the } \\
\text { first phase at all } \\
\text { and did not find it } \\
\text { helpful }\end{array}$ & & & & $\begin{array}{l}\text { I loved the first } \\
\text { phase and believe it } \\
\text { strengthened my } \\
\text { relationship with } \\
\text { my child }\end{array}$ & $\begin{array}{l}\text { I did not participate } \\
\text { in the first phase of } \\
\text { treatment }\end{array}$ \\
\hline
\end{tabular}

9. How satisfied were you with completing daily homework in the form of special playtime at home?:

1

Very dissatisfied

Somewhat dissatisfied

I did not like/did

not have time to

have special play

time with my child

at home
4

Neutral

Somewhat satisfied

\section{6}

N/A

I did not participate in special play time with my child at all special play time with my child at home and did so every day 


\begin{tabular}{|c|c|c|c|c|c|}
\hline $\begin{array}{c}1 \\
\text { Very dissatisfied }\end{array}$ & $\begin{array}{c}2 \\
\text { Somewhat dissatisfied }\end{array}$ & $\begin{array}{c}3 \\
\text { Neutral }\end{array}$ & $\begin{array}{c}4 \\
\text { Somewhat satisfied }\end{array}$ & $\begin{array}{c}5 \\
\text { Very satisfied }\end{array}$ & $\begin{array}{c}6 \\
\text { N/A }\end{array}$ \\
\hline $\begin{array}{c}\text { I did not like the } \\
\text { second phase at all } \\
\text { and did not find it } \\
\text { helpful }\end{array}$ & & & & $\begin{array}{l}\text { I loved the second } \\
\text { phase and believe it } \\
\text { reduced negative } \\
\text { child behaviors }\end{array}$ & $\begin{array}{l}\text { I did not participat } \\
\text { in the second phase } \\
\text { of treatment }\end{array}$ \\
\hline \multicolumn{6}{|c|}{ 11. How satisfied were you with the use of a timeout chair as the discipline technique used in PCIT?: } \\
\hline $\begin{array}{c}1 \\
\text { Very dissatisfied }\end{array}$ & $\begin{array}{c}2 \\
\text { Somewhat dissatisfied }\end{array}$ & $\begin{array}{c}3 \\
\text { Neutral }\end{array}$ & $\begin{array}{c}4 \\
\text { Somewhat satisfied }\end{array}$ & $\begin{array}{c}5 \\
\text { Very satisfied }\end{array}$ & $\begin{array}{c}6 \\
\text { N/A }\end{array}$ \\
\hline $\begin{array}{l}\text { I did not like the } \\
\text { use of a timeout } \\
\text { chair at all and/or } \\
\text { did not find it } \\
\text { helpful }\end{array}$ & & & & $\begin{array}{l}\text { I loved the use of } \\
\text { the timeout chair } \\
\text { and it worked very } \\
\text { well for my family }\end{array}$ & $\begin{array}{l}\text { I did not use a } \\
\text { timeout chair }\end{array}$ \\
\hline \multicolumn{6}{|c|}{ 12. How satisfied were you with the use of a timeout room as a backup to the timeout chair?: } \\
\hline $\begin{array}{c}1 \\
\text { Very dissatisfied }\end{array}$ & $\begin{array}{c}2 \\
\text { Somewhat dissatisfied }\end{array}$ & $\begin{array}{c}3 \\
\text { Neutral }\end{array}$ & $\begin{array}{c}4 \\
\text { Somewhat satisfied }\end{array}$ & $\begin{array}{c}5 \\
\text { Very satisfied }\end{array}$ & $\begin{array}{c}6 \\
\text { N/A }\end{array}$ \\
\hline $\begin{array}{l}\text { I did not like the } \\
\text { use of a backup } \\
\text { room at all and did } \\
\text { not find it helpful }\end{array}$ & & & & $\begin{array}{l}\text { I loved the use of } \\
\text { the backup room } \\
\text { and it worked very } \\
\text { well for my family }\end{array}$ & $\begin{array}{l}\text { I did not use a } \\
\text { timeout room }\end{array}$ \\
\hline
\end{tabular}


13. How satisfied were you with the use of "swoop and go" (e.g., taking the toys and leaving the room) as the discipline technique used in PCIT?:

$$
1
$$

Very dissatisfied

Somewhat dissatisfied

I did not like the

use of swoop and

go at all and/or did

not find it helpful

$\begin{array}{cccc}3 & 4 & 5 & 6 \\ \text { Neutral } & \text { Somewhat satisfied } & \text { Very satisfied } & \text { N/A } \\ & & \text { I loved the use of } & \text { I did not use swoop } \\ & \text { swoop and go and } & \text { and go } \\ & \text { it worked very well } & \\ & \text { for my family } & \end{array}$


Therapeutic Alliance Scale for Caregivers and Parents (TASCP)

1. I liked spending time with my child's therapist.

$\begin{array}{cccc}1 & 2 & 3 & 4 \\ \text { Not true } & & & \text { Very much true }\end{array}$

2. I found it hard to work with my child's therapist on solving problems in our lives.

$\begin{array}{cccc}1 & 2 & 3 & 4 \\ \text { Not true } & & & \text { Very much true }\end{array}$

3. I felt like my child's therapist was on my side and tried to help me.

1

Not true
2
3
4 Very much true

4. I worked with my child's therapist on solving our problems.
1
2
3
4
Not true
Very much true

5. When I was with my child's therapist, I wanted the sessions to end quickly.
1
2
3
4
Not true
Very much true

6. I looked forward to meeting with my child's therapist.

1

Not true
2

3

4

Very much true

7. I felt like my child's therapist spent too much time working on our problems.

1

Not true
2

3

4

Very much true

8. I would have rather done other things than meet with my child's therapist.

1

Not true
2

3

4

Very much true 
9. I used my time with my child's therapist to make changes in our lives.

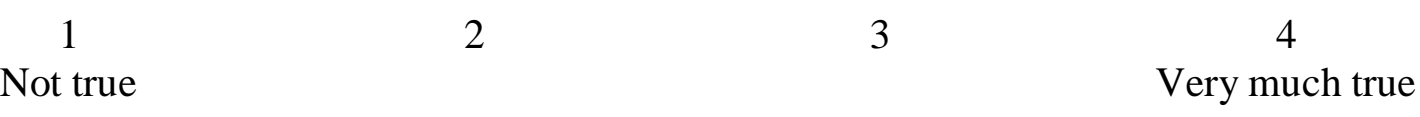

10. I liked my child's therapist.

12

2

Not true

Very much true

11. I would have rather not worked on our problems with my child's therapist.

1

Not true
2

3

4

Very much true

12. I think my child's therapist and I worked well together on dealing with our problems.

1

Not true
2

3

(1)

4

Very much true 


\section{Perceived Cultural Competency Scale}

For these questions, we are interested how well your PCIT therapist understood your specific culture, heritage and ethnicity. We are also interested in your impressions of his or her acceptance of your culture. Please answer each question using the seven-item scales that are provided. Also remember that there are no right or wrong answers to any of these questions only your opinion.

1. How knowledgeable do you feel that your PCIT therapist was of your culture?

1

Not at all
2
4

Neutral
6 7 Very much

2. How well do you think your PCIT therapist understood your culture's specific characteristics?

$\begin{array}{ccccccc}1 & 2 & 3 & 4 & 5 & 6 & 7 \\ \text { Not at all } & & & \text { Neutral } & & & \text { Very much }\end{array}$

3. How informed did your PCIT therapist seem to be about your culture?

$\begin{array}{ccccccc}1 & 2 & 3 & 4 & 5 & 6 & 7 \\ \text { Not at all } & & \text { Neutral } & & & \text { Very much }\end{array}$

4. Do you feel as though your PCIT therapist was aware of the views that he or she may have towards specific cultural groups?
1
2
3
4
5
6
7
Neutral
Very much

Not at all

5. Do you feel as though your PCIT therapist made an effort to understand cultural differences?
2
3
4
5
6
Neutral
Very much

1

Not at all

6. Did your PCIT therapist seem to be aware of cultural differences?

1

Not at all

2

3

4

Neutral
6 7 Very much 
7. Do you think that your PCIT therapist was well equipped to treat patients of your ethnic or cultural background?

$\begin{array}{lllcccc}1 & 2 & 3 & 4 & 5 & 6 & 7 \\ \text { at all } & & & \text { Neutral } & & & \text { Very much }\end{array}$

8. Did your PCIT therapist possess the skills that are needed to treat a patient from your cultural or ethnic background?

$\begin{array}{lllcccc}1 & 2 & 3 & 4 & 5 & 6 & 7 \\ \text { at all } & & & \text { Neutral } & & & \text { Very much }\end{array}$

9. Would you recommend your PCIT therapist to someone with your same ethnic or cultural background?

1

Not at all
2

3

4

Neutral
6

5

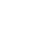

7 Very much 
Treatment Summary Report—Parent

\section{BEFORE TREATMENT}

Rate your motivation for your child to participate in treatment before your family started PCIT:

\begin{tabular}{|c|c|c|c|c|}
\hline Very Low & & Moderate & & Very High \\
\hline$\square$ & $\square$ & $\square$ & $\square$ & $\square$ \\
\hline
\end{tabular}

Before PCIT, did you and/or your family feel you could change your child's behavior on your own?

\begin{tabular}{|c|c|c|c|c|}
\hline Definitely Not & Probably Not & May/Unsure & Probably & Definitely \\
\hline$\square$ & $\square$ & $\square$ & $\square$ & $\square$ \\
\hline
\end{tabular}

Rate your commitment to services before your first PCIT session (e.g., attendance, participation in sessions, follow through on recommendations, completion of homework):

\begin{tabular}{|c|c|c|c|c|}
\hline Very Low & & Moderate & & Very High \\
\hline$\square$ & $\square$ & $\square$ & $\square$ & $\square$ \\
\hline
\end{tabular}

How many PCIT sessions did you expect to attend, before beginning treatment?

How often did you expect to see your PCIT therapist?

\begin{tabular}{|c|c|c|c|c|c|}
\hline As needed & Once a year & Once a month & $\begin{array}{c}\text { Twice a } \\
\text { month }\end{array}$ & Once a week & $\begin{array}{c}\text { More than } \\
\text { Once a week }\end{array}$ \\
\hline$\square$ & $\square$ & $\square$ & $\square$ & $\square$ & $\square$ \\
\hline
\end{tabular}

How long did you expect your child to be in PCIT?

\begin{tabular}{|c|c|c|c|c|c|}
\hline Two weeks & One month & Three months & Six months & One year & $\begin{array}{c}\text { More than } \\
\text { One year }\end{array}$ \\
\hline$\square$ & $\square$ & $\square$ & $\square$ & $\square$ & $\square$ \\
\hline
\end{tabular}

\section{IN TREATMENT}

Approximately when did you start PCIT?

Rate your commitment to services after your first PCIT session: Child Directed Interaction teach session (e.g., attendance, participation in sessions, follow through on recommendations, completion of homework):

\begin{tabular}{|c|c|c|c|c|}
\hline Very Low & & Moderate & & Very High \\
\hline$\square$ & $\square$ & $\square$ & $\square$ & $\square$ \\
\hline
\end{tabular}

How often did you actually see your PCIT therapist?

\begin{tabular}{|c|c|c|c|c|c|}
\hline As needed & Once a year & Once a month & $\begin{array}{c}\text { Twice a } \\
\text { month }\end{array}$ & Once a week & $\begin{array}{c}\text { More than } \\
\text { Once a week }\end{array}$ \\
\hline$\square$ & $\square$ & $\square$ & $\square$ & $\square$ & $\square$ \\
\hline
\end{tabular}




\section{END OF TREATMENT}

Approximately when did you finish or end PCIT?

About how many PCIT sessions did you attend?

How many PCIT sessions would you have liked to attend?

Did you meet your treatment goals in PCIT? Yes No (Circle one)

If Yes, how many PCIT sessions do you think it took to meet your treatment goals?

If No, how many PCIT sessions do you think it would have taken to meet your treatment goals?

Rate your commitment to PCIT at your last session (e.g., attendance, participation in sessions, follow through on recommendations, completion of homework):

\begin{tabular}{|c|c|c|c|c|}
\hline Very Low & & Moderate & & Very High \\
\hline$\square$ & $\square$ & $\square$ & $\square$ & $\square$ \\
\hline
\end{tabular}

How long was your child actually in PCIT?

\begin{tabular}{|c|c|c|c|c|c|}
\hline Two weeks & One month & Three months & Six months & One year & $\begin{array}{c}\text { More than } \\
\text { One year }\end{array}$ \\
\hline$\square$ & $\square$ & $\square$ & $\square$ & $\square$ & $\square$ \\
\hline
\end{tabular}

Rate your desire for PCIT to end when it did:

\begin{tabular}{|c|c|c|}
\hline $\begin{array}{c}\text { No, I did not want to end } \\
\text { therapy at that time }\end{array}$ & $\begin{array}{c}\text { I somewhat wanted therapy to } \\
\text { end }\end{array}$ & Yes, I wanted therapy to end \\
\hline$\square$ & $\square$ & $\square$ \\
\hline
\end{tabular}

After PCIT ended, did you and/or your family feel you could have changed your child's behavior on your own more or as effectively as with the help of PCIT?

\begin{tabular}{|c|c|c|c|c|}
\hline Definitely Not & Probably Not & Maybe/Unsure & Probably & Definitely \\
\hline$\square$ & $\square$ & $\square$ & $\square$ & $\square$ \\
\hline
\end{tabular}

Overall, how much progress did your family make in PCIT?

\begin{tabular}{|c|c|c|c|c|}
\hline None & & Some & & A Lot \\
\hline$\square$ & $\square$ & $\square$ & $\square$ & $\square$ \\
\hline
\end{tabular}


Why did you end PCIT services? Please fill in all that apply.

○ Problems got better/clinical improvement

- Graduated from treatment (met mastery criteria)

- Therapist felt PCIT services were no longer needed

- You or other family members felt that PCIT services were no longer needed

○ Problem got worse/clinical deterioration (e.g., level/type of treatment not working)

$\circ$ Disinterest in PCIT/low motivation

$\circ$ Did not agree with/did not want to follow PCIT suggestions

- No-shows (List frequency)

- Cancellations (List frequency)

- You and/or your family moved

- Major crises or family emergency, including serious illness (Describe)

- Limited resources/unable to attend due to time, transportation, or money

- Do not like therapy (i.e., PCIT), therapist, or other aspects of the service

- Legal problems that prevented participation

- Schedule conflicts

- Insurance company or policy constraints/issues

- Child removed from home

○ Therapist left

O Other (Describe)

Did any of the following issues have a negative impact on the overall course and outcome of PCIT (fill in all that apply):

\begin{tabular}{|l|l|l|}
\hline a. Marital discord/conflict & $\square$ Yes & $\square$ No \\
\hline $\begin{array}{l}\text { b. Family involvement in other treatment programs that } \\
\text { interfere/compete with your PCIT services }\end{array}$ & $\square$ Yes & $\square$ No \\
\hline c. Conflict with an outside family member/friend & $\square$ Yes & $\square$ No \\
\hline d. Conflict with work and family schedules/too busy & $\square$ Yes & $\square$ No \\
\hline e. Dangerous community & $\square$ Yes & $\square$ No \\
\hline f. I/my partner was struggling with anger & $\square$ Yes & $\square$ No \\
\hline g. Drug/alcohol problem & $\square$ Yes & $\square$ No \\
\hline $\begin{array}{l}\text { h. I/my partner was struggling with our own mental health } \\
\text { problem(s) }\end{array}$ & $\square$ Yes & $\square$ No \\
\hline i. PCIT was difficult for me/my partner to understand & $\square$ Yes & $\square$ No \\
\hline j. Residential instability - moves, no phone, etc. & $\square$ Yes & $\square$ No \\
\hline k. Child out of home & $\square$ Yes & $\square$ No \\
\hline l. Parent out of home & $\square$ Yes & $\square$ No \\
\hline m. Limited child cognitive skills & $\square$ Yes & $\square$ No \\
\hline n. Involvement with child welfare & $\square$ Yes & $\square$ No \\
\hline o. Domestic violence & $\square$ Yes & $\square$ No \\
\hline p. Other (Specify) & $\square$ Yes & $\square$ No \\
\hline Specify Other: & & \\
\hline
\end{tabular}


Indicate which, if any, of these services you or your family sought out for your child after he/she was discharged from PCIT (fill in all that apply):

- Partial hospitalization or day treatment

- Residential treatment

- Inpatient hospitalization or day treatment

○ Support group

○ Community support services

- Administrative case management (not face-to-face)

- Intensive case management/resource coordination (face-to-face)

○ Family-based

- Family therapy

- Outpatient treatment

- BHRS (wraparound)

- Other (Specify) 
The following are questions about your experiences in PCIT and with your PCIT therapist; what you expected from treatment, how you liked it, and any barriers you experienced. We would also like to learn about anything that could be improved.

1. What was particularly helpful about PCIT?

2. What was particularly frustrating about PCIT or what was not very helpful?

3. If you had a chance to give advice to your therapist, others at the agency, or other parents in PCIT, what advice would you give?

4. Why did you start PCIT? What were your goals for treatment? 
5. How did you stop participating in PCIT? Why did you end treatment?

6. I ended PCIT because I did not think it would work for my child and I.

True

False

7. I ended PCIT because I felt like I got enough out of it and met my treatment goals.

True

False

8. I ended PCIT because I did not like my therapist.

True

False

9. I ended PCIT because life got in the way (e.g., transportation, child care, too busy, other commitments)?

True

False

What, specifically, got in the way of completing treatment? 
10. I ended PCIT because it was a bigger commitment than I was expecting.

True

False

11. I ended PCIT because it was too much for my child and I at that time in our lives. True

False

12. How satisfied were you with participating in the previous research study, PCIT Across PA (e.g., completing questionnaires). 